\section{Received by OSTI}

AUG 281990
NUREG/CR-5373

SAND89-1135

\title{
A Demonstration Experiment of Steam-Driven, High-Pressure Melt Ejection
}

The HIPS-10S Test

Prepared by M. D. Allen, R. T. Nichols, M. Pilch

Sandia National Laboratories

Operated by

Sandia Corporation

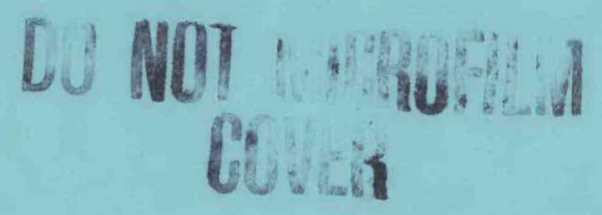

Prepared for

U.S. Nuclear Regulatory Commission 


\section{AVAILABILITY NOTICE}

Availability of Reference Materials Cited in NRC Publications

Most documents clted in NRC publications will be avallable from one of the following sources:

1. The NRC Public Document Room, 2120 L Street, NW, Lower Level, Washington, DC 20555

2. The Superintendent of Documents, U.S. Government Printing Office, P.O. Box 37082, Washington, DC 20013-7082

3. The National Technical Information Service, Springfield, VA 22161

Although the listing that follows represents the majority of documents cited in NRC publications, it is not Intended to be exhaustive.

Referenced documents available for inspection and copying for a fee from the NRC Public Document Room include NRC correspondence and Internal NRC memoranda; NRC Offlce of Inspection and Enforcement bulletins, circulars, Information notices, inspection and investigation notices; Licensee Event Reports; vendor reports and correspondence; Commission papers; and applicant and licensee documents and correspondence.

The following documents in the NUREG series are avallable for purchase from the GPO Sales Program: formal NRC staff and contractor reports, NRC-sponsored conference proceedings, and NRC booklets and brochures. Also avallable are Regulatory Guides, NRC regulations in the Code of Federal Regulations, and Nuclear Regulatory Commission Issuances.

Documents avallable from the National Technical Information Service Include NUREG series reports and technical reports prepared by other federal agencies and reports prepared by the Atomic Energy Commission, forerunner agency to the Nuclear Regulatory Commission.

Documents avallable from public and special technical libraries include all open literature items, such as books, Journal and periodical articles, and transactions. Federal Register notices, federal and state legislation, and congressional reports can usually be obtained from these libraries.

Documents such as theses, dissertations, forelgn reports and translations, and non-NRC conference proceedings are avallable for purchase from the organization sponsoring the publication clted.

Single coples of NRC draft reports are avallable free, to the extent of supply, upon written request to the Office of Information Resources Management, Distribution Section, U.S. Nuclear Regulatory Commission, Washington, DC 20555.

Coples of industry codes and standards used in a substantive manner in the NRC regulatory process are maintained at the NRC Library, 7920 Norfolk Avenue, Bethesda, Maryland, and are avallable there for reference use by the public. Codes and standards are usually copyrighted and may be purchased from the originating organization or, If they are American National Standards, from the American National Standards Institute, 1430 Broadway, New York. NY 10018.

\section{DISCLAIMER NOTICE}

This report was prepared as an account of work sponsored by an agency of the United States Government. Neither the United States Government nor any agency thereof, or any of their employees, makes any warranty, expresed or implied, or assumes any legal liability of responsibility for any third party's use, or the results of such use, of any information, apparatus, product or process disclosed in this report, or represents that its use by such third party would not infringe privately owned rights. 


\section{DISCLAIMER}

Portions of this document may be illegible in electronic image products. Images are produced from the best available original document. 


\section{A Demonstration Experiment of Steam-Driven, High-Pressure Melt Ejection}

The HIPS-10S TEST

Manuseript Completed: June 1990

Date Publıshed: August 1990

Prepared by

M. D. Allen. R. I. Nichols. M. Pilch

Sandia Natuonal I aboratores

Albuquerque. NM 87185

\section{Mrepared for}

Division of Systems Research

Office of Nuclear Regulatory Research

U.S. Nuclear Regulatory Commission

Washington, DC 20555

NRC FIN A1406

"Kicch Corporation

Albuquerque, NM 87110

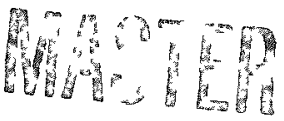


Blank Page 


\section{ABSTRACT}

A steam blowdown test was performed at the Surtsey Direct Heating Test Facility to test the steam supply system and burst diaphragm arrangement that will be used in subsequent Surtsey Direct Containment Heating (DCH) experiments. Following successful completion of the steam blowdown test, the HIPS-1OS (High-Pressure Melt Streaming) experiment was conducted to demonstrate that the technology to perform steam-driven, high-pressure melt ejection (HPME) experiments had been successfully developed. In addition, the HIPS-1OS experiment was used to assess techniques and instrumentation designed to create the proper timing of events in HPME experiments.

The HIPS-10S test used $80 \mathrm{~kg}$ of iron oxide/aluminum thermite to simulate molten corium in a severe LWR accident. This mass included chromium metal, amounting to $18 \mathrm{wt} . \%$ of the total metal phase in the products of the reaction. The thermite was ignited remotely by a pyrofuse. The reaction front propagated downward and melted a brass plug in the bottom of the melt generator. The thermite melt simulant was then forcibly ejected by steam at $3.6 \mathrm{MPa}$ into a $1: 10$ linear scale model of the Surry reactor cavity which included scaled models of the instrument guide tubes.

Analyses of gases in the cavity during the steam-driven, high-pressure melt ejection indicated that steam reacted very efficiently to form hydrogen, as expected from consideration of the chemical reaction rates. Of the $80 \mathrm{~kg}$ of melt similant, $88 \%$ was dispersed from the cavity into the atmosphere and formed a luminous debris plume. Debris ejection took about 700 ms and formed a plume of molten debris that was about $50 \mathrm{~m}$ high. The debris tore the stainless steel wires used to simulate the instrument guide tubes out of the cavity and ejected pieces of them over $100 \mathrm{~m}$ from the cavity exit. The HIPS-10S experiment suggested improvements in the system that will be incorporated in future DCH tests, in which debris will be dispersed into the Surtsey vessel. 
Blank Page 
CONTENTS

$\underline{\text { Section }}$

Page

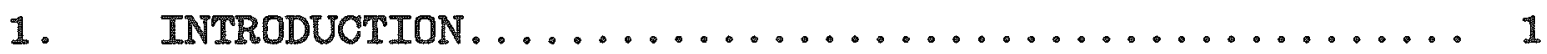

1.1 Background......................... 1

1.2 Steam Blowdown Test................. 5

1.3 The HIPS-10S Experiment................ 5

2. EXPERIMENT DESCRIPTION.................. 6

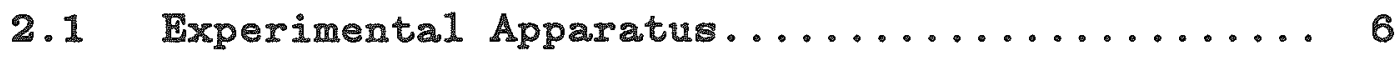

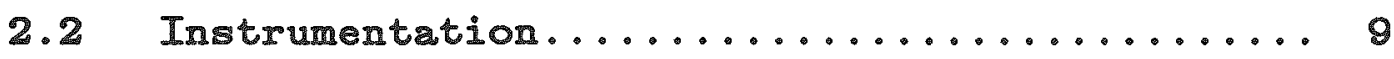

2.2.1 Pressure Meassurements............ 10

2.2.2 Temperature Measurements............ 10

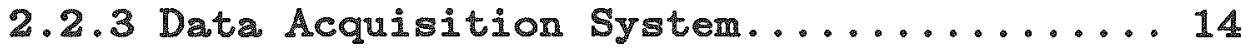

2.2.4 Gas Analyses................... 14

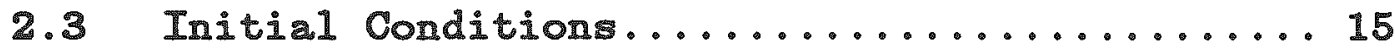

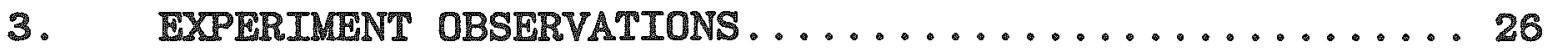

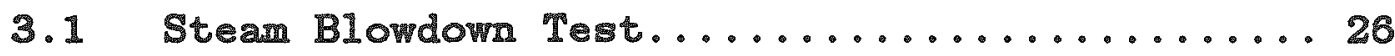

3.2 The HIPS-10S Experiment............... 26

4. EXPERIMENT RESULTS. . . . . . . . . . . . . . . 35

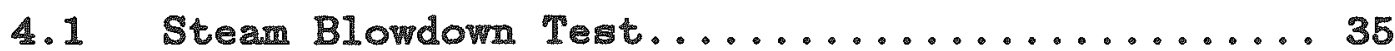

4.2 The HIPS-10S Experiment............... 36

4.2.1 Pressure and Temperature Measurements... 36

4.2.2 Results of Gas Analyses............ 39

4.2.3 Debri. Ejection Measurements..........41 4

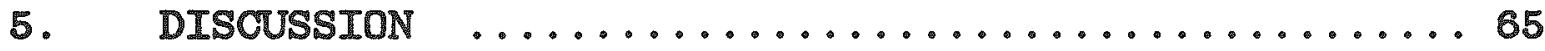

6. CONCLUSION $\ldots \ldots \ldots \ldots \ldots \ldots \ldots \ldots \ldots \ldots \ldots . \ldots \ldots 6 . \ldots \ldots$

7. REFERENCES $\ldots \ldots \ldots \ldots \ldots \ldots \ldots \ldots \ldots \ldots \ldots \ldots$ 


\section{LIST OF FIGURES}

Figure

Page

2-1. HIPS-10S Experimental Apparatus................. 20

2-2. Exploded View of the Burst Diaphragm............ 21

2-3. Cross-sectional View of the Burst Diaphragm....... 21

2-4. 1:10 Linear Scale Models of the Surry Reactor

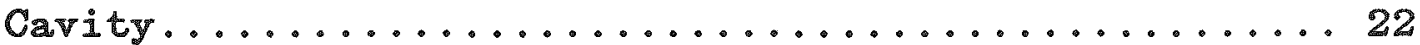

2-5. Photograph of the HIPS-10S Experimental Setup

Showing the Surtsey Direct Heating Test Facility

in the Background.

2-6. Photograph of the HIPS-10S Experimental Setup...... 24

2-7. Instrumentation Locations in the HIPS-1OS Test..... 25

3-1. Photograph of the Steam Blowdown Test Plume at Approximately 500 ms After the Burst Diaphragm Ruptured................................ 29

3-2. Photograph of the Plume at Approximately $300 \mathrm{~ms}$ After Melt Ejection in the HIPS-10S Test..........30

3-3. Photograph of the Plume at Approximately $400 \mathrm{~ms}$ After Melt Ejection in the HIPS-1OS Test..........31

3-4. Photograph of the Plume at Approximately $500 \mathrm{~ms}$ After Melt Ejection in the HIPS-1OS Test...........32

3-5. Photograph of the Plume at Approximately $600 \mathrm{~ms}$ After Melt Ejection in the HIPS-10S Test.......... 33

3-6. Photograph of the Plume at Approximately $1 \mathrm{~s}$ After Melt Ejection in the HIPS-1OS Test........... 34

4-1. Gas Temperature Measured in the Accumulator Tank in the Steam Blowdown Test....................43

4-2. Gas Temperatures Measured in the Steam Blowdown Test..................................44 


\section{LIST OF FIGURES (continued)}

Figure

Page

4-3. Measured Pressures in the Steam Blowdown Test.......45

4-4. Cavity Pressure in the Steam Blowdown Test........46

4-5. Differential Pressure Measured with the Bottom

Pitot Tube in the Steam Blowdown Test.............44 47

4-6. Differential Pressure Measured with the Middle

Pitot Tube in the Steam Blowdown Test............ 47

4-7. Differential Pressure Measured with the Top

Pitot Tube in the Steam Blowdown Test.............47

4-8. Accumulator Steam Temperature in the HIPS-1OS Test... 48

4-9. Steam Temperature in the 10-cm Pipe Exiting the Accumulator Tank in the HIPS-10S Test............48

4-10. Crucible Gas Temperature in the HIPS-10S Test...... 49

4-11. Ignition Timing Signal in the HIPS-10S Test........50

4-12. Crucible Timing Probe for the HIPS-10S Test

(data channel 3: type-K thermocouple)............50

4-13. Photodiode Below the Melt Plug in the HIPS-10S

Test.................................. 51

4-14. Photodiode at the Cavity Exit in the HIPS-10S

Test.................................. 51

4-15. Accumulator Pressure (Channel 31) in the HIPS-10S

Test................................ 52

4-16. Accumulator Pressure (Channe1 32) in the HIPS-10S

Test.................................. 52

4-17. Crucible Pressure (Channel 34) from -25 to

+5 Seconds in the HIPS-10S Test................ 53 


\section{LIST OF FIGURES (continued)}

Figure

Page

4-18. Crucible Pressure (Channel 35) from-25 to +5 Seconds in the HIPS-10S Test................. 53

4-19. Crucible Pressure (Channel 34) from 0 to 4 Seconds in the HIPS-10s Test.................. 54

4-20. Crucible Pressure (Channel 35) from 0 to 4 Seconds in the HIPS-10S Test................. 54

4-21. Pressure Between the Rupture Discs of the Burst Diaphragm in the HIPS-1OS Test................ 55

4-22. Measured Pressures in the HIPS-10S Test...........56

4-23. Cavity Pressure in the HIPS-10s Test............. 57

4-24. Temperature Measured with the 11x20 Optical

Pyrometer Focused at the Top of the Lucite Exit Chute in the HIPS-10S Test................... 58

4-25. Temperature Measured with the Two-Color Pyrometer Focused at the Cofferdam Exit in the HIPS-10S Test... 59

4-26. Background Gas Composition in the CavityPrior to Melt Ejection Measured from Gas Grab Sample Set C,

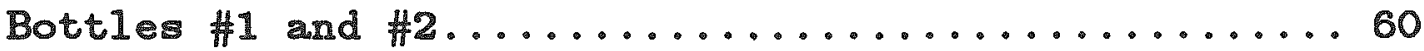

4-27. Gas Composition from Gas Grab Sample Set A,

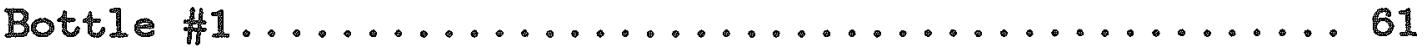

4-28. Gas Composition from Gas Grab Sample Set A, Bottle $\# 2 \ldots . . . . . . . . . . . . . . . . . . . . .662$

4-29. Gas Composition from Gas Grab Sample Set B,

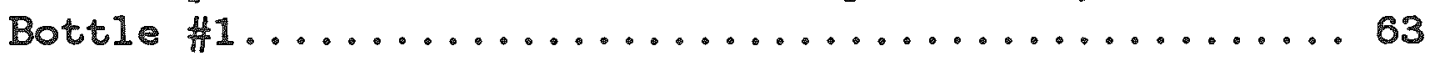

4-30. Gas Composition from Gas Grab Sample Set B, Bottle \#2................................64 


\section{LIST OF FIGURES (continued)}

\section{Figure}

Page

5-1. Experimental Setup To Be Used in Future DCH

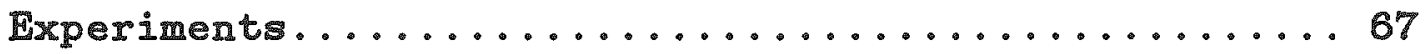




\section{LIST OF TABLES}

Table

Page

1. HIPS-1OS Instrumentation.................... 12

2. HIPS-10S Initial Conditions................... 19

3. Gas Grab Sample Data from the HIPS-10S Experiment.. 42 


\subsection{INTRODUCTION}

\subsection{Background}

Reactor safety studies $[1,2]$ indicate that degradation and melting of the core may occur in some severe reactor accident sequences while the reactor coolant system (RCS) is still at an elevated pressure. Molten core debris that relocates to the lower plenum of the reactor pressure vessel (RPV) may fail the lower head at an instrument tube penetration. This may result in the forcible ejection of molten core debris into the reactor cavity. This process has been termed High Pressure Melt Ejection (HPME).

Experiments and analyses $[3,4,5,6]$ have shown that blowdown of the reactor coolant system into the cavity may fragment the core debris into small particles, entrain them in the blowdown gas, and disperse the fragmented, molten debris from the cavity into the reactor containment building (RCB). Analyses have indicated that HPME and debris dispersal may:

1. create a potential threat to the containment integrity from overpressurization by heating the containment atmosphere $[7,8,9]$, and

2. create a source term of radioactive and nonradioactive aerosols [10] that will be available for release to the environment should the containment fail.

There are three processes that may heat the containment atmosphere: (1) the direct exchange of thermal energy between the molten debris and the atmosphere; (2) the exothermic reaction between the metallic debris and oxygen in the containment atmosphere; and (3) the reaction of the metallic debris with steam to produce hydrogen, which can subsequently combust. The processes leading to increased loads on the containment building and generation of corium aerosols in a HPME accident have been termed Direct Containment Heating (DCH). 
The risk significance of DCH was identified as one of the eight major areas of technical uncertainties in NUREG-0956 [11]. The NUREG-1150 study [12] implies that the contribution of HPME/DCH to the mean risk of early fatalities from the PWR reference plants is between 8 and $17 \%$ and of latent cancer fatalities is between 7 and $23 \%$. In addition, the DCH safety issue is identified in SECY-88-147 [13] and NUREG-1265 [14] as an important safety-related issue.

The CONTAIN code [15] is a system level, lumped parameter code for computing containment response in severe reactor accidents. CONTAIN-DCH is a developmental version of CONTAIN that includes a partially parametric DCH model. Analyses using the CONTAIN-DCH code [9] have indicated that hydrogen generation and combustion are important aspects of the DCH process. Code predictions suggest that:

1. rapid oxidation of the metallic constituents by steam can occur within the reactor cavity or regions immediately outside the cavity, and that

2. the hydrogen can be easily transported throughout the containment without interference from intervening structures. Furthermore, although data on the combustion of hydrogen at elevated temperatures is at present sparse, it is considered likely that prompt combustion of preexisting hydrogen plus some of the DCH-produced hydrogen will occur in the hot atmosphere regardless of the amount of steam present.

CONTAIN-DCH calculations $[9,16]$ using a five-cell model of the Surry plant predicted a pressure rise due to DCH of approximately $0.7 \mathrm{MPa}$ for a base case in which it was assumed that $75 \%$ of the in-vessel inventory of corium was ejected into the reactor cavity during a five second period. This calculation was performed assuming essentially no hydrogen combustion (as predicted by conventional hydrogen combustion criteria for the containment which are based on low temperature data, and therefore, allow for the inhibiting influence of steam on hydrogen combustion). Updated hydrogen combustion models incorporated into CONTAIN-DCH show that hydrogen generation and combustion could add an aditional 0.1 to $0.3 \mathrm{MPa}$ to the $0.7 \mathrm{MPa}$ pressure rise due to DCH. The added 
pressure due to hydrogen combustion could result in containment threatening pressures.

To date, quantitative predictions of the generation and combustion of hydrogen during DCH accidents are totally the product of numerical simulation and have not been validated by we11-designed, we11-documented experiments. The CONTAIN code has operational models describing the oxidation of metallic core melt constituents by steam. The model accounts for both gas-side and drop-side kinetic limitations to the transport of oxidant to the metallic content of the debris drops. Key areas of uncertainty are the gas/debris surface area and the amount of steam available locally to the debris for oxidation. The CONTAIN model predicts that rapid oxidation of the metallic constituents can occur in the reactor cavity or the region immediately outside the cavity. The DCH-related production of nearly $600 \mathrm{~kg}$ of hydrogen is predicted to occur on a time frame of about $5 \mathrm{~s}$ for a typical reactor accident [9]. The rapid rate at which this process occurs might limit the effectiveness of hydrogen mitigation schemes such as ignitors and catalytic recombiners.

The numerical prediction of the rapid transport of hydrogen and other atmospheric gases throughout the containment during the blowdown phase is an established capability of the CONTAIN code $[17,18,19,20]$. Substantial portions of the HPMEproduced hydrogen are predicted to reside in the oxygen-starved lower compartments of the containment. However, some of the HPME-produced hydrogen is predicted [0] to be transported to the upper dome of the containment where it, along with hydrogen produced prior to the HPME, can combust.

Sensitivity sudies using CONTAIN-DCH bow that atmospheric temperatures in the upper dome of the containment can reach $1000 \mathrm{~K}$ with considerably higher temperatures predicted for the lower compartments. There is experimental and theoretical evidence $[21,22,23]$ indicating that at these bigh temperatures any mixture (regardless of steam content) containing both hydrogen and oxygen is expected to be hypergolic (i.e., ignites spontaneously without external aid). 
Recent work [22] indicates that steam-air-hydrogen mixtures may be much more likely to undergo detonation at high temperatures than at lower temperatures. Obviously, the occurrence of detonations, rather than simple deflagrations, could have important implications for the consequences of DCH scenarios. CONTAIN-DCH does not include models for detonations and their effects; however, the atmospheric conditions calculated by CONTAIN-DCH show that the possibility of detonability at high temperatures is an important issue that requires further study.

The objective of the current research is to provide experimental data using steam-driven melts to test the ability of current models to predict the extent of hydrogen generation during steam-driven, high-pressure melt ejection sequences.

The experiment approach involves three activities:

1. develop the technology to generate steam-driven melts,

2. develop the technology to deliver a thermitically generated melt containing chromium, and

3. perform a steam-driven melt ejection test.

This report describes the results of a steam blowdown test and the HIPS-1OS experiment, which were conducted to demonstrate the technique and instrumentation for performing steam-driven, high-pressure melt ejection experiments. This technology will be used in subsequent DCH tests at Sandia National Laboratories (SNL) in which the debris will be ejected into the Surtsey vessel. 


\subsection{Steam Blowdown Test}

The purpose of the steam blowdown test was to test the steam supply system and burst diaphragm arrangement that will be used in subsequent DCH experiments, including the HIPS-1OS experiment. Specifically, the objectives were (1) to demonstrate that the stean accumulator tank could be pressurized to over $4 \mathrm{MPa}$ without significant leaks or steam condensation, (2) to demonstrate that the burst diaphragms would fail if the pressure differential across them was sudden 1y greater than $2.7 \mathrm{MPa}$, and (3) to measure the steam discharge characteristics.

\subsection{The HIPS-10S Experiment}

The purpose of the HIPS-1OS test was to demonstrate the capability to successiuly perform steam-driven, high-pressure melt ejection experiments. HIPS-1OS was the first high-pressure melt ejection experiment ever performed in which the driving gas was steam. The primary goal of the HIPS-1OS experiment was to assess methods and instrumentation used to create the proper timing of events in HPME experiments. A secondary goal was to determine the extent of the hydrogen production by the chemical reaction between metallic debris and steam. With this in mind, it was decided to include chromium powder in the melt to approximate the composition of steel used in LWRs and to more accurately simulate the steam/metal reaction during blowdown. Thus, another objective of HIPS-1OS was to determine whether the presence of chromium powder would influence the propagation of the thermitic reaction. This report gives a description of the experimental setup, initial conditions, test observations from photographic records, and results of pressure, temperature, and gas composition measurements. 


\subsection{EXPERIMENT DESCRIPTION}

\subsection{Experimenta1 Apparatus}

A schematic diagram of the experimental apparatus used in both the steam blowdown test and the HIPS-1OS experiment is shown in Figure 2-1. The only differences between the stean blowdown test and the HIPS-1OS experiment were that there was no thermite, brass melt plug, or lucite exit chute in the steam blowdown test. The basic components of the system were the boiler, which supplied superheated steam to the steam accumulator tank; the burst diaphragm, which acted as a fast opening valve that separated the steam and thermite until a few seconds prior to the melt ejection; the melt generator, which housed a steel-1ined MgO crucible that contained the melt simulant; a 1:10 linear scale model of the Surry reactor cavity with scale models of the instrument guide tubes; and a lucite exit chute to deflect debris away from the apparatus. A more complete description of each of the components is given below.

\section{Boiler}

Superheated steam was supplied to the steam accumulator tank using a $75 \mathrm{~kW}$ self-contained electric boiler (Hydro Steam Industries, Springfield, VA, model number STR 1638). It is capable of producing $91 \mathrm{~kg}$ of steam per hour at $7.8 \mathrm{MPa}$. The steam pressure in the boiler was regulated by a proportional controller to within $0.3 \mathrm{MPa}$ of the set point pressure.

\section{Steam Accumulator Tank}

The steam accumulator tank was a 2-m-long, schedule 140 pipe section fitted with blind flanges on both ends so that it had an internal volume of $0.267 \mathrm{~m}^{3}$. The total interior volume of the steam accumulation system, including the 10-cm-diameter pipe to the burst diaphragm, was $0.29 \mathrm{~m}^{3}$. The accumulator was heated around its circumference with six 3-kW band heaters. Each flange at the end of the accumulator was heated with eight $1.2-\mathrm{kW}$ calrod heaters. The entire accumulator was wrapped with fiberfrax insulation. The heaters were used to 
maintain the interior walls of the accumulator at temperatures reater than $255^{\circ} \mathrm{C}$, which is the saturation temperature of steam at $4.1 \mathrm{MPa}$. This prevented condensation of steam on the interior walls of the accumulator tank.

There were vent valves located on the accumulator tank and the 10-cm-diameter pipe (Figure $2-1$ ). These valves were initially open so that steam could be flowed through the accumulator and 10-cm-diameter pipe to purge them of air prior to each experiment. This purging process minimized the air contamination in the steam driving gas. The vent valves were closed prior to the pressurization sequence.

\section{Burst Diaphragm}

An exploded view and a cross-sectional view of the burst diaphragm (Fike Metal Products, Blue Springs, MO) are shown in Figures 2-2 and 2-3, respectively. The complete double disc holder assembly consists of two rupture discs installed in a permanent holder made of three separate components: the base, midflange, and holddown (Figure 2-2). The burst diaphragm was designed for ease of installation and maintenance, with preassembly and leak testing of the unit on a workbench before insertion between companion flanges (Figure 2-3). The burst diaphragm was designed to rupture when the differential pressure across the diaphragms exceeded $2.68 \mathrm{MPa}$ at $310^{\circ} \mathrm{C}$. The pressure in the space between the rupture discs was continuously monitored with a model XTM-190 Kulite pressure transducer, and the output, in engineering units, was continuously displayed in the experiment control room.

\section{Melt Generator}

The melt generator, shown in Figure 2-1, housed a crucible that contained the thermite melt simulant. The inner liner of the crucible was made from 14 gauge mild steel rolled to an inner diameter of approximately $25.9 \mathrm{~cm}$. This was placed inside a nominal 30.5 -cm diameter schedule 20 pipe section that was $76.2 \mathrm{~cm}$ long. The annulus was filled with a wet $\left(5 \% \mathrm{H}_{2} \mathrm{O}\right) \mathrm{ram} \mathrm{MgO}$ insulating material. The end of the cylinder was closed by wolding a $5.1-\mathrm{cm}$ thick steel plate to the outer 
she11. The bottom plate was tapped and fitted with a 4.8 -cm fusible brass plug. Melt ejection occurred when the thermite melted through this plug. A hole was drilled and tapped in the side of the crucible at 66 cm from the top. A timing probe (a type $K$ thermocouple) was inserted into the thermite and was fixed in place using a standard bored-through Swagelok fitting.

\section{Cavity}

A view of the 1:10 linear scale model of the Surry reactor cavity is shown in Figure 2-4. The model was constructed of reinforced steel with concrete inner walls. The floor was Iined with a 1.9-cm thick steel plate. There was an 18-inch-diameter $(45.72 \mathrm{~cm})$ pipe section with 0.5 -inch-thick $(1.27 \mathrm{~cm})$ walls with an archway cut into it that simulated the reactor pressure vessel (RPV) support skirt. The ceiling of the cavity was steel. The walls of the simulated in-core instrument tunnel and cofferdam exit were concrete. There were 44 simulated in-core instrument guide tubes constructed of 12 gauge steel wire (2.67-m diameter). These wires were approximately one-tenth linear scale of the in-core instrument guide tubes in the Surry reactor.

The side of the cavity had nine tapped ports for instrumentation (Figure 2-4). In the steam blowdown test, three ports were used for pitot tubes, one port was used for a pressure transducer, and one port was used for a type-K aspirated thermocouple. In the HIPS-10S experiment, threo ports were used for gas grab sample bottles, one port was used for a pressure transducer, and one port was used to purge the cavity with argon prior to the experiment.

Figure 2-5 is a photograph of the experimental setup with the base of the Surtsey ressel in the background. The steam is supplied from the left side of the picture into the stean accumulator tank. The burst diaphragm, melt generator, cavity, and lucite exit chute are surrounded with concrete barriers to protect personnel and equipment. Figure $2-6$ is a closer view of the experimental hardware. This photograph shows the steam accumulator tank, burst diaphragn, melt generator, and cofferdam of the scaled Surry cavity. 
The steam blowdown test and the HIPS-10S experiment were performed using the following pressurization sequence. Initially, the valve (V3) in the vent line (see Figure 2-1) that connects the space between the rupture discs of the burst diaphragm and the crucible was closed, and the valve (V4) on the crucible vent to the atmosphere was open. When it was time to perform the experiment, the space between the rupture discs in the burst diaphragm was pressurized with nitrogen to $2 \mathrm{MPa}$ by opening a remotely operated, pneumatically actuated valve. Then a valve between the boiler and the accumulator was remotely opened to allow the accumulator tank to pressurize with superheated steam to 4 MPa. Thus, when this pressurization was complete, the accumulator tank was at approximately $4 \mathrm{MPa}$, the space between the rupture discs of the burst diaphragm was at about $2 \mathrm{MPa}$, and the space inside the 10-cm-diameter steel pipe from the burst diaphragm to the crucible was at atmospheric pressure. Using this pressurization scheme, the differential pressure did not exceed $2.68 \mathrm{MPa}$, and the burst diaphragm remained intact until actuators for valves $V 3$ and $V 4$ received a signal from the timing probe (a type-K thermocouple) that was located about $7.5 \mathrm{~cm}$ above the brass melt plug. The signal caused valve V3 to open and valve V4 to close. This vented the space between the rupture discs to the space above the crucible. This design was intended to create a pressure differential across the burst diaphragm greater than 2.68 $\mathrm{MPa}$, and quickly fail the burst diaphragm, bringing the highpressure steam into contact with the molten thermite.

\subsection{Instrumentation}

Table 1 is a list of the ingtrumentation used in HIPS-10S. This table gives the channel number from the data acquistion system (section 2.2.3), location, and purpose of each device. In addition, the locations of most of the instruments are shown in the schematic diagram of the experimental setup in Figure 2-7. 


\subsubsection{Pressure Measurements}

The instruments that measured pressures in the accumulator tank (channels 31 and 32), between the rupture discs of the burst diaphragm (channel 33), and in the crucible (channels 34 and 35) were Kulite model XTM-190 presare transducers (Kulite Semiconductor Products Inc., Ridgefield, NJ). The pressure in the cavity (channel 36) was measured with a Precise Sensor model 141-1 pressure transducer (Precise Sensors, Monrovia, CA). This device was a metal diaphragm strain gage type transducer with a range of 0 to $1.4 \mathrm{MPa}$. The pressure transducers were factory calibrated by the manufacturer and are recalibrated at regular intervals against standards traceable to the National Bureau of Standards (NBS) by the Sandia Calibrations Laboratory. The data acquisition system records data from the pressure transducers at a rate of 1400 data points per second during the HPME transient.

\subsubsection{Temperature Measurements}

Temperatures in the HIPS-10S test were measured with 15 type K thermocouples. The location and purpose of each of these thermocouples are given in Table 1 . The locations of these thermocouples are also shown in the schematic diagram of the experimental apparatus in F1gure 2-7. These thermocouples are calibrated at regular intervals against NBS traceable standards by the Sandia Calibrations Laboratory.

Three pyrometers were used to measure the temperature of the ejected debris. A two-color pyrometer (Modline R Series, Model Number R-35C10, Ircon Inc., Stokie, IL) and an optical pyrometer (Series 1100, Type 11x30, Ircon Inc., Stokie, IL) were focused at the cavity exit. The two-color pyrometer had a temperature range of 1500 to $3500^{\circ} \mathrm{C}$ and a calibrated accuracy of $1 \%$ of the full-scale temperature; the response time of the two-color pyrometer was 0.1 s at the sensing head. Another optical pyrometer (Series 1100, Type 11x20, Ircon, Inc., Stokie, IL) was focused at the top of the lucite exit chute. The response time of the Ircon Series 1100 pyrometers was 1.5 ms to $95 \%$ of the full range; they were 
capable of measuring temperatures between 1700 and $2800^{\circ} \mathrm{C}$ with an specified accuracy of $1 \%$ of the full-scale temperature. In a transient event such as a HPME experiment, the pyrometer accuracy is expected to be no better than $\pm 25^{\circ} \mathrm{C}$. These pyrometers were factory calibrated and were also recalibrated by the Sandia Calibrations Laboratory. Data points from the thermocouples and the pyrometers were recorded by the data acquisition system at a rate of 10 per second prior to thermite ignition, and then just prior to thermite ignition the data acquisition system was switched to the fast mode, in which data points were recorded at a rate of 1400 per second. 
Table 1

HIPS-1OS Instrumentation

Instrument

(Channel Number)
Photodiode(5)

Ignitor Signal(7)

2-Color Pyrometer(28)

11x30 Optical(29)

Pyrometer

11×20 Optical(30)

Pyrometer

Pressure Transducer(31)

Pressure Transducer(32)

Pressure Transducer(33)

Pressure Transducer(34)

Pressure Transducer(35)
Location

Top of Crucible

Top of Crucible

Crucible $(7.5 \mathrm{~cm}$

above melt plug)

Below melt plug

Cavity Exit

Purpose

Gas Temperature

Above Thermite

Gas Temperature

Above Thermite

To Actuate Valves V3 and V4

To Signal Melt Ejection from the Melt Generator

To Detect Ejection from Cavity

To Time Thermite Ignition

Focused at Cavity

Exit

Debris Temperature

Focused at Cavity

Exit

Focused at Top of

Chute

Accumulator

Steam Pressure

Accumulator

Steam Pressure

Burst Diaphragm

Crucible

Crucible
Pressure Between

Rupture Discs of

Burst Diaphragm

Pressure Above

Thermite

Pressure Above

Thermite 
Table 1

HIPS-1OS Instrumentation

(continued)

\begin{tabular}{|c|c|c|}
\hline $\begin{array}{l}\text { Instrument } \\
\text { (Channel Number) }\end{array}$ & Location & Purpose \\
\hline Pressure Transducer(36) & Cavity & Cavity Pressure \\
\hline Thermocouple(81) & Accumulator & $\begin{array}{l}0.32 \mathrm{~cm} \text { from Inner } \\
\text { Wall }\end{array}$ \\
\hline Thermocouple(82) & Accumulator & $\begin{array}{l}0.32 \mathrm{~cm} \text { from Inner } \\
\text { Wall }\end{array}$ \\
\hline Thermocouple(83) & Accumulator & $\begin{array}{l}0.32 \mathrm{~cm} \text { from Inner } \\
\text { Wall }\end{array}$ \\
\hline Thermocouple(84) & Accumulator & $\begin{array}{l}0.32 \mathrm{~cm} \text { from Inner } \\
\text { Wall }\end{array}$ \\
\hline Thermocouple(85) & Accumulator & $\begin{array}{l}0.32 \mathrm{~cm} \text { from Inner } \\
\text { Wall }\end{array}$ \\
\hline Thermocouple(86) & Accumulator & $\begin{array}{l}0.32 \mathrm{~cm} \text { from Inner } \\
\text { Wall }\end{array}$ \\
\hline Thermocouple(87) & Accumulator & $\begin{array}{l}\text { Flange Outside } \\
\text { Surface Temp }\end{array}$ \\
\hline Thermocouple(88) & Accumulator & $\begin{array}{l}\text { Outside Surface } \\
\text { Temp }\end{array}$ \\
\hline Thermocouple(90) & Accumulator & $\begin{array}{l}\text { Outside Surface } \\
\text { Temp }\end{array}$ \\
\hline Thermocouple(91) & Accumulator & $\begin{array}{l}\text { Temp Inside } \\
\text { Accumulator }\end{array}$ \\
\hline Thermocouple(92) & Accumulator & $\begin{array}{l}\text { Temp Inside } \\
\text { Accumulator }\end{array}$ \\
\hline Thermocouple(93) & Accumulator & $\begin{array}{l}\text { Temp in Steam Exit } \\
\text { Pipe }\end{array}$ \\
\hline
\end{tabular}


The data acquisition system is based on a Hewlett Packard model 1000 series A-600 minicomputer [24]. The four analogto-digital converters are located within the chassis of the computer with each converter multiplexing 40 analog channels; thus, this system has the capability to record 160 analog data channels. In the HIPS-10S experiment, 10 data points per second were sampled prior to thermite ignition. At thermite ignition, the data acquisition system was witched into the fast data acquisition mode so that 1400 data points per second were sampled. For the HIPS-10S experiment 28 data channels, corresponding to the instrumentation listed in Table 1, were recorded.

\subsubsection{Gas Analyses}

\section{- Hardware and Sampling Schedule}

Three sets of gas samples were taken. Each set consisted of two grab amples taken simultaneously. All grab sample bottles were pre-evacuated by a high vacuum pumping system and ralved off by a solenoid ralve. Set $A$ consisted of two $500-\mathrm{cm}^{3}$ stainless steel bottles and was taken from the top port of the scaled in-core instrument tunnel during the thermite ejection; the solenoid valve was opened by a signal from the photodiode under the melt plug and was closed one second later. Set B consisted of two 150-cm stainless steel bottles and was taken from the middle port; these bottles were opened at one second after the HPME started (i.e., when gas grab ample set $\mathbb{A}$ was closed) and was closed three seconds later. Gas sampling was complete at 4 seconds arter the beginning of the HPME. Set $C$ also consisted of two stainless steel gas grab sample bottles and was taken from the bottom port, prior to melt ejection to obtain the background composition of gases in the cavity. To minimize the dead volume in the 1.9-cm 0.D. sampling lines, the gas grab sample bottles were located as close to the cavity as possible. 
The gas samples collected were analyzed posttest with a Hewlett Packard 5836 Gas Chromatograph. Samples were injected directly from grab sample bottles into a Porapak Q, 80/100 mesh column that was time-temperature programmed from $223 \mathrm{~K}$ to $473 \mathrm{~K}\left(-50^{\circ} \mathrm{C}\right.$ to $\left.200^{\circ} \mathrm{C}\right)$. The porous polymer beads in the column provide sharp symmetrical peaks and low retention volumes for polar materials such as water, alcohols, acids, and glycols. Porapak has the partition properties of a highly extended liquid without the problems of support polarity, liquid phase volatility, or freezing point, which normally restrict gas/liquid chromatography.

Detection was accomplished by using a thermal conductivity detector that was finely tuned to the primary standard gas mixture made up of the following constituents: hydrogen, nitrogen, argon, carbon monoxide, methane, carbon dioxide, ethane, ethylene, oxygen, and water. These gas species were used to calibrate the gas chromatograph. Only peaks that were assignable to the gases in the calibration standard were detected.

The ample introduction loop into the gas chromatograph was preceded by an activated charcoal trap and a slurry acetoneIiquid nitrogen filter to trap impurities and condensibles such as water. This is a necessary step to minimize overloading of the gas separation columns and also to prevent masking the quantitative analysis of the gas compositions. Unfortunately, this means that the water measurements from the gas grab samples are not reliable.

\subsection{Initial Conditions}

The initial condition for HIPS-10S are sumarized in Tab1e 2. HIPS-10S was the first HPME experiment to use steam as the driving ras and to include chromium in the thermite molt simulant. Previous Sandia experiments had used dry bottled nitrogen, carbon dioxide, or hydrogen as the driving gas. The melt simulant in previous experiments was composed of a stoichiometric mixture of iron oxide $\left(\mathrm{Fe}_{3} \mathrm{O}_{4}\right) \mathrm{and}$ 
aluminum powders (without chromium). The idealized metallothermitic reaction between these constituents is shown below:

$$
3 \mathrm{Fe}_{3} \mathrm{O}_{4}+8 \mathrm{AI} \rightarrow 9 \mathrm{Fe}+4 \mathrm{Al}_{2} \mathrm{O}_{8}
$$

This reaction achieves temperatures similar to those predicted in serere reactor accidents (2300 K). If this debris were forcibly ejected by steam, the molten iron would react with steam according to the reaction:

$$
\mathrm{Fe}(1)+\mathrm{H}_{2} \mathrm{O} \rightarrow \mathrm{FeO}(1)+\mathrm{H}_{2}
$$

This reaction will progress to the right until the iron is consumed, or until the equilibrium hydrogen-to-steam partial pressure ratio is reached. The equilibrium hydrogen-to-steam partial pressure ratio for situations in which the FeO product of reaction does not dissolve in other oxides such as $\mathrm{Al}_{2} \mathrm{O}_{3}$ at 1500 to $2500 \mathrm{~K}$ is about 2. That is, a limit to the reaction of steam with the molten iron is encountered when only about two-thirds of the steam in the vicinity of the melt has been converted into hydrogen.

This thermodynamic limit to steam reaction with iron does not represent the situation with core debris well. In reactor core debris, highly reducing materials such as zirconium metal and chromium metal will be present. When zirconium is present, a thermodynamic limit to the reaction of steam will not be encountered until the hydrogen-to-stean partial pressure ratios are on the order of $10^{4}$ or $10^{5}$. Operationally this means nearly all of the steam in the vicinity of a metal droplet can react to form hydrogen at least until the zirconium is consumed.

To improve the representation of core debris, chromium metal was added to the iron oxide/aluminum thermite melt used in the HIPS-1OS test. The amount of chromium added to the melt was selected so that it would be about $18 \mathrm{wt} . \%$ of the metal phase. The chromium does not participate in the reactions used to form the melt. The reaction

$$
\mathrm{Cr}_{2} \mathrm{O}_{3}+2 \mathrm{Al} \rightarrow 2 \mathrm{Cr}+\mathrm{Al}_{2} \mathrm{O}_{3}
$$




$$
\Delta \mathrm{G}_{\mathrm{f}}(1500 \mathrm{~K})=-98.5 \mathrm{kcal} / \mathrm{mole}
$$

is strongly allowed. That is, $\mathrm{Al}$ reacts with $\mathrm{Cr}_{2} \mathrm{O}_{3}$ rather that $\mathrm{Cr}$ reacting with $\mathrm{Al}_{2} \mathrm{O}_{3}$. Therefore, the chromium metal acts as an inert diluent in the reaction mixture used to form the melt in the HIPS-10S test.

When the melt is expelled with steam, the chromium in the melt can react:

$$
2 \mathrm{Cr}(1)+2 \mathrm{H}_{2} \mathrm{O} \rightarrow \mathrm{Cr}_{2} \mathrm{O}_{3}+3 \mathrm{H}_{2} \mathrm{O}
$$

This reaction will proceed to the right until the hydrogen-to-steam partial pressure ratio is on the order of 100 ( 377 at $1500 \mathrm{~K}$ and 23 at $2000 \mathrm{~K}$ ). That is, as with core debris containing zirconium, no thermodynamic limit to the reaction with steam is encountered until nearly all of the steam has reacted or the chromium has been consumed.

Another advantage of including chromium in the melt is that it makes steam reactions with the metal phase exothermic, like they are with the metallic phases of core debris:

$$
\begin{aligned}
\mathrm{Zr}+2 \mathrm{H}_{2} \mathrm{O} & \rightarrow \mathrm{ZrO}_{2}+2 \mathrm{H}_{2} \quad \Delta \mathrm{H}(1500 \mathrm{~K})=-1.5 \mathrm{kcal} / \mathrm{g} \mathrm{Zr} \\
2 \mathrm{Cr}+3 \mathrm{H}_{2} \mathrm{O} & \rightarrow \mathrm{Cr}_{2} \mathrm{O}_{3}+3 \mathrm{H}_{2} \quad \Delta \mathrm{H}(1500 \mathrm{~K})=-0.8 \mathrm{kcal} / \mathrm{g} \mathrm{Cr}
\end{aligned}
$$

The reaction or iron with steam at $1500 \mathrm{~K}$ is actually endothermic:

$$
\mathrm{Fe}+\mathrm{H}_{2} \mathrm{O} \rightarrow \mathrm{FeO}+\mathrm{H}_{2} \quad \Delta \mathrm{H}(1500 \mathrm{~K})=+0.02 \mathrm{kcal} / \mathrm{g} \mathrm{Fe}
$$

Were iron the only metal phase present, the reaction of the iron would contribute to the cooling of the dispersed melt, whereas with core debris the reactions with steam help to keep the dispersed debris hot.

HIPS-10S was performed by mixing stoichiometric amounts of iron oxide and aluminum powders with chromium granules. The masses of each constituent of the thermite melt simulant are 
given in Table 2. The initial pressure, temperature, and volume of the steam are also listed in Table 2.

The addition of chromium to the thermite raises the possibility that the inert material will quench the reaction temperature sufficiently to preclude a self-sustaining propagation of the reaction. Bogolyubov [25] states that a minimum heat release of $2.3 \mathrm{MJ} / \mathrm{kg}$ is required for an aluminothermic system to be self-propagating. This empirically-based criterion is based on a large number of experiments with $0.5 \mathrm{~kg}$ of thermite. Physically this criterion seems to correspond to a heat release sufficient to produce fully molten alumina.

The DCH-3,4 experiments used thermitic melts that were nearly identical to the current melt, only without the chromium. The specific heat content of those melts is estimated to be about $3.0 \mathrm{MJ} / \mathrm{kg}$, based upon the measured peak temperatures of $2600 \mathrm{~K}$. The addition of chromium to the melt is expected to further reduce the heat content to $2.8 \mathrm{MJ} / \mathrm{kg}$, which is still above Bogolyubov's criterion of $2.3 \mathrm{MJ} / \mathrm{kg}$ for a self-propagating reaction.

The scaled model of the Surry reactor cavity was dry, as opposed to having water in the cavity. The cavity exit was covered with 0.076 -mm-thick plastic and the cavity was purged with argon to reduce the oxygen concentration. Prior to HIPS-1OS, the oxygen concentration in the cavity was measured with a handheld oxygen monitor that had a probe extending into the cavity; readings were $2 \pm 0.4 \%$. 
Table 2

HIPS-10S Initial Conditions

Material

Thermite Composition

Driving Gas

- Pressure

- Temperature

- Volume

- Mass

Fusible Plug Diameter

Cavity Conditions

\begin{tabular}{|c|c|}
\hline \multicolumn{2}{|l|}{ Material } \\
\hline $\begin{array}{l}\mathrm{Fe}_{3} \mathrm{O}_{4} \text { Powder } \\
\text { (MS30 } 60 / 200 \text { Lot \#12632) } \\
\text { Cr Platelets }\end{array}$ & $\begin{array}{r}55.52 \\
7.23\end{array}$ \\
\hline \multirow{2}{*}{$\begin{array}{l}\text { A1 Powder } \\
\text { (Alcoa 101-3-3199) }\end{array}$} & 17.25 \\
\hline & 80.00 \\
\hline \multicolumn{2}{|l|}{$\begin{array}{c}\text { Superheated Steam } \\
3.6 \mathrm{MPa} \\
420^{\circ} \mathrm{C} \\
0.29 \mathrm{~m}^{3} \\
3.3 \mathrm{~kg}\end{array}$} \\
\hline $4.8 \mathrm{~cm}$ & \\
\hline $\begin{array}{c}\text { Surry Model } \\
44 \text { Scaled Instrument Tu } \\
\text { Dry }\end{array}$ & \\
\hline
\end{tabular}




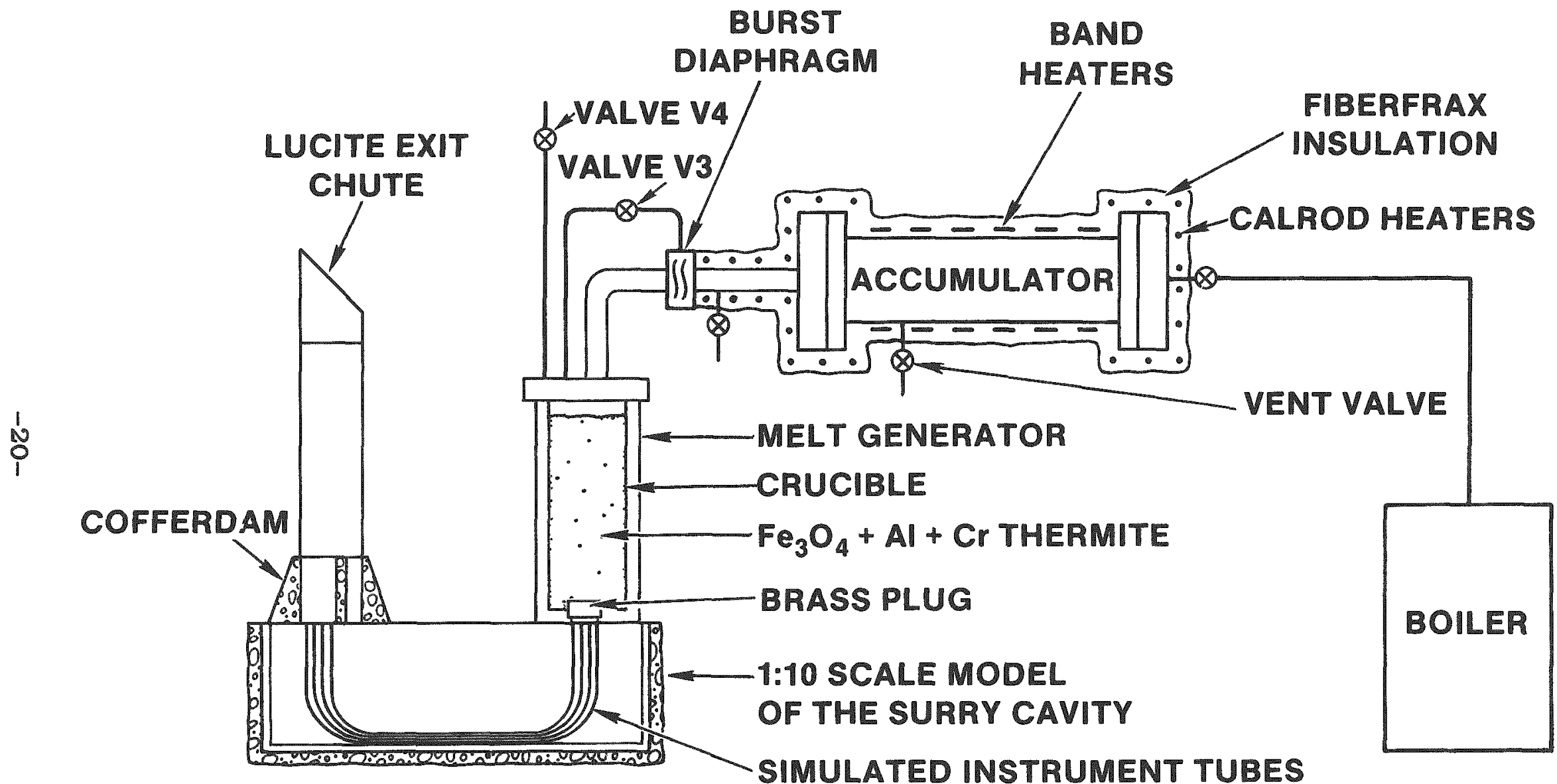

Figure 2-1. HIPS-10S Experimental Apparatus 


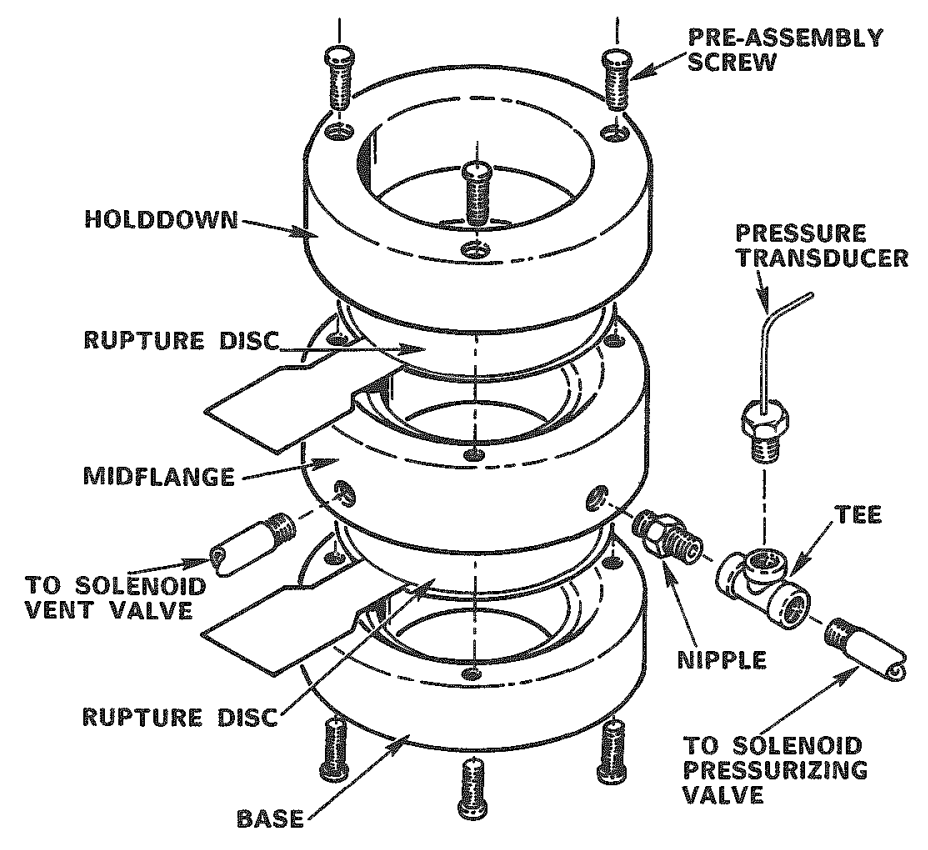

Figure 2-2. Exploded View of the Burst Diaphragm

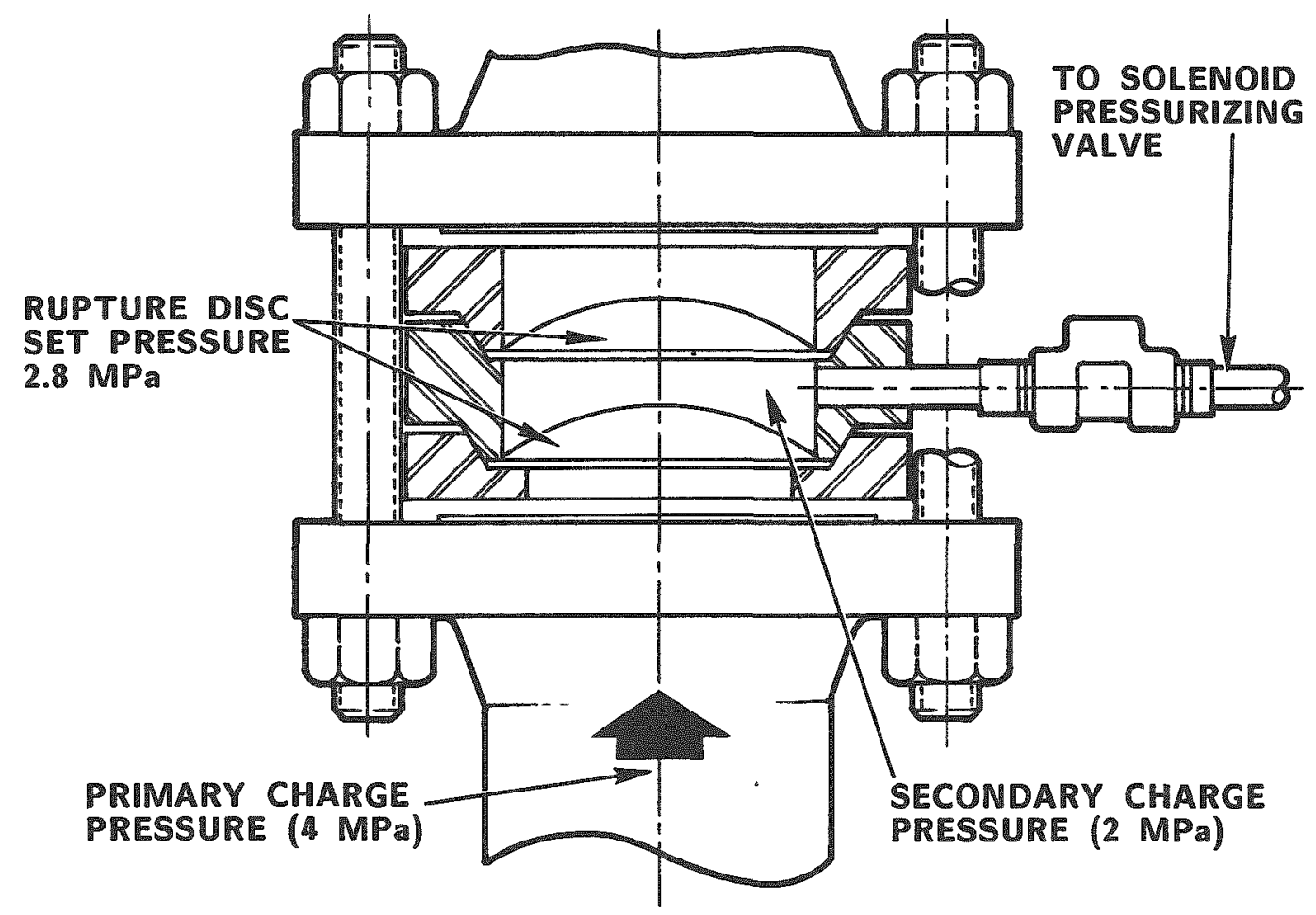

Figure 2-3. Cross-sectional View of the Burst Diaphragm 


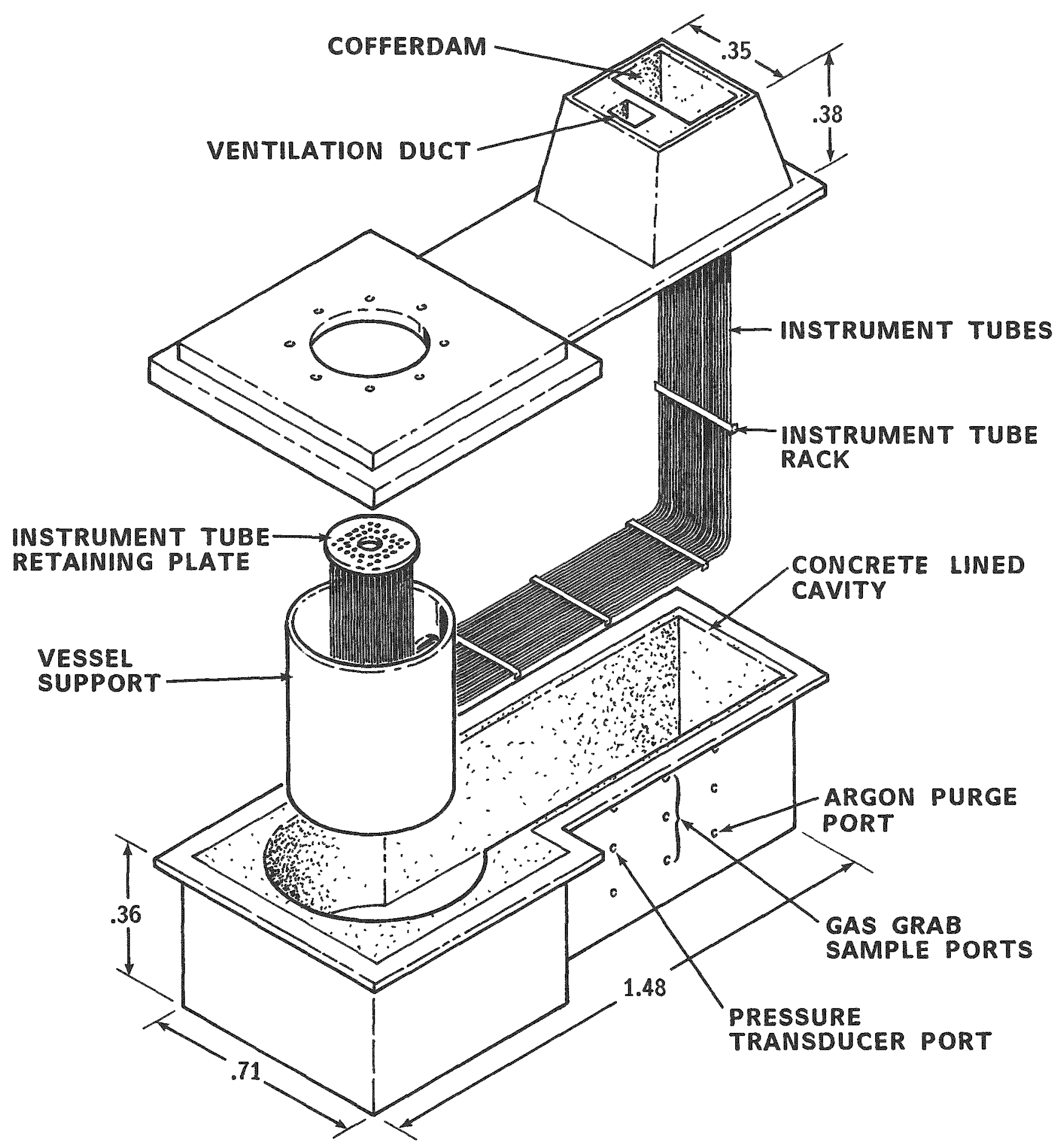

DIMENSIONS IN METERS DRAWING NOT TO SCALE

Figure 2-4. 1:10 Linear Scale Model of the Surry Reactor Cavity 


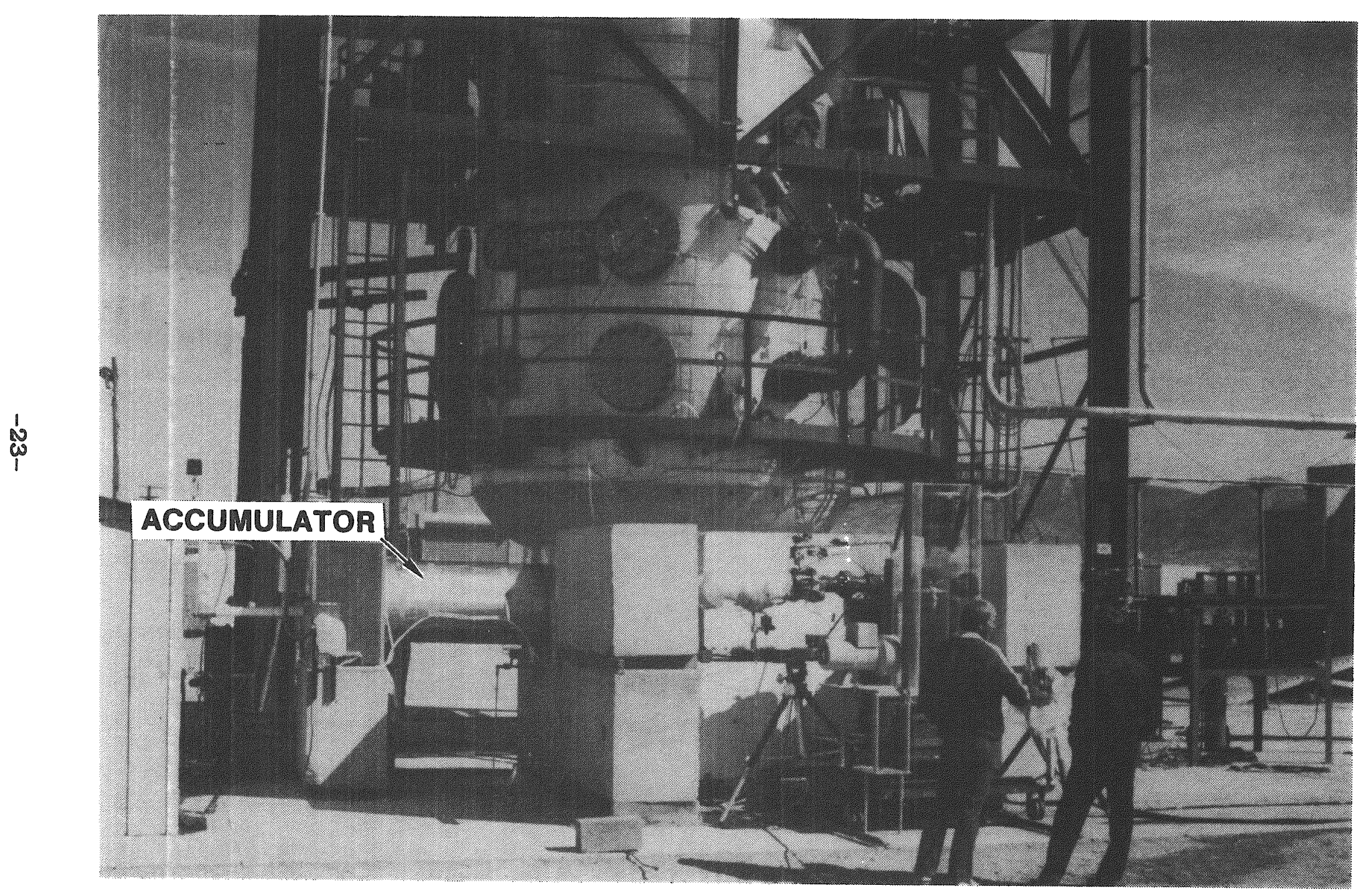

Figure $2-5$.

Photograph of the HIPS-10S Experimental Setup Showing the Surtsey Direct Heating Test Facility in the Background 


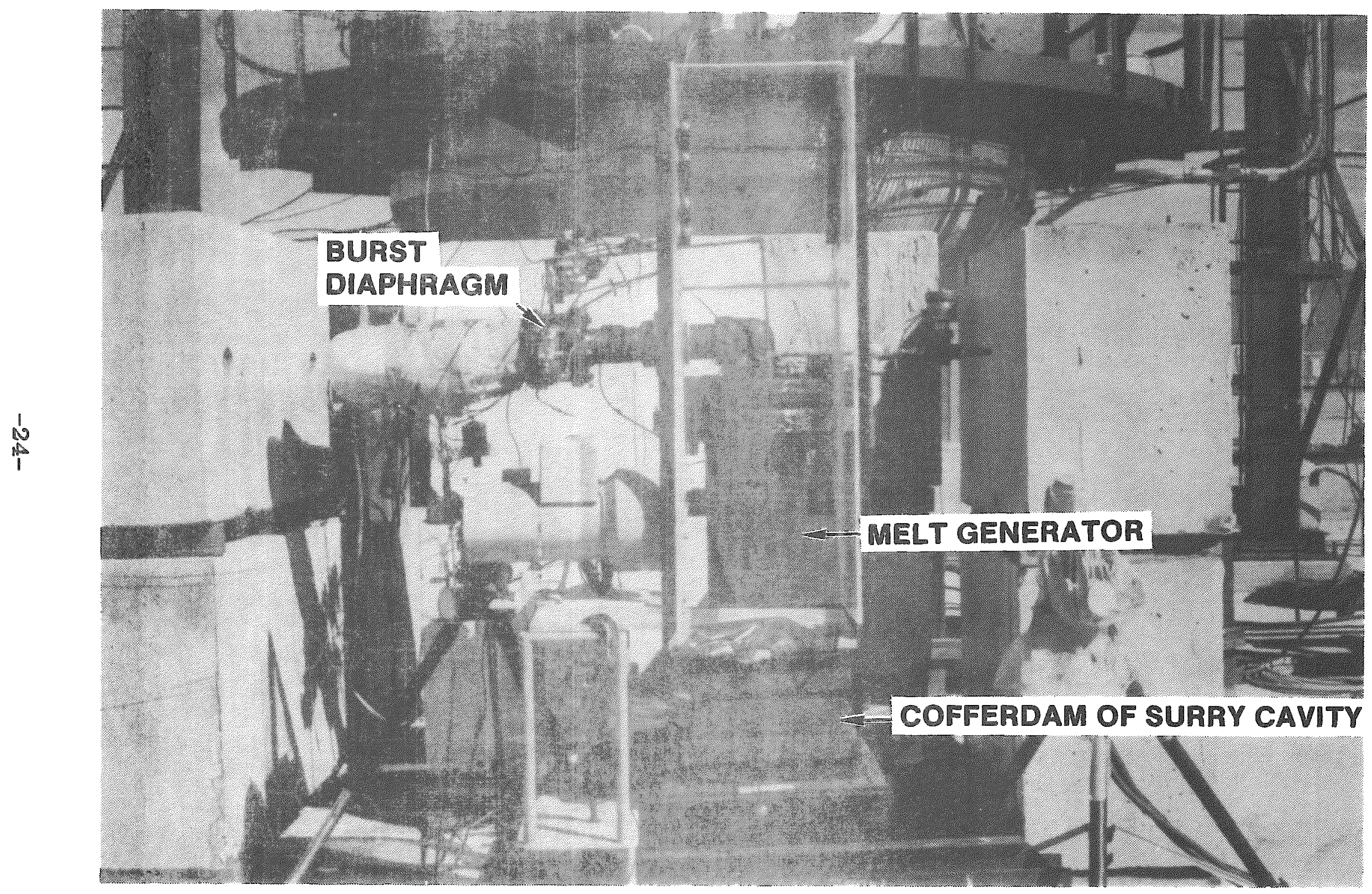

Figure 2-6. Photograph of the Intry-los expeximental Setup 


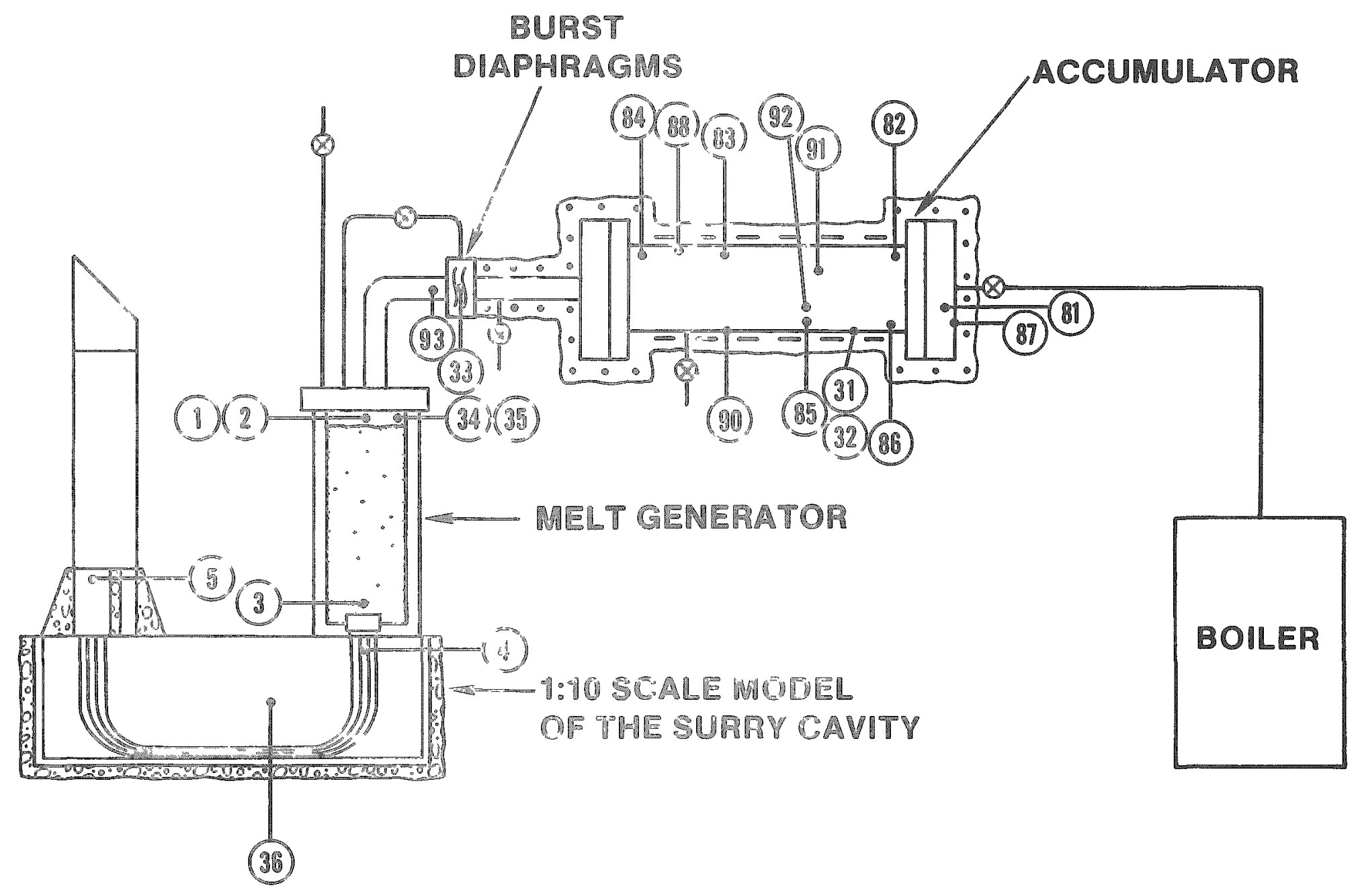

Tigure 2-7. Instringntan,

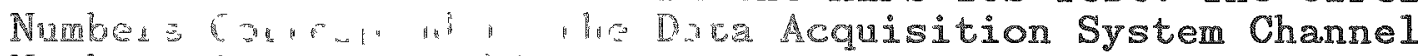

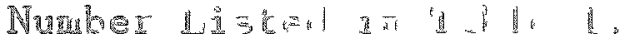




\subsection{EXPERIMENT OBSERVATIONS}

\subsection{Steam B1owdown Test}

Tho steam blowdown test was successfully performed on March 9, 1989. The burst diaphragm failed immediately after valve V3 was opened. This vented the space between the rupture discs to the crucible, thus making the pressure differential across the burst diaphragm greater than 2.68 MPa. The failed rupture discs were ejected from the cavity by the high-pressure steam blowdown. The steam plume visibly reached a maximum height of approximately 12 meters. The scaled instrument tubes remained intact in the cavity. Steam condensed in the cavity, especially on the aspirated thermocouples and steel plate lining the floor of the cavity.

Figure $3-1$ is a photograph of the steam blowdown experiment at about 0.5 after the burst diaphragm ruptured. This photograph was made from a single frame of a 16-mm film and is thus rather grainy. The steam plume exiting the cavity condensed as it mixed with air. It rose to a maximum height of about 12 meters.

\subsection{The HIPS-10S Experiment}

The HIPS-10S test was successfully conducted on March 15 , 1989. During the HIPS-10S experiment the accumulator tank was pressurized with superheated steam. The accumulator leak rate was higher than expected based on pretest leak rate measurements, but the decision was made to run the test as long as the pressure was greater than $3.45 \mathrm{MPa}$ (500 psig). After the pressure in the accumulator tank was brought to about $3.7 \mathrm{MPa}$ (536 psig), the thermite reaction was initiated. The thermite burn lasted approximately 25 seconds before failing the fusible brass plug in the bottom of the crucible. This initiated ejection of thermite into the cavity. 
It was observed through video monitors that debris ejection seemed to occur in two separate stages. After studying the timing and pressure records, it is believed that the vent to the atmosphere on the melt generator may have plugged; this allowed the gas volume above the thermite to pressurize due to heat from the thermite reaction. This back pressure caused the timing of the burst diaphragm failure to be late by a few hundred milliseconds. When the timing probe signaled valve V3 to close and valve V4 to open, thus venting the space between the rupture discs to the space in the melt generator above the thermite, the pressure differential across the burst diaphragm was less than $2.68 \mathrm{MPa}$, and failure of the rupture discs did not occur immediately. After the brass plug melted and molten thermite began to flow out into the cavity, the back pressure on the burst diaphragm was reduced, allowing failure of the rupture discs and pressurization of the melt generator by steam. The high-pressure steam then initiated the dispersal.

A series of photographs of the HIPS-1OS debris plume are shown in Figures 3-2 through 3-6. These photographs were also developed from individual frames of a 16-mm film and are thus rather grainy. The debris was violently ejected from the cavity and formed a bright-orange, luminous plume that was deflected at a $60^{\circ}$ angle (from horizontal) by the lucite deflection shield and spread into the atmosphere. The leading edge of the plume was composed of highly luminous debris. After traveling for a distance, a dark aerosol cloud began to form behind the main plume of the highly luminous material. It is estimated that the plume reached a height of 50 meters and traveled approximately 70 meters longitudinally.

Posttest examination showed that the cavity floor and walls were coated with a thin layer (about $0.5 \mathrm{~mm}$ thick) of dark gray debris. The wires used to simulate the instrument guide tubes were torn out of the cavity and ejected with the debris plume. Pieces of these wires, which varied in length from 5 to $25 \mathrm{~cm}$, were found at distances up to $100 \mathrm{~m}$ from the test apparatus. Other forms of debris found at large distances from the cavity included small prolate spheroids with dimensions on the order of $3 \mathrm{~mm}$. These spheroids were usually at leat partially hollow with a hole in one end. This is consistent with unreported observations from a large number 
of experiments at Sandia that utilized thermite. This morphology may be due to the fact that the exterior of the sphere cooled faster than the interior, thus forming a hard crust on the outside of the spheroid. Volatile gases increased pressure inside the spheroid until it vented, leaving it partially hollow.

The film records and the sound track left some observers with the subjective opinion that there was a hydrogen burn in the plume outside the cavity. The plume in HIPS-10S appeared to be more luminous than in previous HIPS experiments [3]. Cavity dispersal was characterized by a "whumpt" on the sound track, whereas previous HIPS experiments were characterized by more of a "roar". It is recognized, however, that HIPS-10S was the first experiment with the Surry cavity and the unique sequence of events leading to melt ejection could have contributed to these subjective differences. 


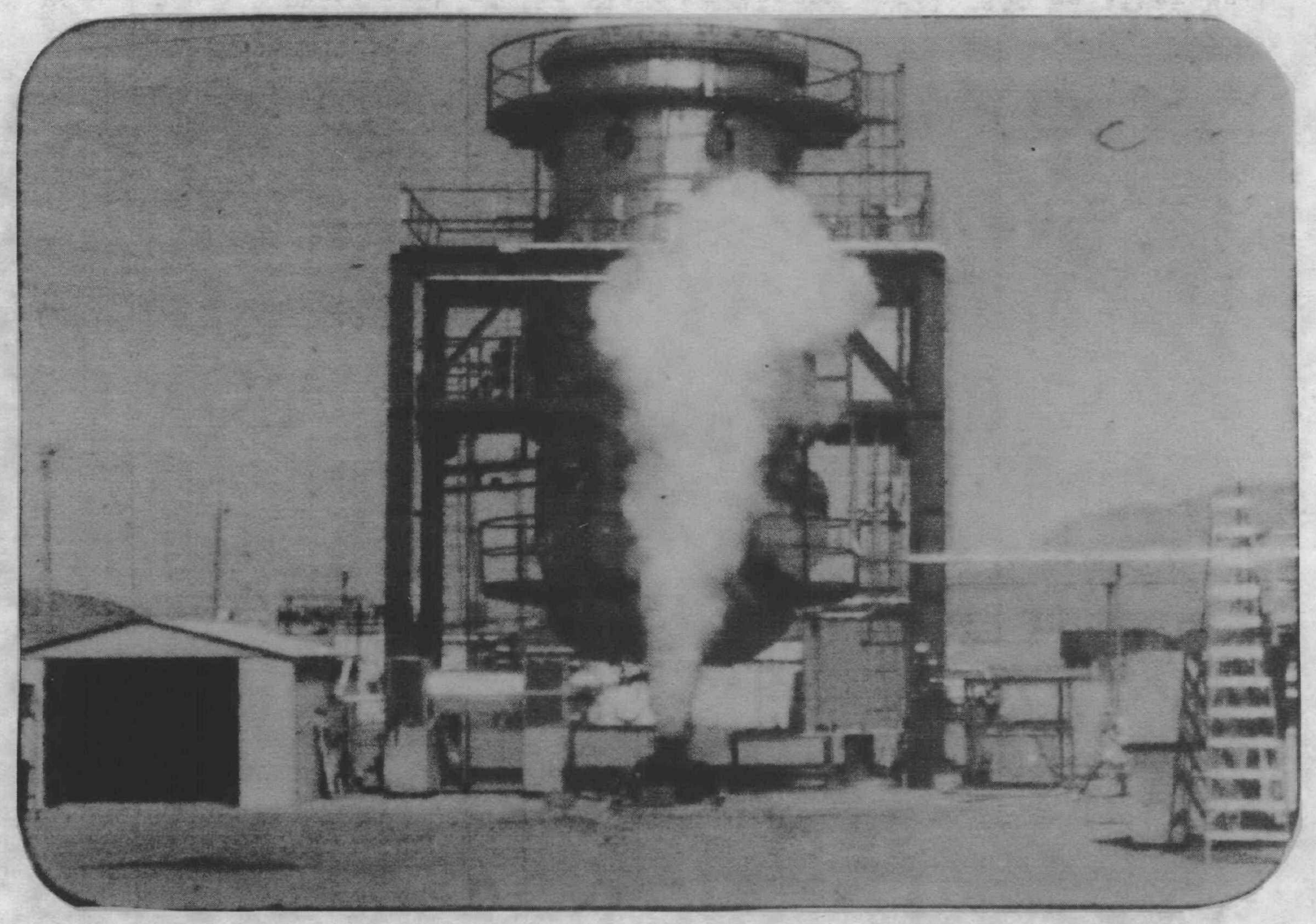

Figure 3-1.

Photograph of the Steam Blowdown Test Plume at Approximately 500 ms After the Burst Diaphragms Ruptured 


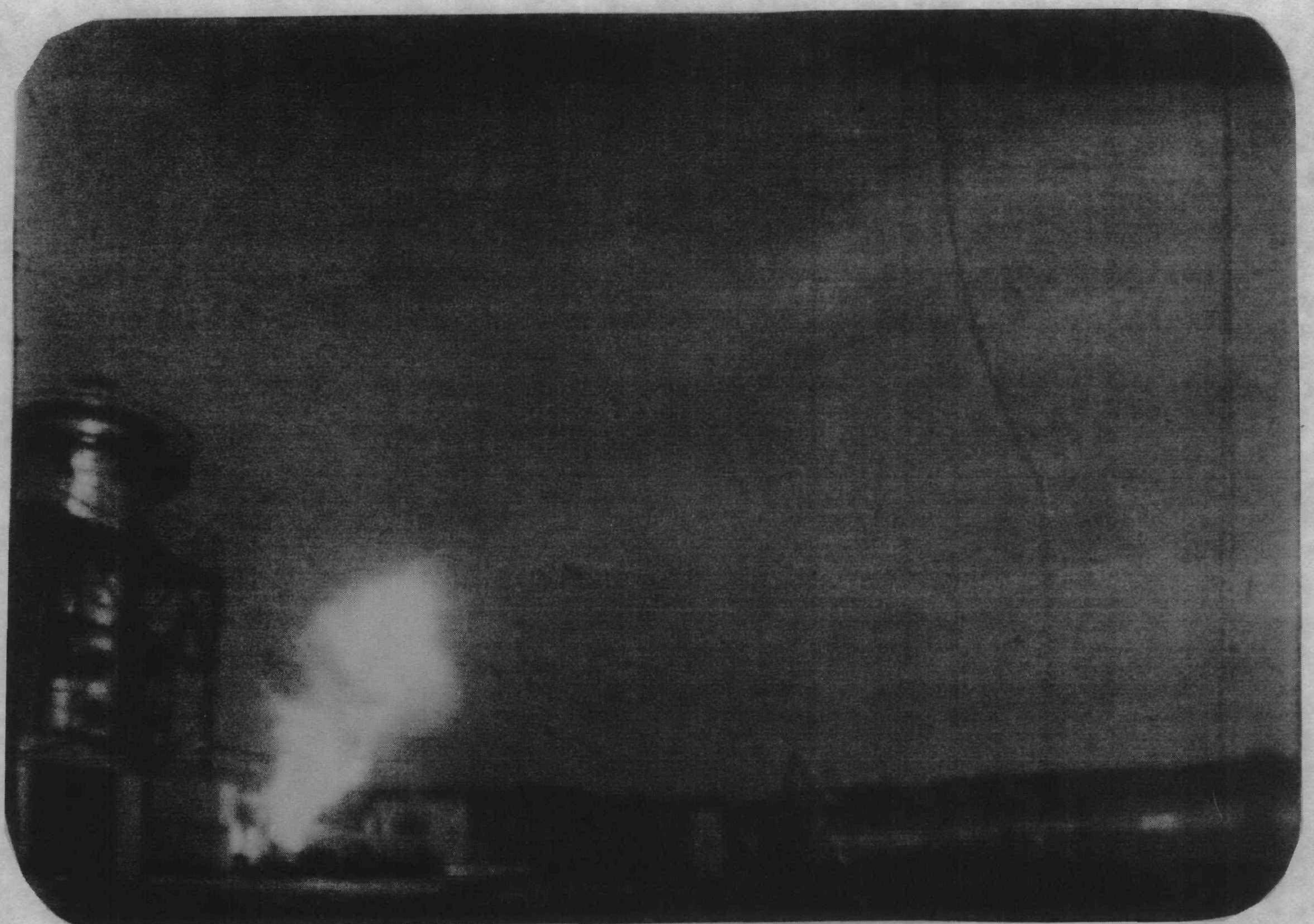

Figure 3-2. Photograph of the Plume at Approximately 300 ms After Melt Ejection in the HIPS-10S Test 


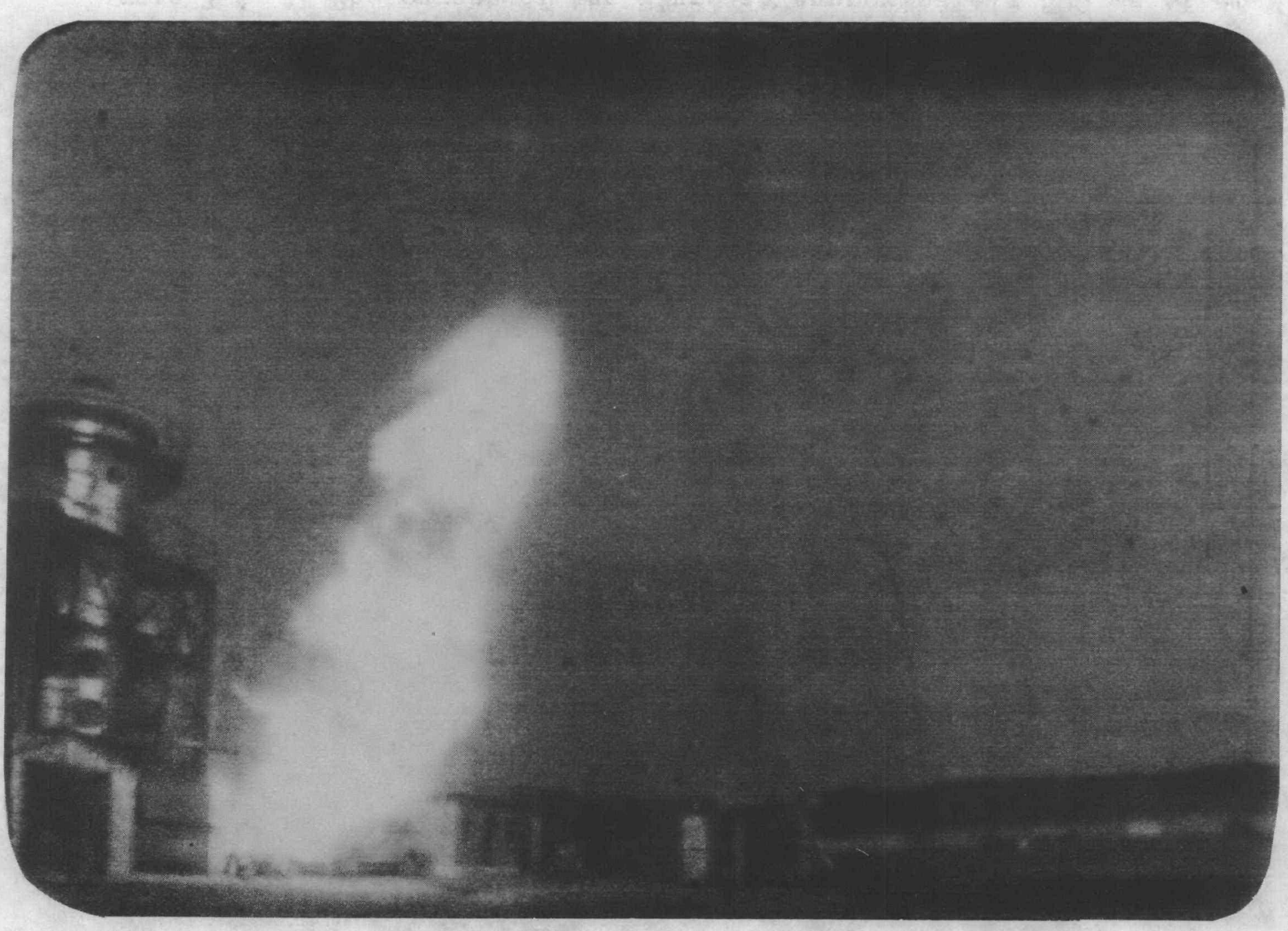

Figure 3-3. Photograph of the Plume at Approximately 400 ms After Melt Ejection in the HIPS-10S Test 


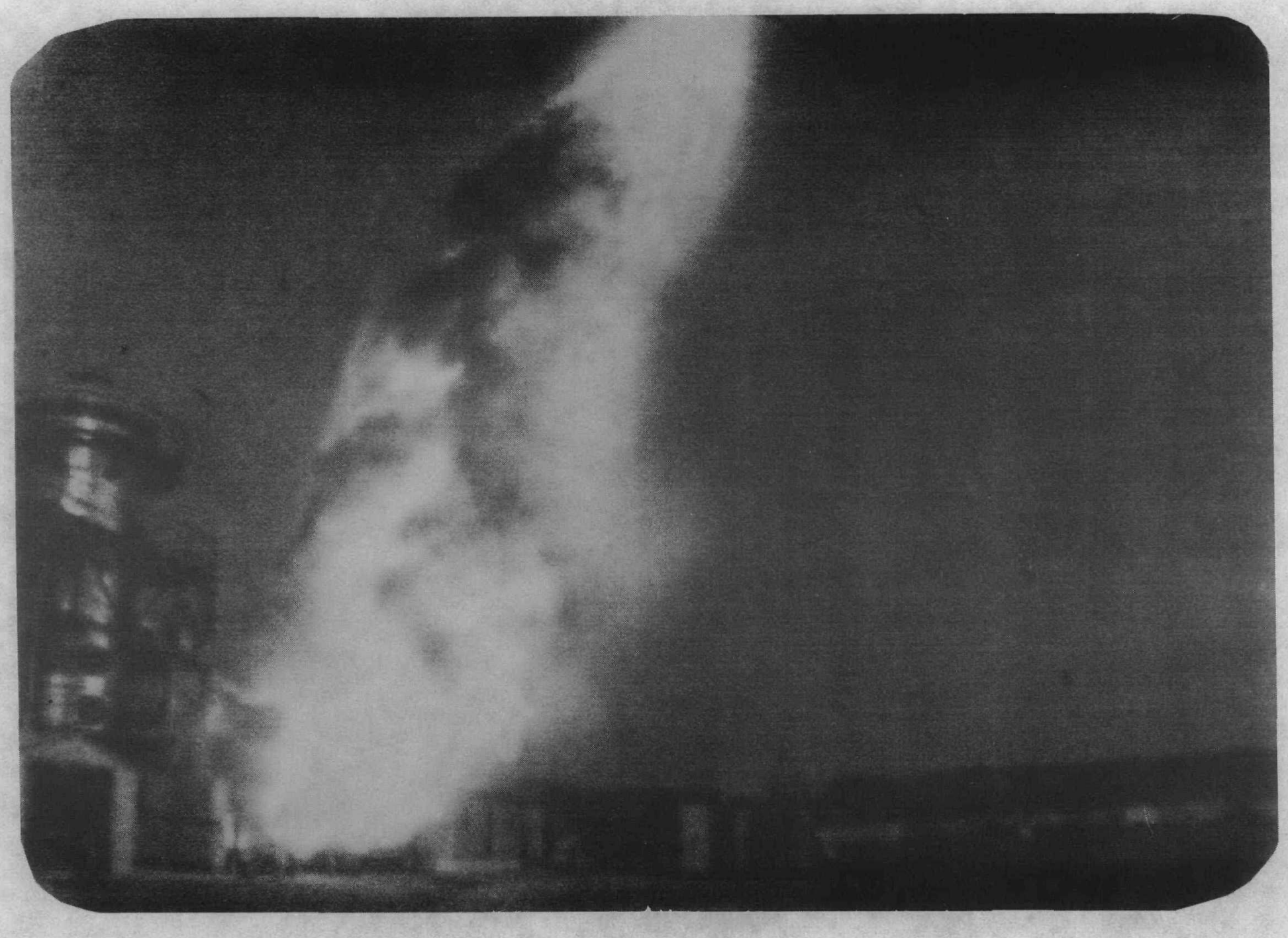

Figure 3-4. Photograph of the Plume at Approximately 500 ms After Melt Ejection in the HIPS-10S Test 


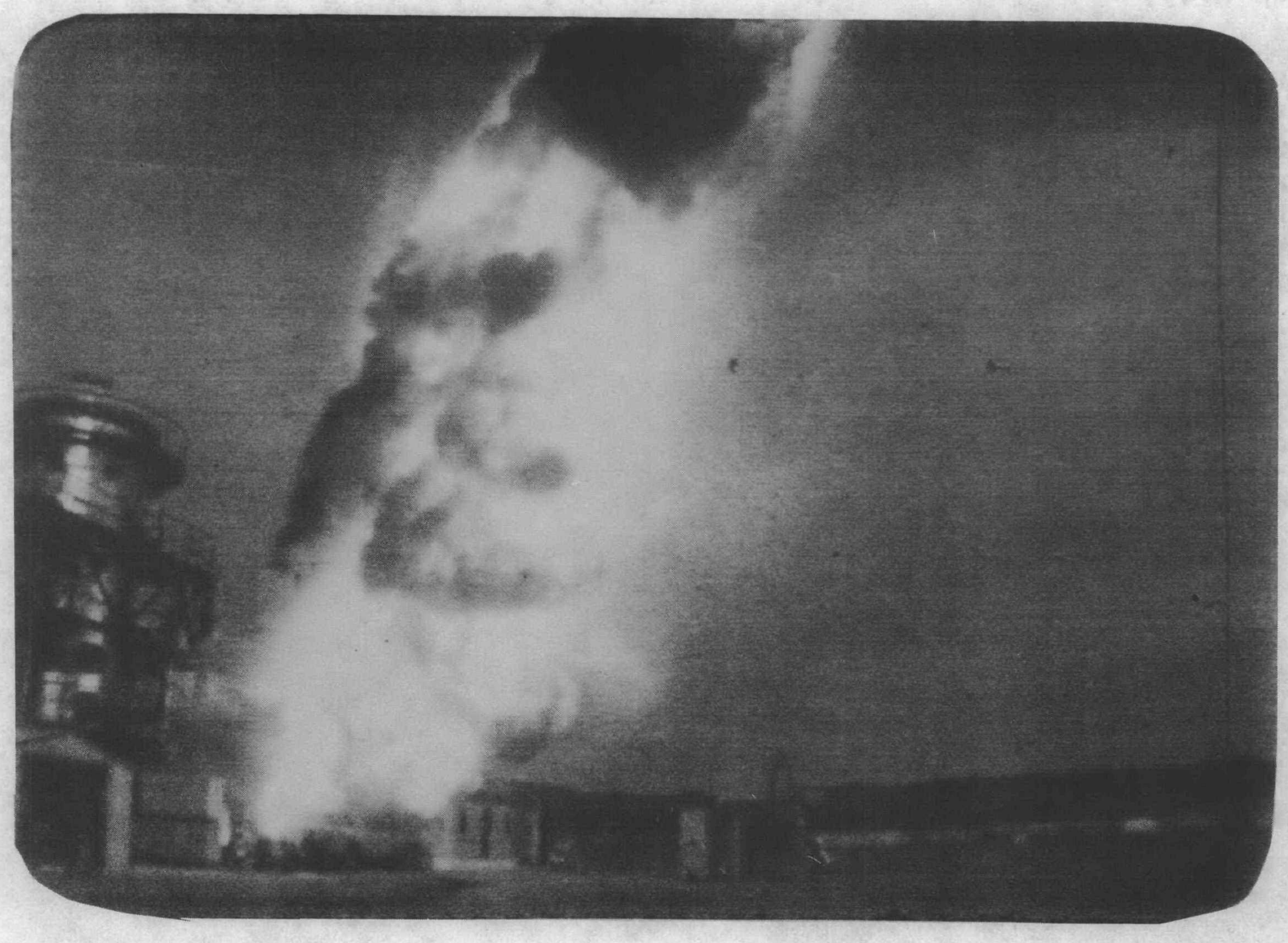

Figure 3-5. Photograph of the Plume at Approximately 600 ms After Melt Ejection in the HIPS-10S Test 


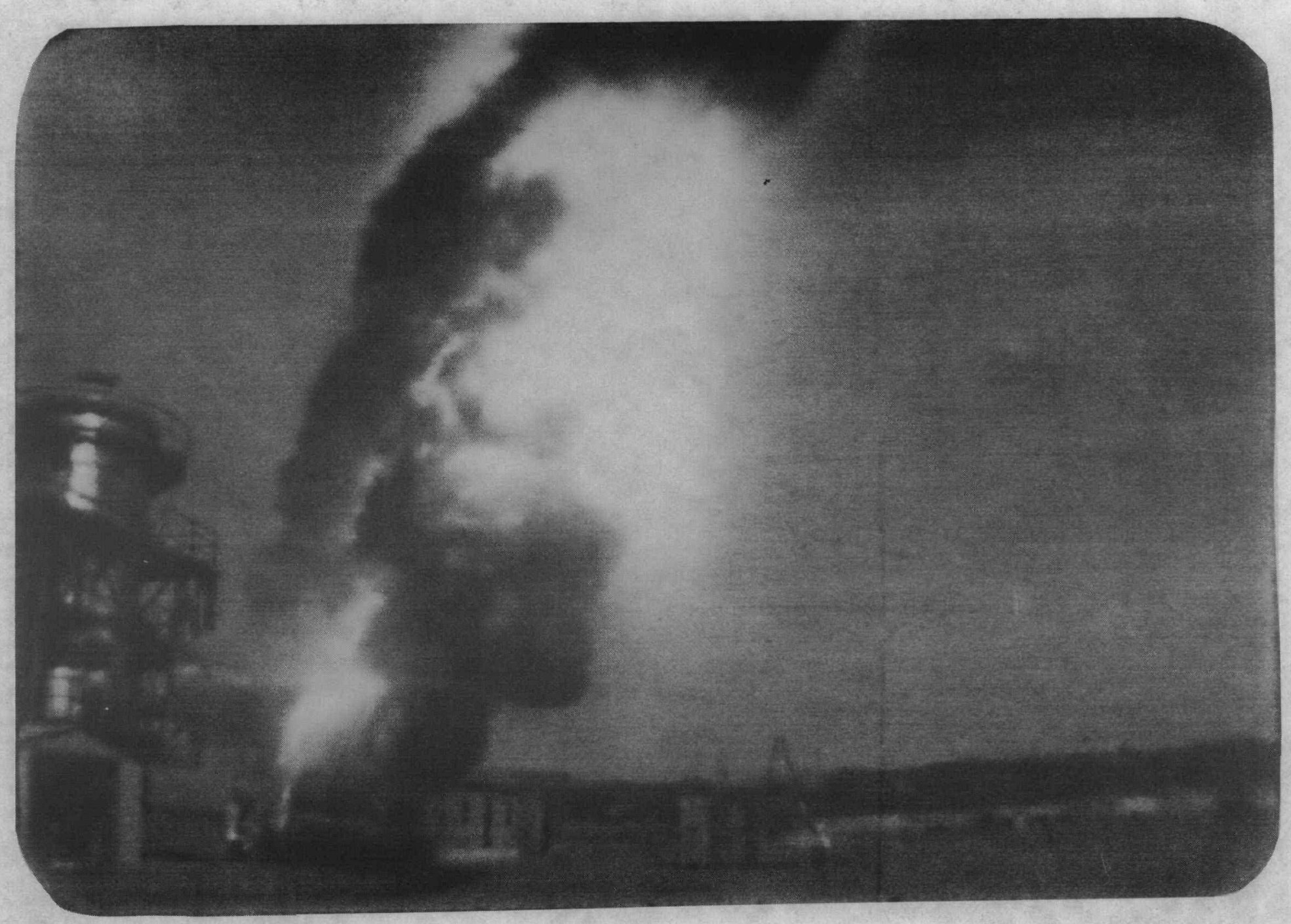

Figure 3-6. Photograph of the Plume at Approximately 1 s After Melt Ejection in the HIPS-10S Test 


\subsection{RESULTS}

\subsection{Steam Blowdown Test}

Figure 4-1 is a plot of the gas temperature in the steam accumulator tank (channel 91) as a function of time. In the steam blowdown test, the time set equal to zero corresponds to the signal that was sent to the actuators which closed valve V3 and opened valve V4, thus failing the burst diaphragn and initiating the steam blowdown. The initial steam temperature in the accumulator was $340^{\circ} \mathrm{C}$, which is well above the saturation temperature $\left(255^{\circ} \mathrm{C}\right)$ at $4 \mathrm{MPa}$.

Figure 4-2 shows gas temperatures in three locations: (1) in the 10-cm diameter pipe between the accumulator and the burst diaphragm (channel 93); (2) at the top of the crucible (channel 34); and (3) at the cavity exit (channel 36). From this figure it can be seen that a sudden increase in the temperature at the top of the crucible and in the cavity occurs at $0.3 \mathrm{~s}$; this corresponds to rupture of the burst diaphragm and initiation of the steam blowdown. The initial temperature in the 10-cm diameter pipe between the accumulator and the burst diaphragmas about $265^{\circ} \mathrm{C}$. The temperature at the top of the crucible increased abruptly to about $200^{\circ} \mathrm{C}$ and then decayed rapidly; this curve agrees with video records which indicate that the steam blowdown was complete within about $1.5 \mathrm{~s}$. The gas temperature at the cavity exit increased instantaneous $1 \mathrm{y}$ to $100^{\circ} \mathrm{C}$ and remained constant for at least 10 : this constant temperature may be due to steam condensation in the aspirated thermocouple.

Figure 4-3 show pressures measured in the steam blowdown experiment. The initial gauge pressure in the accumulator was 3.9 MPa, the space between the rupture discs of the burst diaphragm was $2 \mathrm{MPa}$, and the crucible was at ambient pressure since it was rented to the atmosphere. At about $0.3 \mathrm{~s}$, valve V3 was opened and valve V4 was closed; this vented the space between the rupture discs to the crucible. This caused the differential pressure across the burst diaphragm to be greater than $2.68 \mathrm{MPa}$, and the rupture discs failed immediately, which initiated the stean blowdown. The decay in 
the pressure indicates that the steam blowdown was virtually complete within $1.5 \mathrm{~s}$.

Figure 4-4 shows the cavity pressure (channel 36) plotted against time. The signal from the pressure transducer was very noisy. The pressure in the cavity increased to about 14 $\mathrm{kPa}$ shortly after the initiation of the steam blowdown (at $0.3 \mathrm{~s}$ ). The pressure returned to the background level at about $1 \mathrm{~s}$, even though the steam blowdown was not complete. The cavity was open to the atmosphere and high pressures were not expected.

Figures 4-5 through 4-7 show pitot tube differential pressure measurements for probes located at the bottom, middle, and top of the cavity, respectively. Only qualitative information will be derived from these data. These figures indicate that the steam blowdown started at $0.3 \mathrm{~s}$. The highest differential pressures and thus the highest bulk flows were measured along the bottom of the carity. The measurements from the pitot tube located at the bottom of the cavity also show that the steam blowdown was virtually complete within $1.5 \mathrm{~s}$. Figure 4-6 indicates that there may have been reverse flow at the center of the cavity. The measured differential pressure for the top pitot tube (Figure 4-7) shows that there was very little flow along the top of the cavity.

\subsection{The HIPS-10S Experiment}

\subsubsection{Pressure and Temperature Measurements}

Figure 4-8 shows the steam temperature in the accumulator tank as a function of time in HIPS-10S (channel 91). The initial steam temperature in the accumulator was $420^{\circ} \mathrm{C}$, which is well above the saturation temperature for steam at $4 \mathrm{MPa}$. The temperature decreased when the melt ejection began. The temperature of the steam exiting the 10-cm diameter pipe (channel 93) between the accumulator and burst diaphragm is shown in Figure 4-9. The initial temperature was slightly above $300^{\circ} \mathrm{C}$ and decreased just after melt ejection began. 
The crucible gas temperature (channel 1) is plotted as a function of time in Figure 4-10. The thermite was ignited at an experiment time of -24.75 s. Figure $4-10$ shows that the gas temperature in the crucible started increasing as soon as the thermite was ignited; however, the curve was not smooth and did not show good agreement with the data from the other crucible thermocouple (channel 2), probably because the molten thermite splashed onto these thermocouples.

The timing of the experiment can be determined from Figures 4-11 through 4-14. An experiment time of 0 is when the photodiode under the fusible brass plug first sensed the melt ejection. Figure $4-11$ shows that the thermite was ignited at an experiment time of $-24.75 \mathrm{~s}$; this means that it took 24.75 s for the melt front to propagate downward through the thermite and melt the brass plug. At an experiment time of -1.72 s (Figure 4-12) the timing probe (channel 3 ) in the thermite located $7.5 \mathrm{~cm}$ above the brass plug sensed the melt front and sent signals to valves $V 3$ and $V 4$. Figure $4-13$ is a plot of the signal from the photodiode below the melt plug: this signal sets the experiment time in the data acquisition system equal to 0 . Figure $4-14$ shows the signal from the photodiode at the cavity exit; this figure indicates that it takes about 0.04 for the photodiode at the chute exit to sense the melt front.

Figures $4-15$ and $4-16$ show accumulator pressure as a function of experiment time (channel 31 and 32 , respectively). These curves are in excellent agrement. The initial pressure in the accurulator was $3.6 \mathrm{MPa}$. The pressure decreased sharply at about 0.55 when the burst diaphrag ruptured. The blowdown of the accumulator was complete in about $1.5 \mathrm{~s}$.

The gauge pressures measured in the crucible (channels 34 and 35) at experiment times between -25 and +5 are shown in Figures 4-17 and 4-18, respectively. The measurements from these pressure transducers are in excellent agreement. After thermite ignition at -24.75 , the pressure in the crucible steadily increased. Since the crucible was vented to the atmosphere, this clearly means that the vent plugged, probably due to the thermite violently splashing in the space 
at the top of the crucible. The pressure in the crucible built up to $1.9 \mathrm{MPa}$. When the timing probe signaled valve V3 to open and V4 to close, the differential pressure across the burst diaphragm was only about $1.7 \mathrm{MPa}$, and thus it did not fail when it should have. When the brass plug melted, the burst diaphragm had not failed and the steam was not in contact with the thermite. The back pressure in the crucible above the thermite forced the thermite to flow into the cavity, hence relieving pressure in the top of the crucible. When the back pressure in the crucible was about $1.3 \mathrm{MPa}$ at $0.5 .5 \mathrm{~s}$, the burst diaphragm ruptured and the steam pressurized the crucible, causing a steam-driven, high-pressure melt ejection. Figures $4-18$ and $4-20$ show the pressure measured in the crucible over a shorter time span. From these figures it is obvious that the burst diaphragm failed at about 0.55 and the blowdown was nearly complete 1.5 s later.

Figure 4-21 shows the pressure in the space between the rupture discs of the burst diaphragm as a function of time. This space was initially pressurized with nitrogen to 2.0 MPa. At $-1.7 \mathrm{~s}$, this space was vented to the space in the crucible above the thermite, which should have been at atmospheric pressure, but was not because the vent on the crucible had plugged. The pressure downstream of the burst diaphragm equilibrated at about $1.8 \mathrm{MPa}$ and the pressure in the accumulator was $3.5 \mathrm{MPa}$. Thus, the pressure differential across the burst diaphragm was approximately $1.7 \mathrm{MPa}$, which is less than the $2.68 \mathrm{MPa}$ pressure differential required to fail it. At a time equal to $0 \mathrm{~s}$, the melt plug failed and molten thermite was forced out of the melt generator into the cavity by the back pressure in the crucible. As the thermite flowed out of the melt generator, this relieved the back pressure and allowed the burst diaphragm to fail when the pressure differential was large enough. The rupture discs of the burst diaphragm apparently failed at a diffential pressure of approximately $2.2 \mathrm{MPa}$ according to measured pressures in Figure 4-22. Failure of the burst diaphragm is indicated by the pressure spike at $0.55 \mathrm{~s}$ in Figure 4-21.

Figure 4-22 shows the accumulator pressure, the burst diaphragm pressure, and the crucible pressure plotted against experiment time. At time equal to $0 \mathrm{~s}$, the accumulator was at 
3.5 MPa, and the burst diaphragm and crucible were equilibrated at about 1.2 MPa. Molten thermite was forced out of the melt generator by the back pressure, which decreased until the pressure differential across the burst diaphragm was about $2.2 \mathrm{MPa}$ at this point, the burst diaphragm failed and the high-pressure steam was introduced into the melt generator. Results in Figure 4-22 show that blowdown was virtually complete within $1.5 \mathrm{~s}$.

Figure 4-23 is a plot of cavity pressure against time (channel 36). The cavity pressure started to increase at 0.55 and reached a maximum of about $0.28 \mathrm{MPa}$. The pressure in the cavity was above ambient pressure for about $0.7 \mathrm{~s}$.

Figure $4-24$ is a plot of the data recorded from the $11 \times 20$ optical pyrometer focused at the top of the lucite exit chute. The average temperature of the ejected thermite recorded by the pyrometer through the lucite was about $2000^{\circ} \mathrm{C}$. Figure 4-24 was plotted using a debris emissivity of 0.9 . The data from this figure indicate a debris ojection interval of about $450 \mathrm{~ms}$. No data were obtained from the $11 x 30$ optical pyrometer focused at the chute exit. The data from the two-color pyrometer is plotted in Figure 4-25. These data indicate a debris temperature at the chute exit of about $1750^{\circ} \mathrm{C}$; however, it was later determined that this instrument consistently reads low and needed to be shipped back to the factory for repairs and calibration.

\subsubsection{Result of Gas Analyzer}

The gases found in gas grab samples A (from the top port of the cavity) and $B$ (from the middle port of the cavity) were hydrogen, nitrogen, oxygen, argon, carbon monoxide, methane, carbon dioxide, and water. Grab sample C (from the bottom port of the cavity) was a background sample of gases in the cavity and consisted only of nitrogen, oxygen, and argon. Table 3 lists the volume percent of the gases detected in each gas grab ample. The results of the gas analysis of the background amples (sample C) are plotted in Figure 4-26. The results Irom gas grab samples $A$ and $B$ are plotted in the bar graphs shown in Figures 4-27 through 4-30. 
Gas grab sample set C was taken prior to thermite ignition to obtain the background composition of gases in the cavity. The exit chute was covered with $0.076-\mathrm{mm}$-thick plastic, and the cavity was purged with argon to reduce the oxygen concentration. A handheld personnel monitor indicated that the oxygen concentration in the cavity was approximately 2 = 0.4 volume percent. However, the oxygen concentration measured from sample set-C was $19.4 \%$ from bottle \#1 and $19.6 \%$ from bottle \#2 (Figure 4-26). The nitrogen-to-oxygen ratio was almost identical to the ratio of air. The solenoid valves used on the gas bottles in HIPS-10S were not vacuum rated and apparently leaked; this problem has been corrected for future experiments.

Sample set A was opened at the start of the melt ejection and stayed open for one second. The results of bottles \#1 and \#2, which were opened and closed simultaneously, are in reasonable agreement. Since the cavity was purged with argon, substantial amounts of argon were measured in all of the gas grab samples. For bottle \#1 the hydrogen-to-steam ratio was 21.4, which indicates very efficient conversion of steam to hydrogen. The solenoid valve for these bottles also apparently allowed air to leak into the bottles. However, the nitrogen-to-oxygen ratio is approximately 20 , which is substantially different from air ( $(3.8)$. There are several possible explanations for this disparity: (1) oxygen was depleted by reaction with the metallic debris, (2) oxygen was depleted by recombination with hydrogen to form steam, and/or (3) additional nitrogen was introduced because the space between the rupture discs of the burst diaphragm was pressurized with nitrogen. Probably all three of these mechanisms contributed to this observation. Carbon monoxide, methane, and carbon dioxide were also observed in these samples. These gases were probably generated from impurities in the thermite or from interactions between the melt and concrete in the cavity.

Sample set B was opened one second after the initiation of melt ejection and stayed open for three seconds. The melt ejection was not quite complete when this sample set opened. The gas analysis results for these samples are shown in 
Figures 4-29 and 4-30. The results from bottles \#1 and \#2 are in good agreement. Again, there was a high percentage of hydrogen compared to steam, indicating that steam was being very efficiently converted into hydrogen. There was also leakage of air into these bottles; however, the nitrogen-tooxygen ratio was approximately 5 , which is much closer to the ratio for air ( $(3.8)$. Carbon monoxide, methane, and carbon dioxide were also found in these samples.

\subsubsection{Debris Ejection Measurements}

The mass of debris retained in the cavity was measured by scraping debris out of the cavity, collecting it, and weighing it. The total thermite mass retained in the scaled Surry cavity was $9.44 \mathrm{~kg}$. Hence, of the $80 \mathrm{~kg}$ of melt simulant, 88\% was ejected into the atmosphere and formed the luminous debris plume. 
Table 3. Gas Grab Sample Data from the HIPS-10S Test

\begin{tabular}{|c|c|c|c|c|c|c|c|c|c|}
\hline Sample & Pressure & \multicolumn{8}{|c|}{ Volume Percent $(\%)$} \\
\hline \# & $\mathrm{MPa}$ & $\mathrm{H}_{2}$ & $\mathbf{N}_{2}$ & $\mathrm{O}_{2}$ & Ar & $\mathrm{CO}$ & $\mathrm{CH}_{4}$ & $\mathrm{CO}_{2}$ & $\mathrm{H}_{2} \mathrm{O}$ \\
\hline 1 & 0.063 & 32.127 & 27.750 & 1.378 & 21.101 & 14.239 & 1.127 & 0.749 & 1.528 \\
\hline 2 & 0.061 & 27.179 & 30.364 & 1.445 & 21.912 & 14.841 & 1.205 & 0.787 & 2.267 \\
\hline
\end{tabular}

$\begin{array}{lllllll}\text { Set B } & 1 & 0.042 & 7.865 & 53.885 & 11.516 & 15.984 \\ & 2 & 0.040 & 7.373 & 55.240 & 11.211 & 15.654 \\ & & & & & & \\ \text { Set C } & 1 & 0.083 & & 74.343 & 19.384 & 6.273 \\ & 2 & 0.083 & & 73.403 & 19.632 & 6.965\end{array}$

NOTE: Atmospheric pressure in Albuquerque, NM was $0.083 \mathrm{MPa}$ on the day the HIPS-10S test was run. 


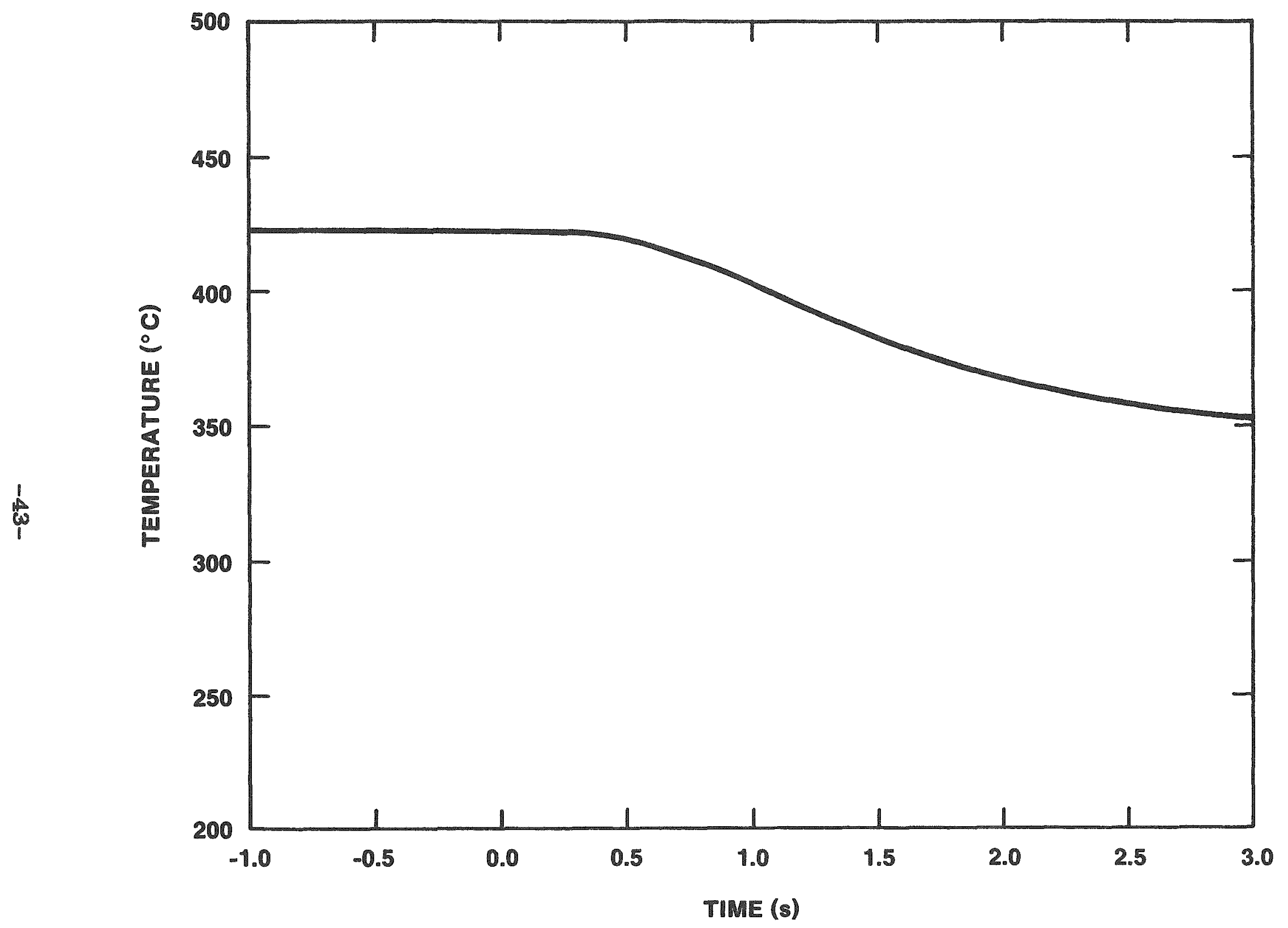

Figure 4-1. Gas Temperatures Measured in the Accumulator Tank in the Steam Blowdown Test 


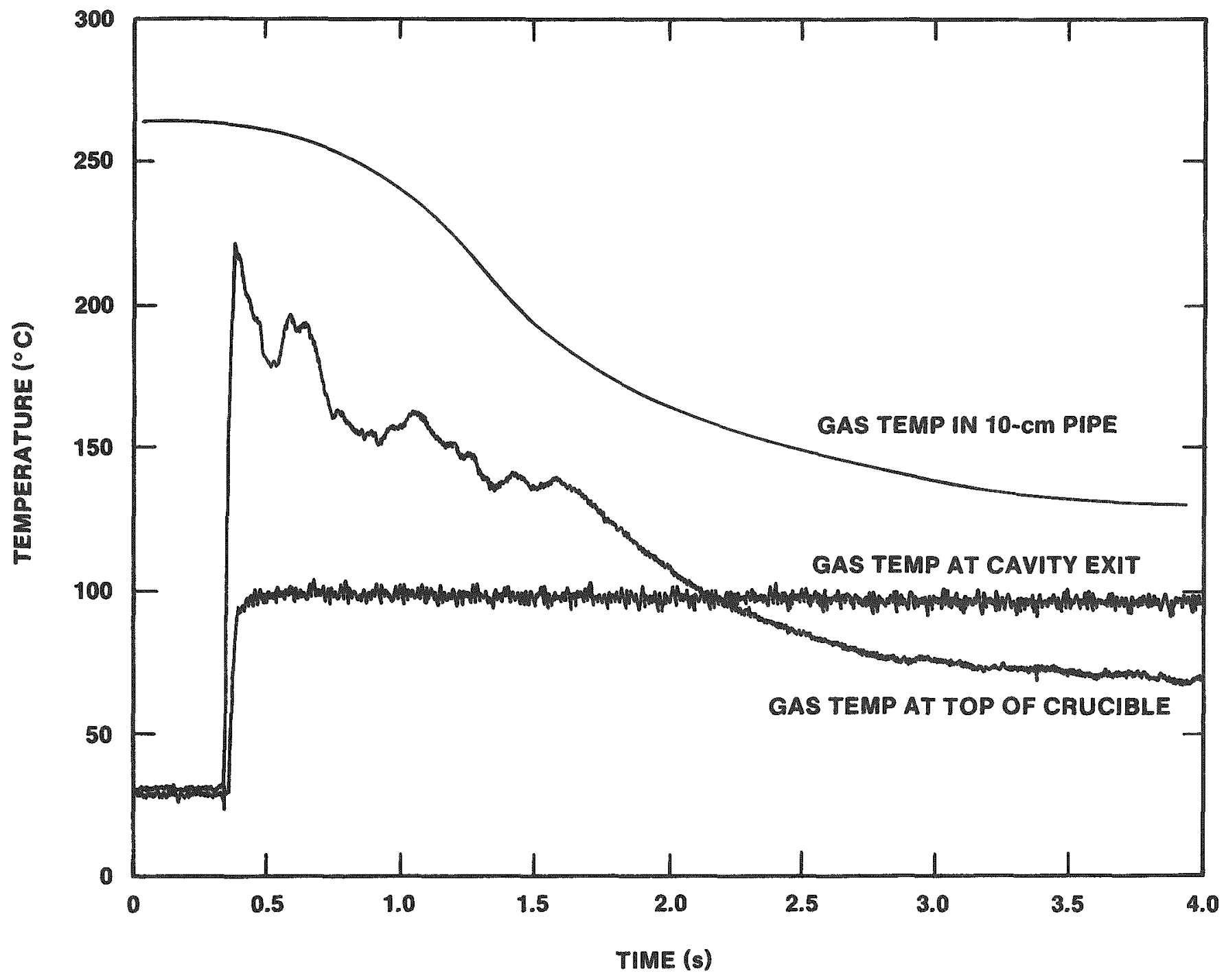

Figure 4-2. Gas Temperatures in the Steam Blowdown Test 


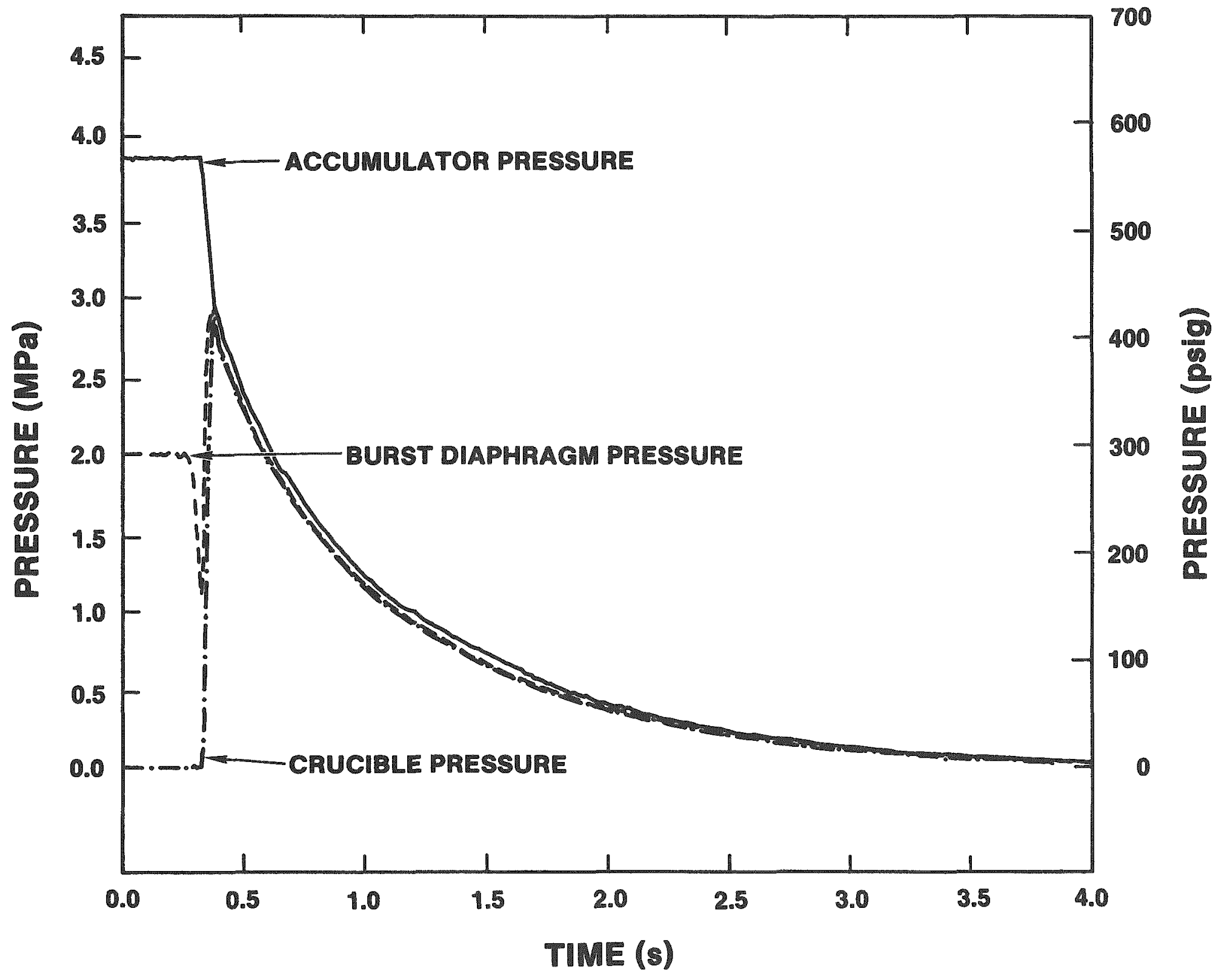

Figure 4-3. Measured Pressures in the Steam Blowdown Test 
PRESSURE (KPa)

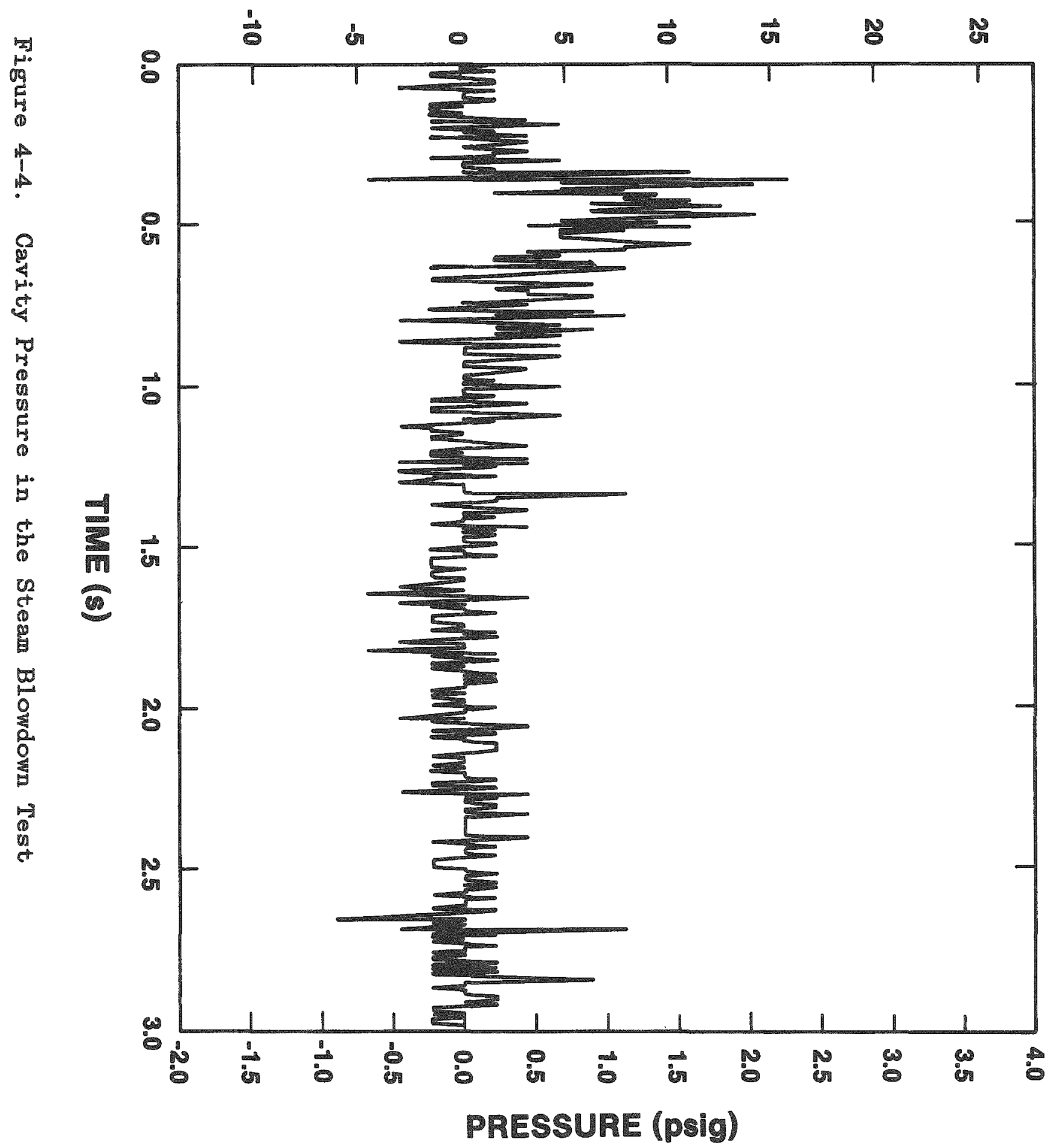




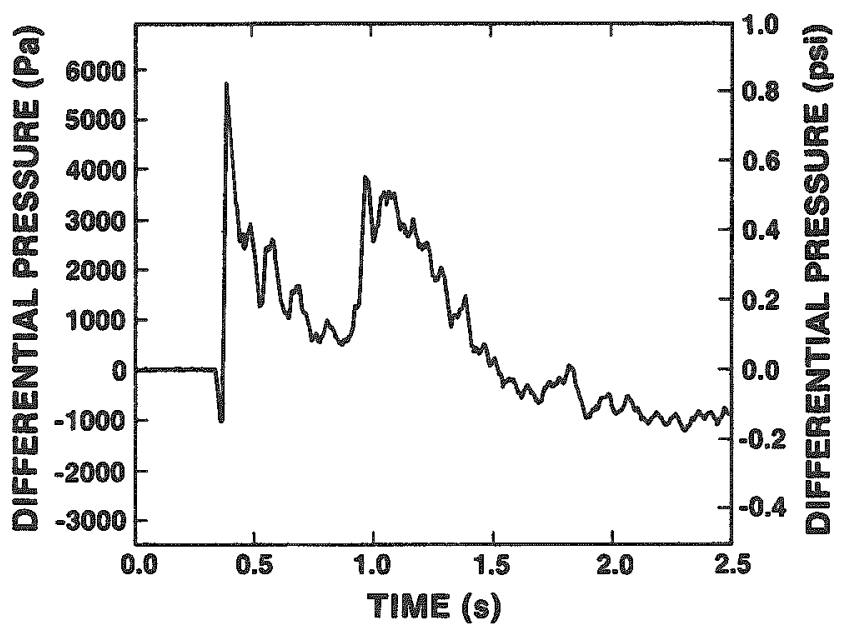

Figure 4-5. Differential Pressure Measured with the Bottom Pitot Tube in the Steam Blowdown Test

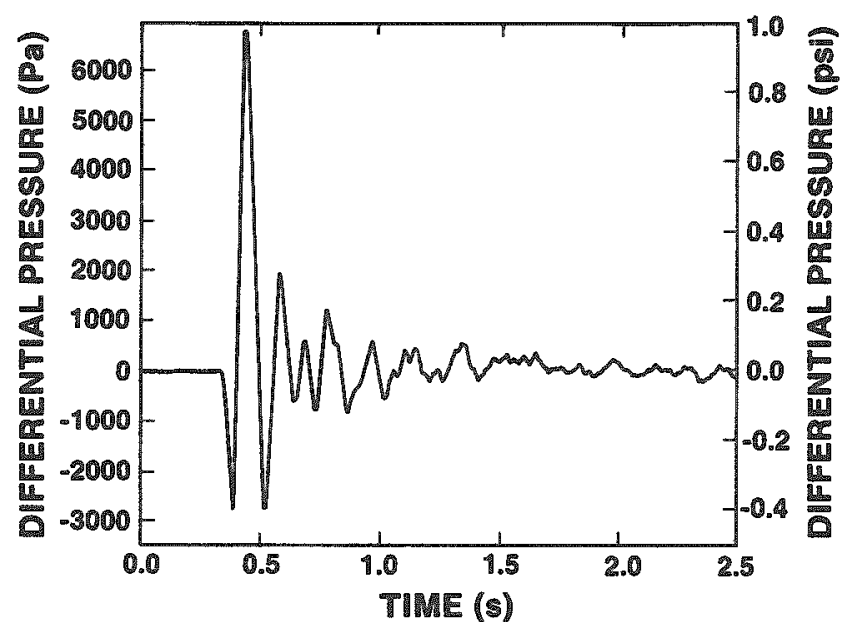

Figure 4-6. Differential Pressure Measured with the Middle Pitot Tube in the Steam Blowdown Test

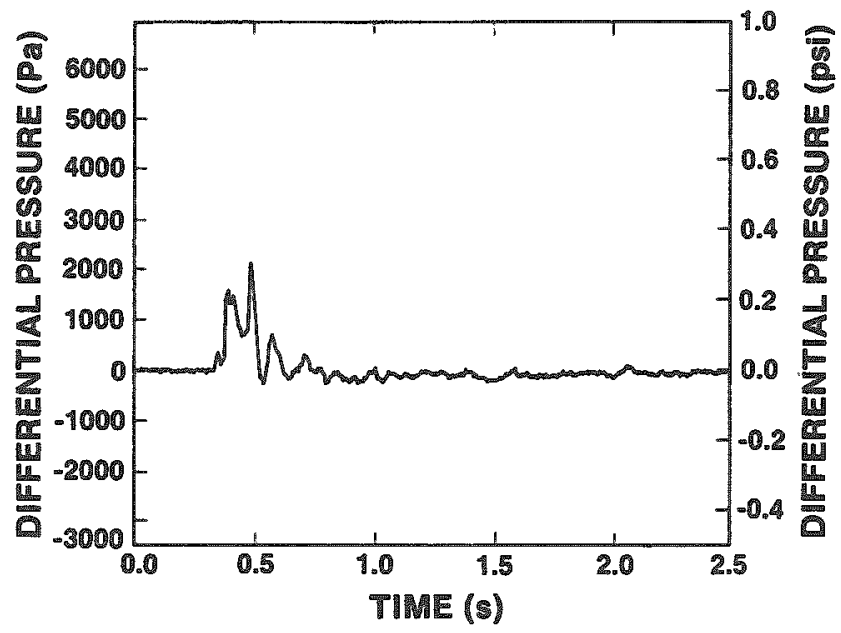

Figure 4-7. Differential Pressure Measured with the Top Pitot Tube in the Steam Blowdown Test 


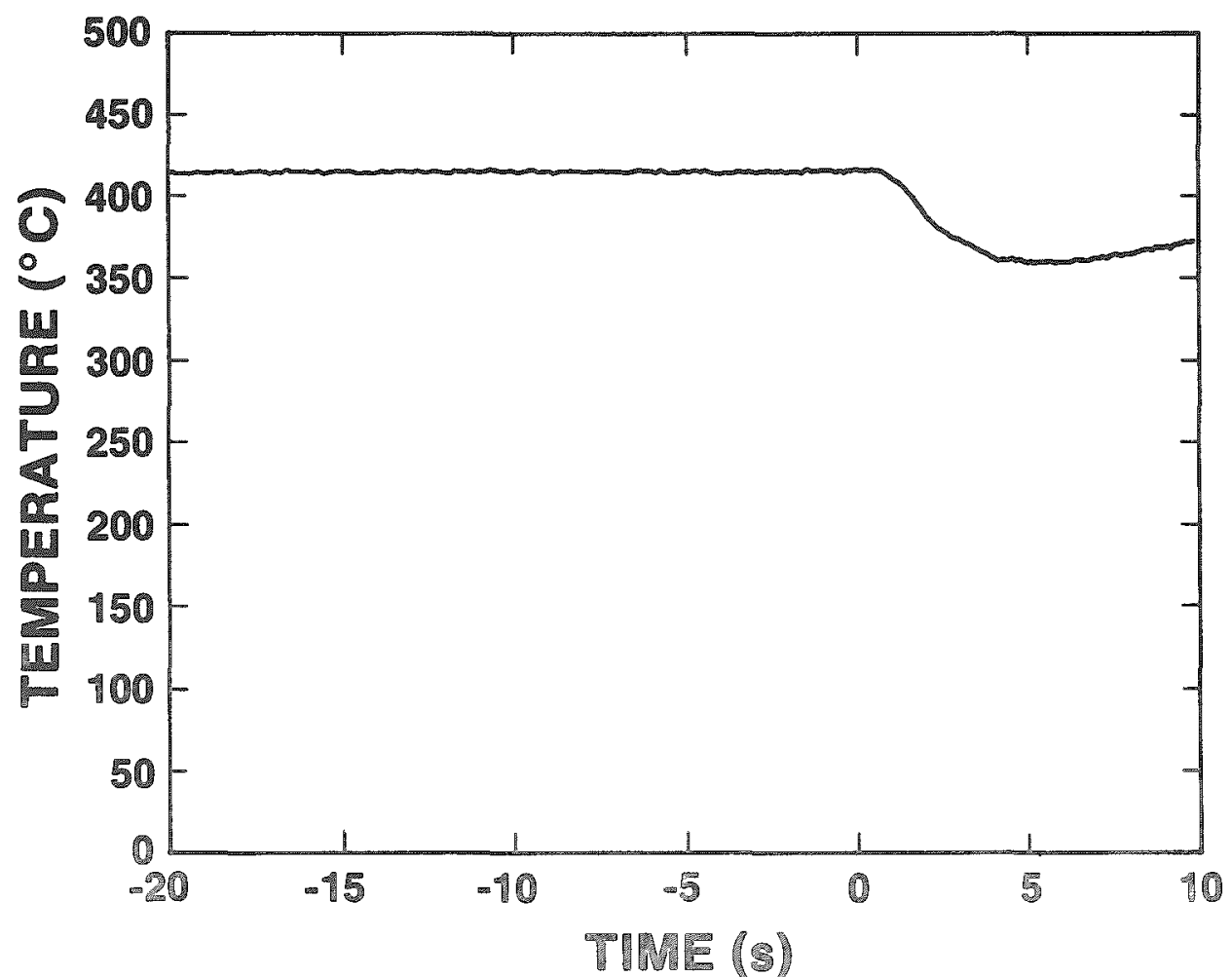

Figure A-8. Accumulator Steam Temperature in the HIPS-10S Test

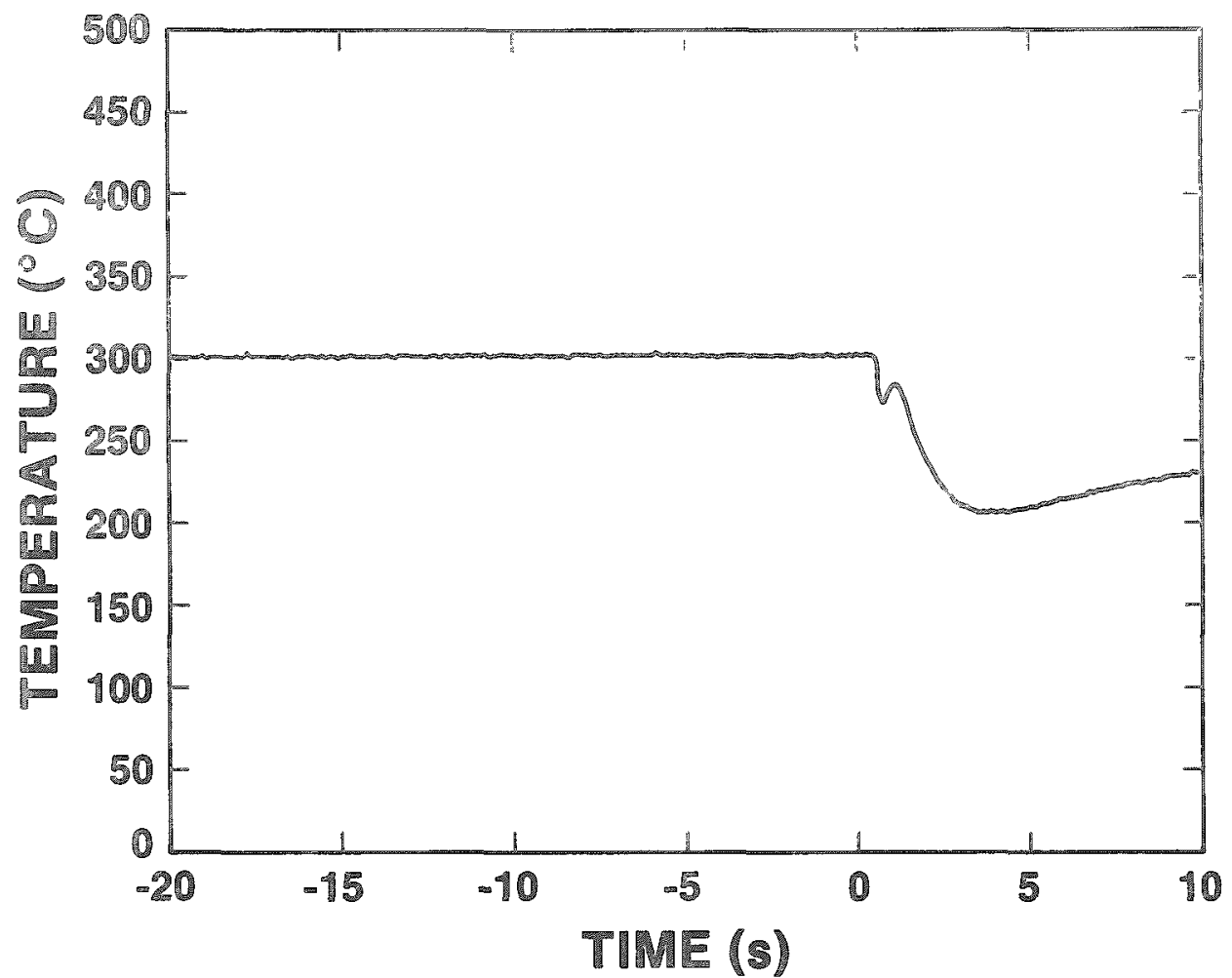

Figure 4-9. Steam Temperature Measure in the 10-cm Pipe Exiting the Accumulator in the HIPS-1OS Test 


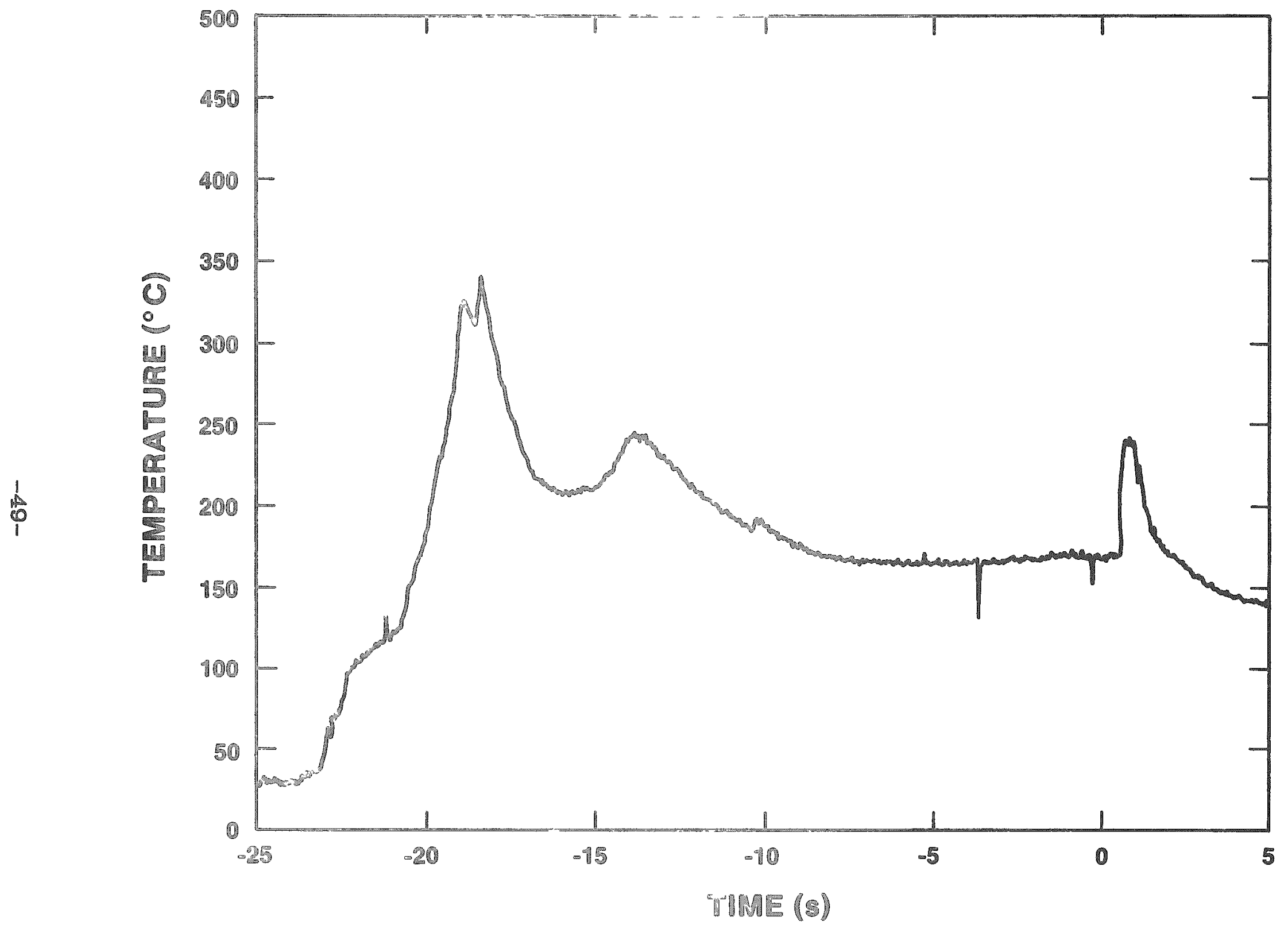

Tigure -10. Grucible Gas Tcupcrare in the HIPS-10S Test 


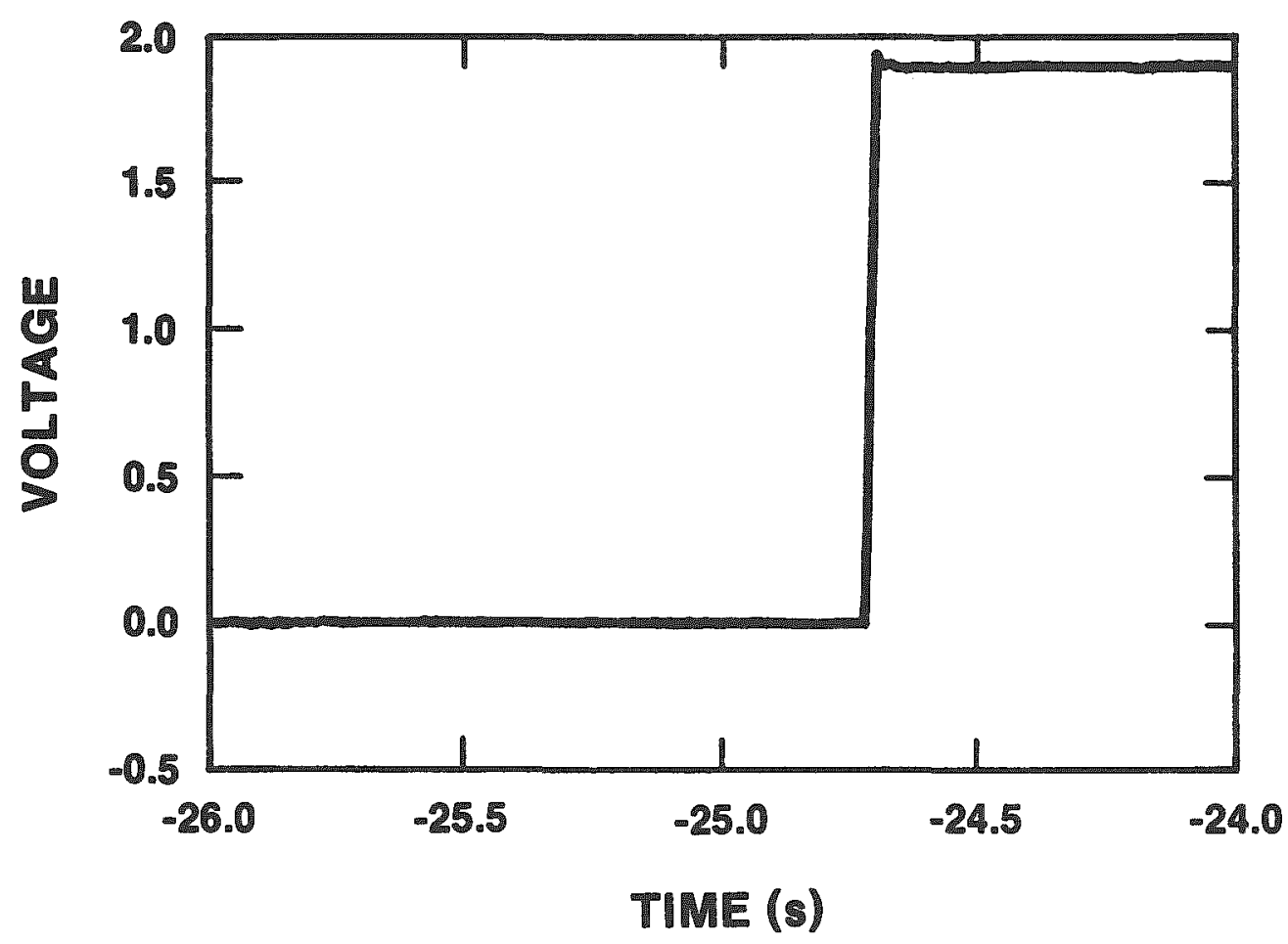

Figure 4-11. Ignition Timing Signal in the HIPS-10S Test

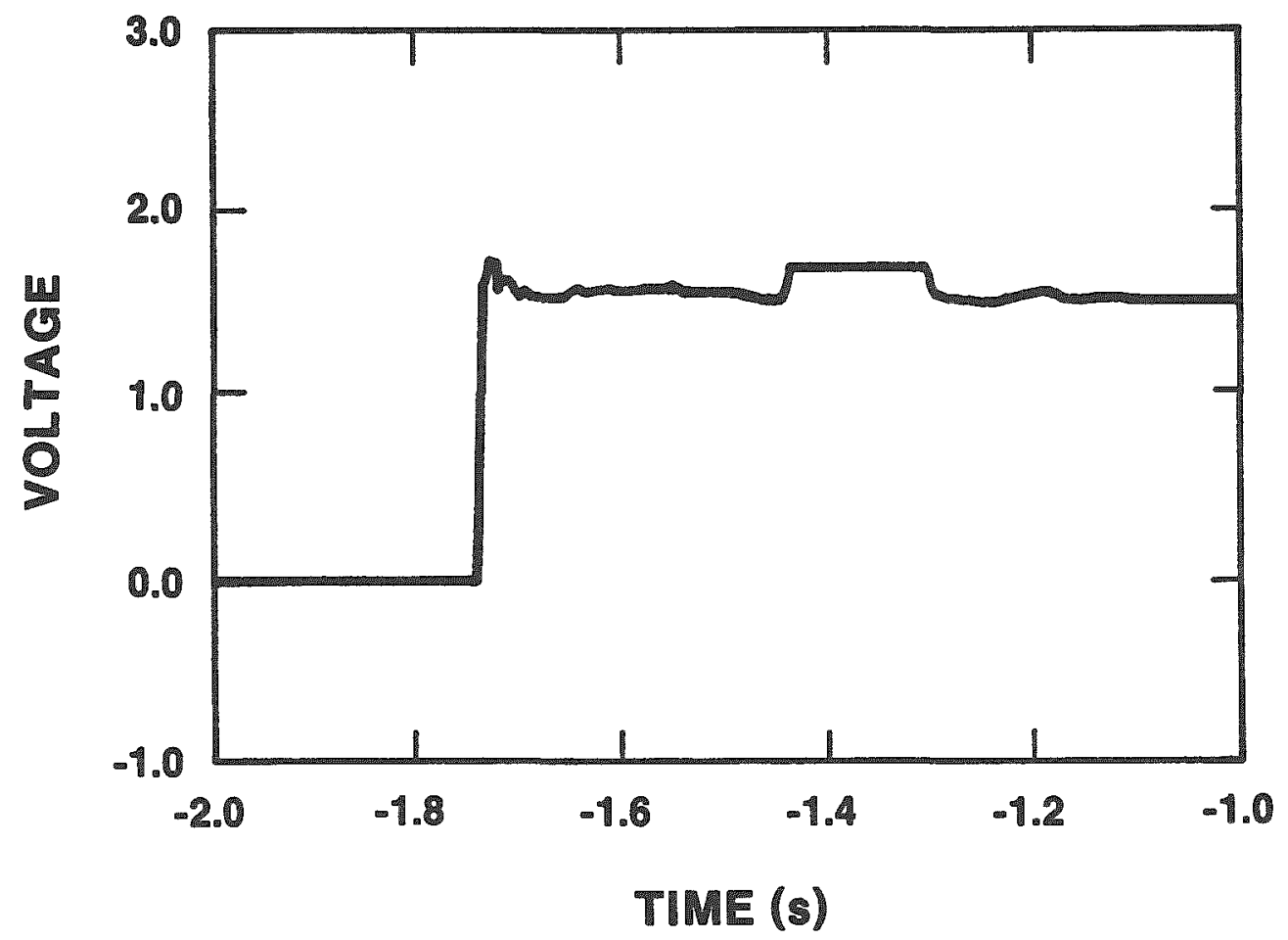

Figure 4-12. Crucible Timing Probe for the HIPS-10S Test (data channel 3: type-K thermocouple) 


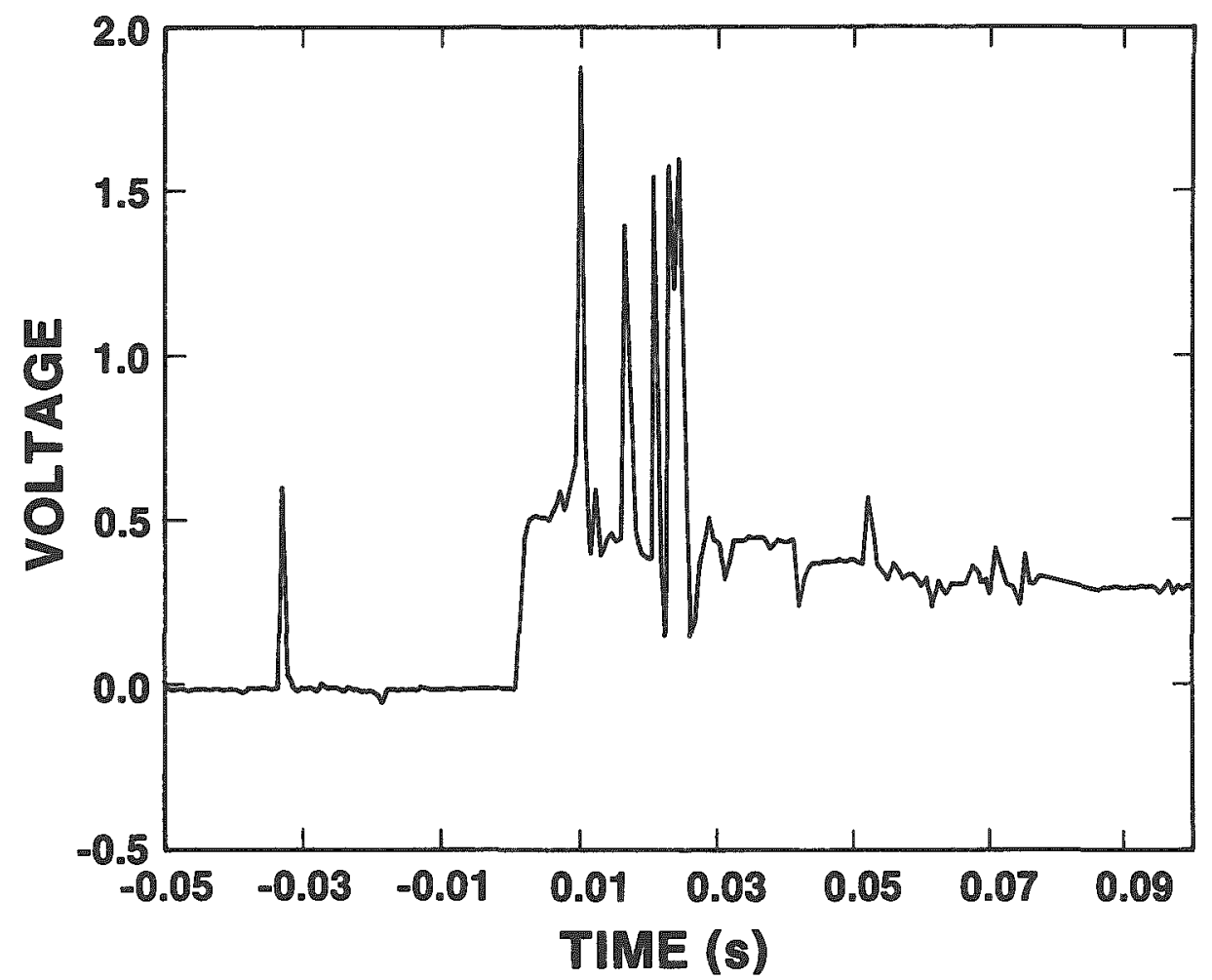

Figure 4-13. Photodiode Below the Melt Plug in the HIPS-10S Test

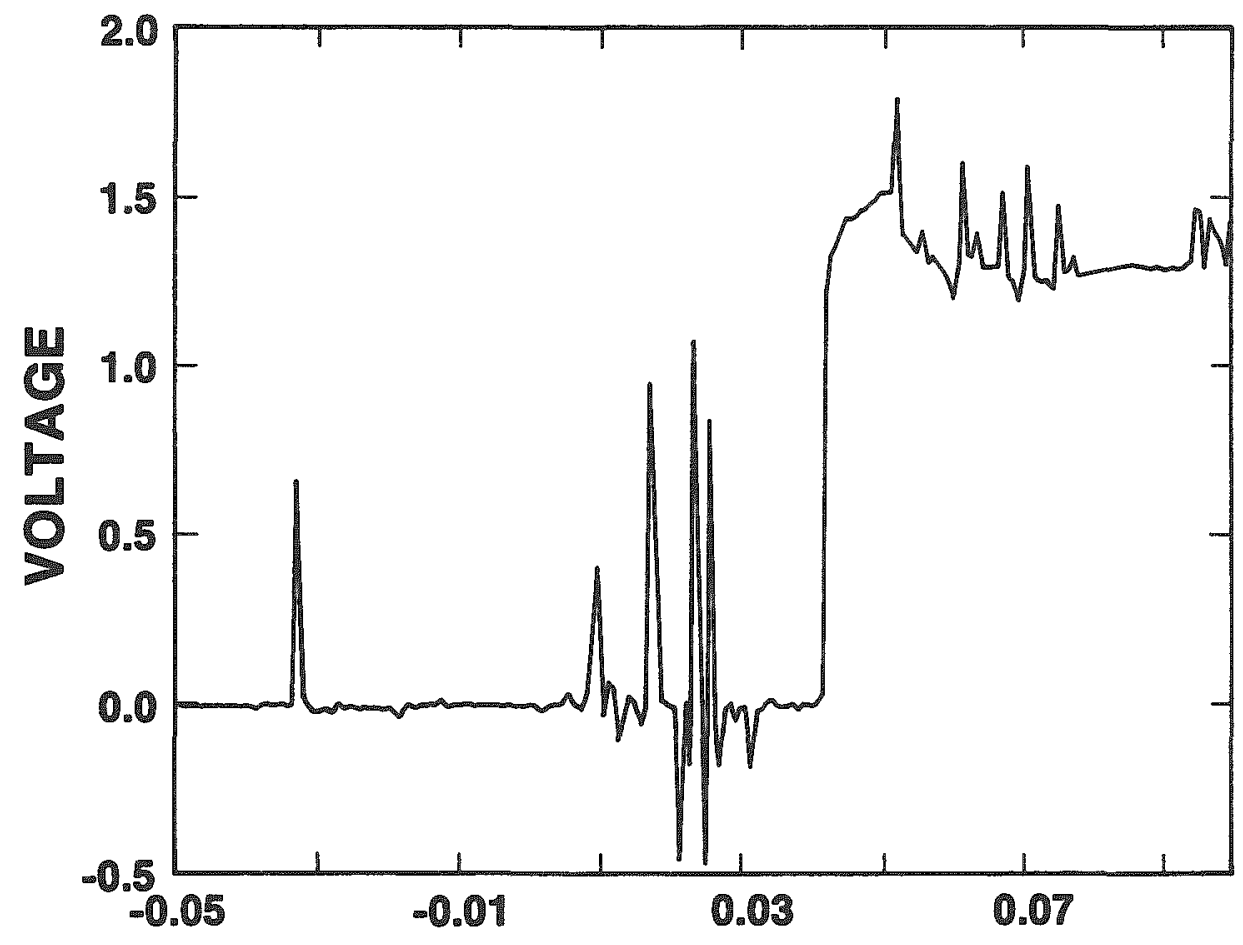

TIME (s)

Figure 4-14. Photodiode at the Cavity Exit in the HIPS-10S Test 

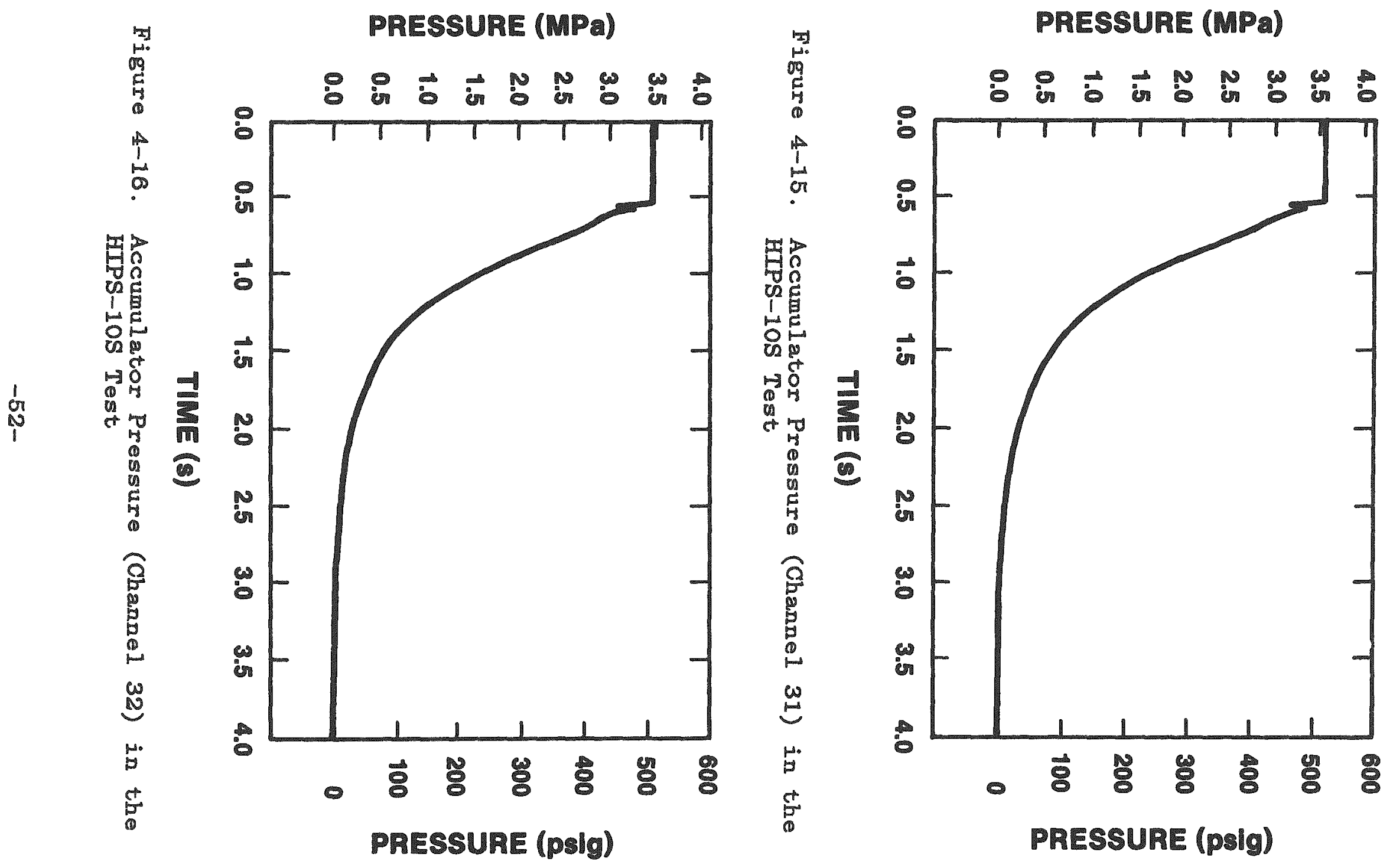


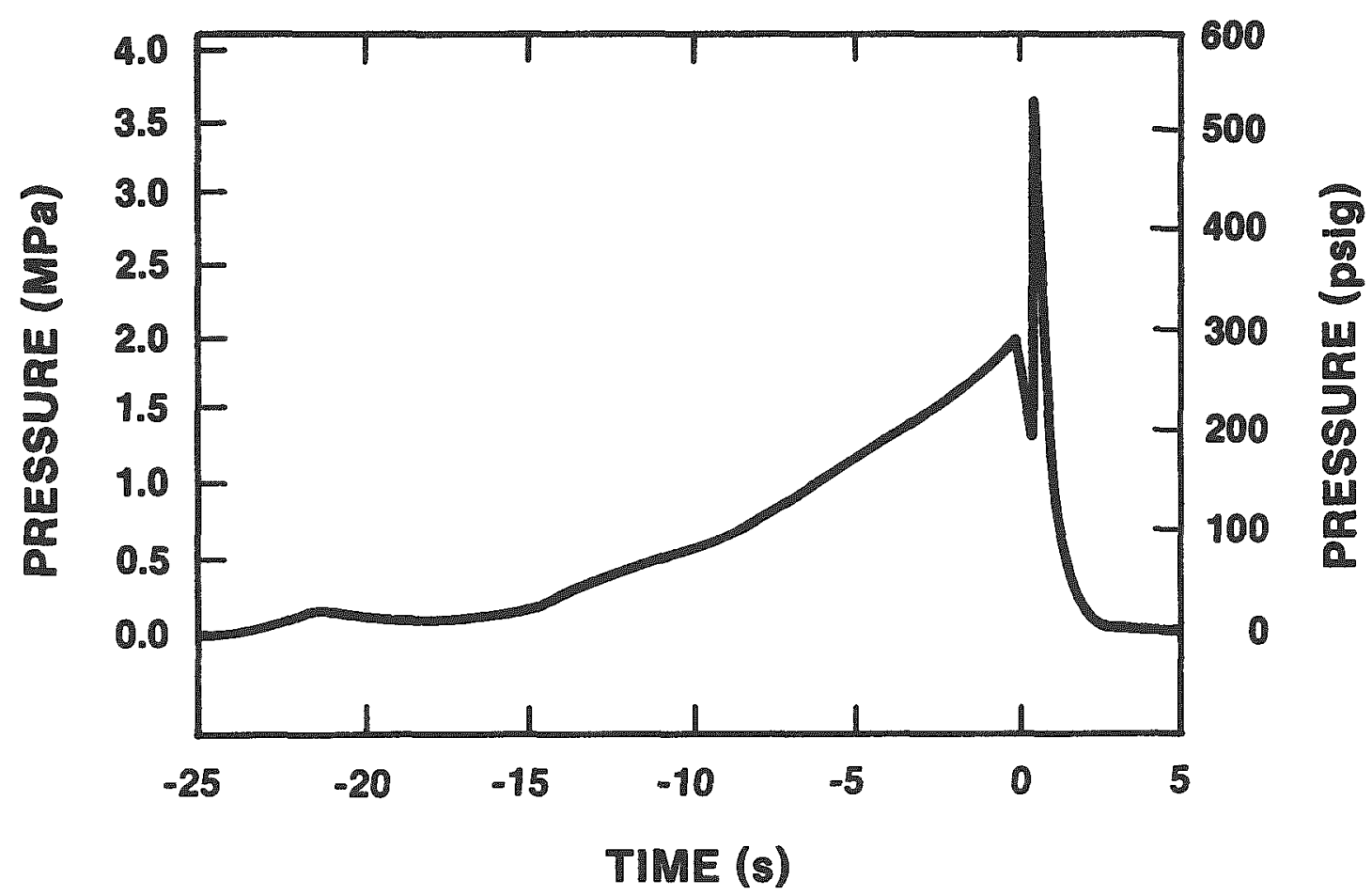

Figure 4-17. Crucible Pressure (Channel 34) from -25 to +5 Seconds in the HIPS-1OS Test

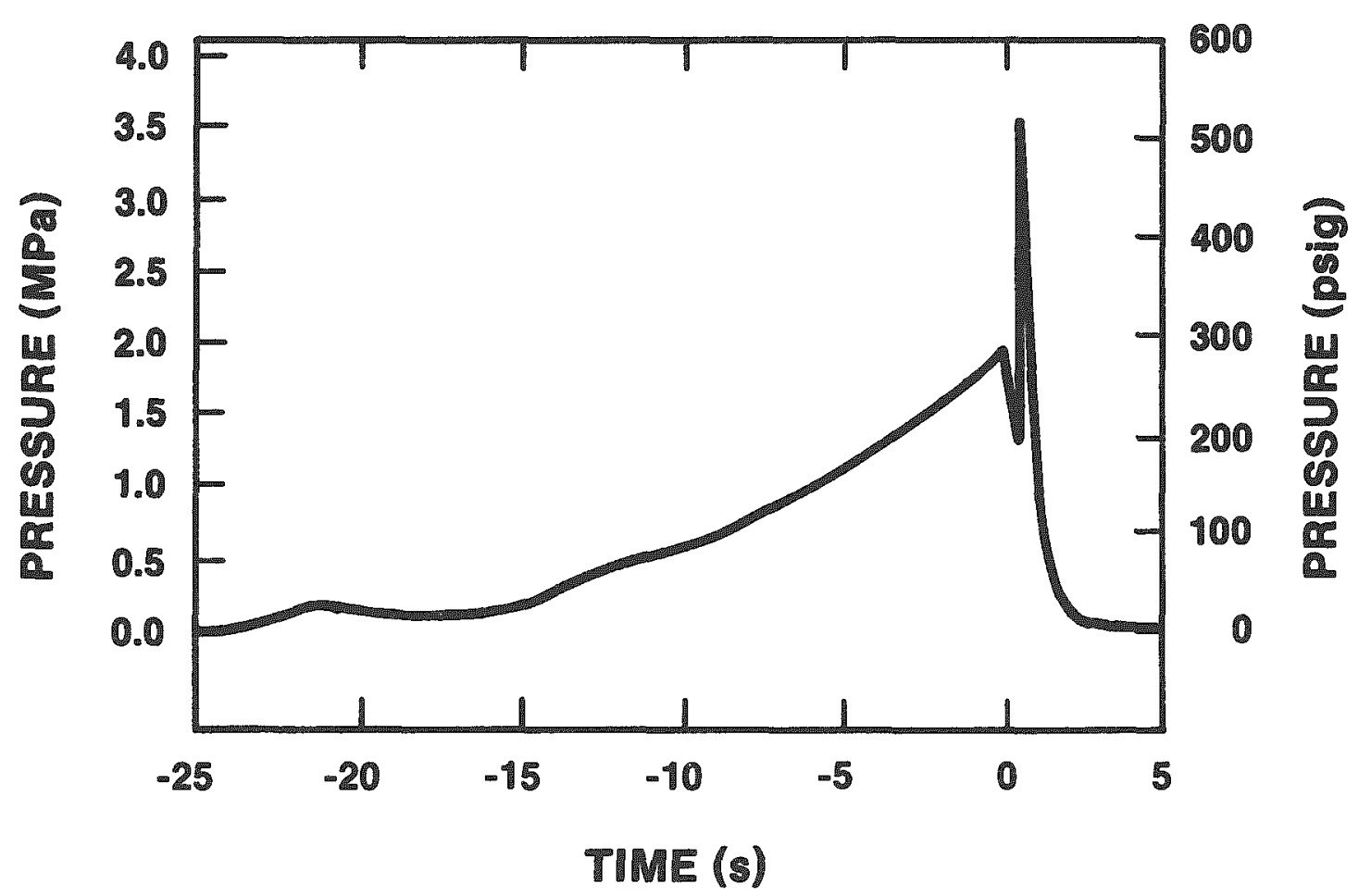

Figure 4-18. Crucible Pressure (Channel 35) from -25 to +5 Seconds in the HIPS-10S Test 


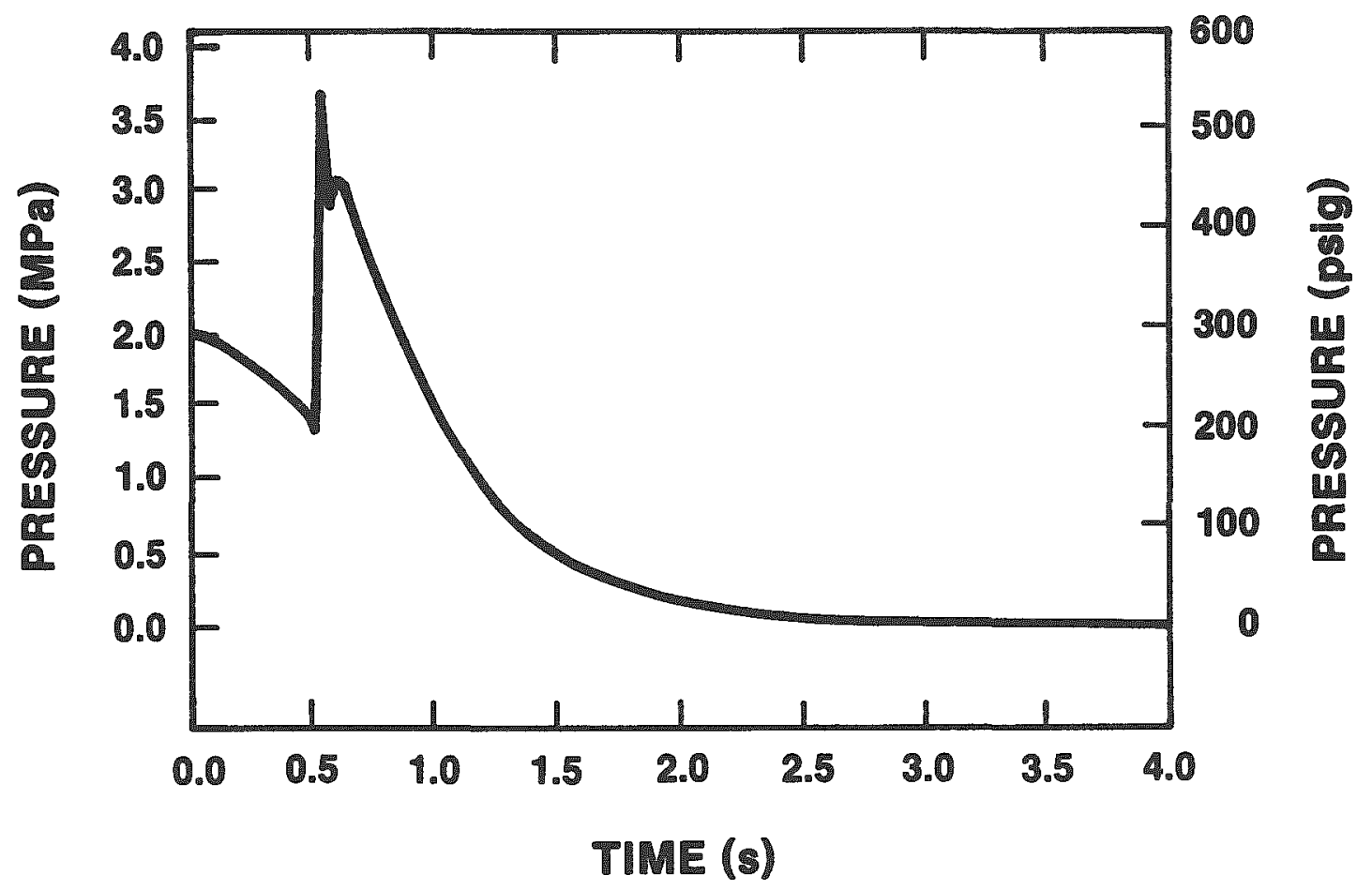

Figure 4-19. Crucible Pressure (Channel 34) from 0 to 4 Seconds in the the HIPS-10S Test

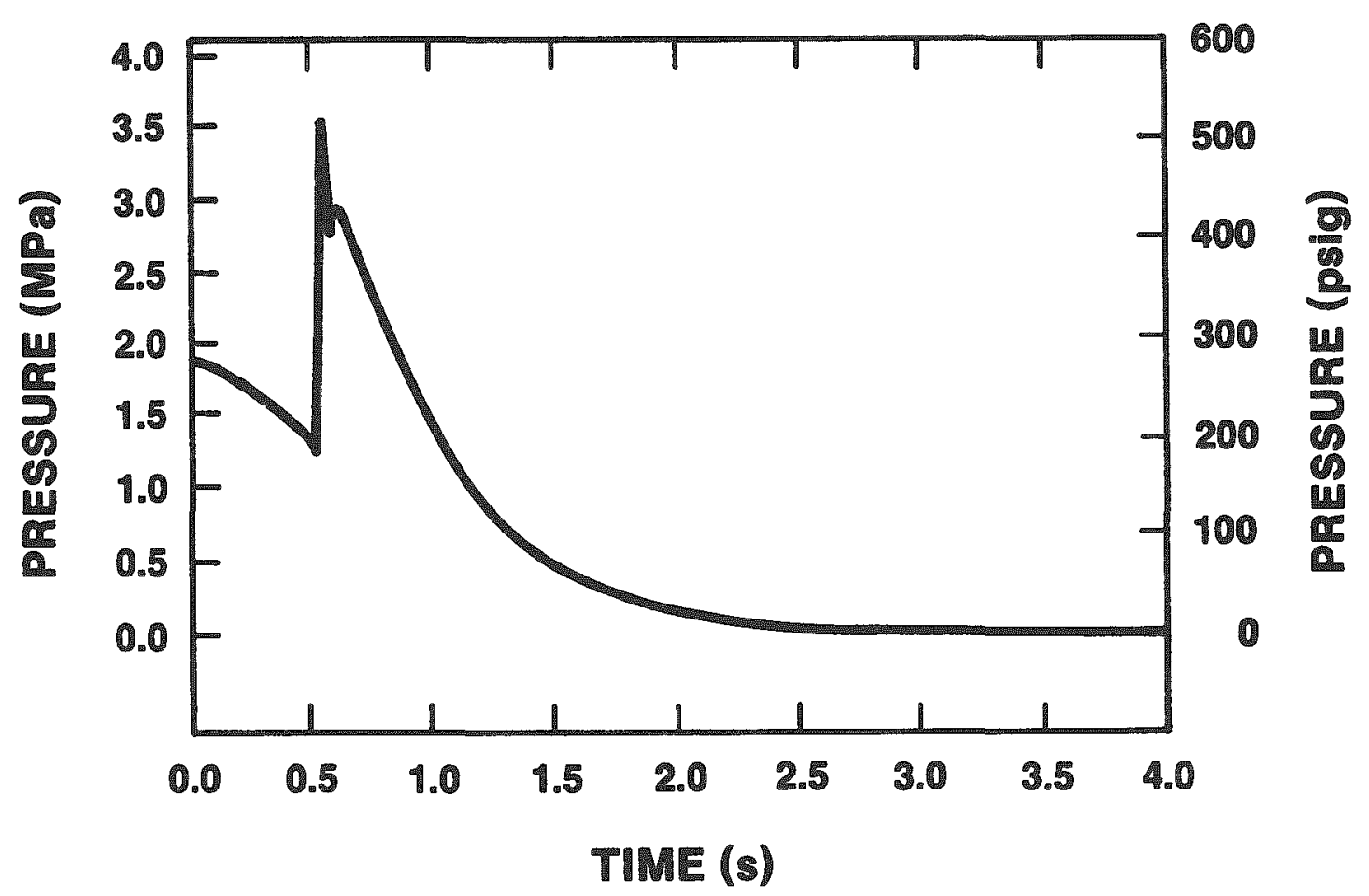

Figure 4-20. Crucible Pressure (Channel 35) from 0 to 4 Seconds in the the HIPS-10S Test 


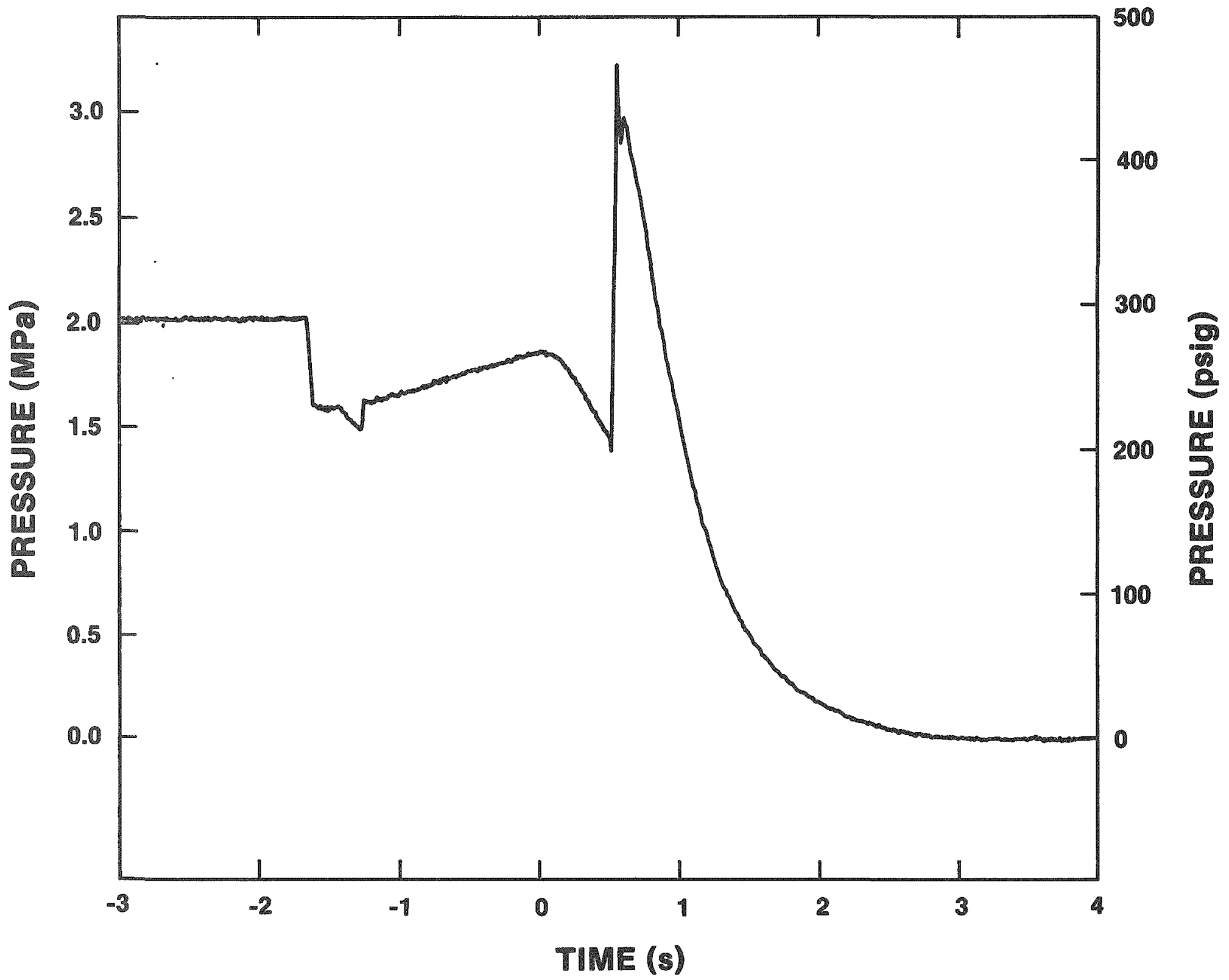

Figure 4-21. Pressure Between the Rupture Discs of the Burst Diaphragm in the HIPS-1OS Test 


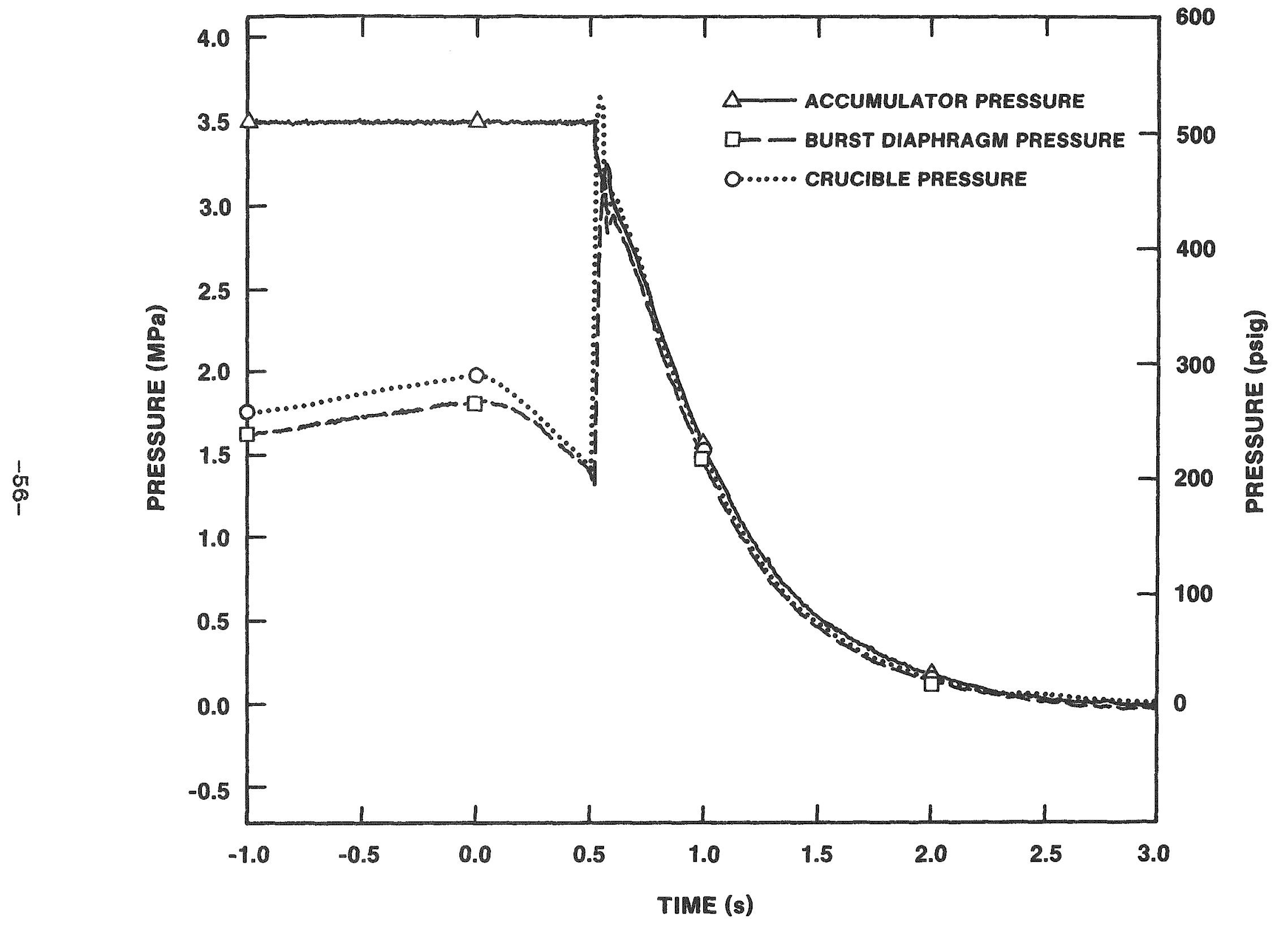

Figure 4-22. Measured Pressures in the HIPS-10S Test 


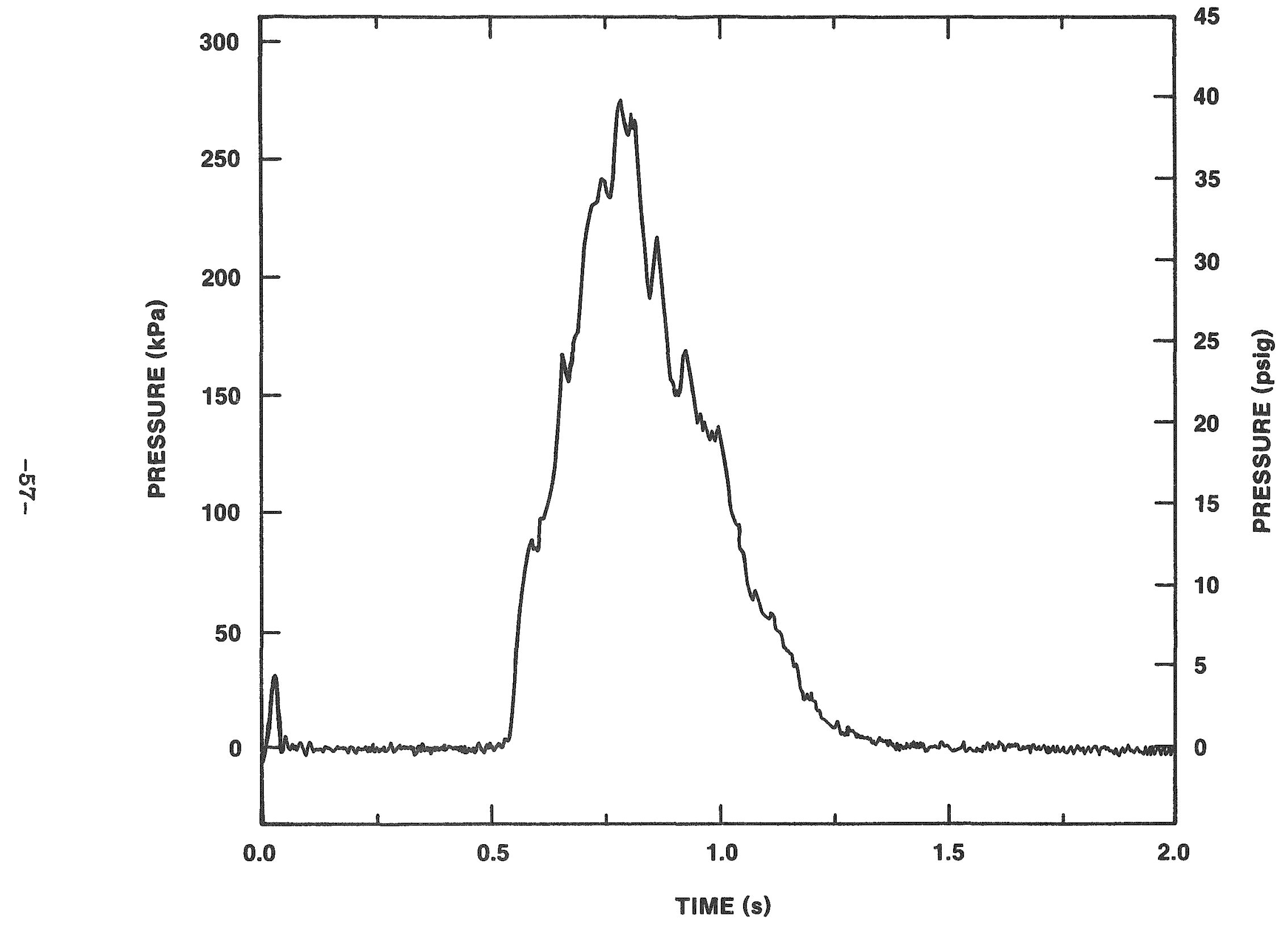

Figure 4-23. Cavity Pressure in the HIPS-10S Test 


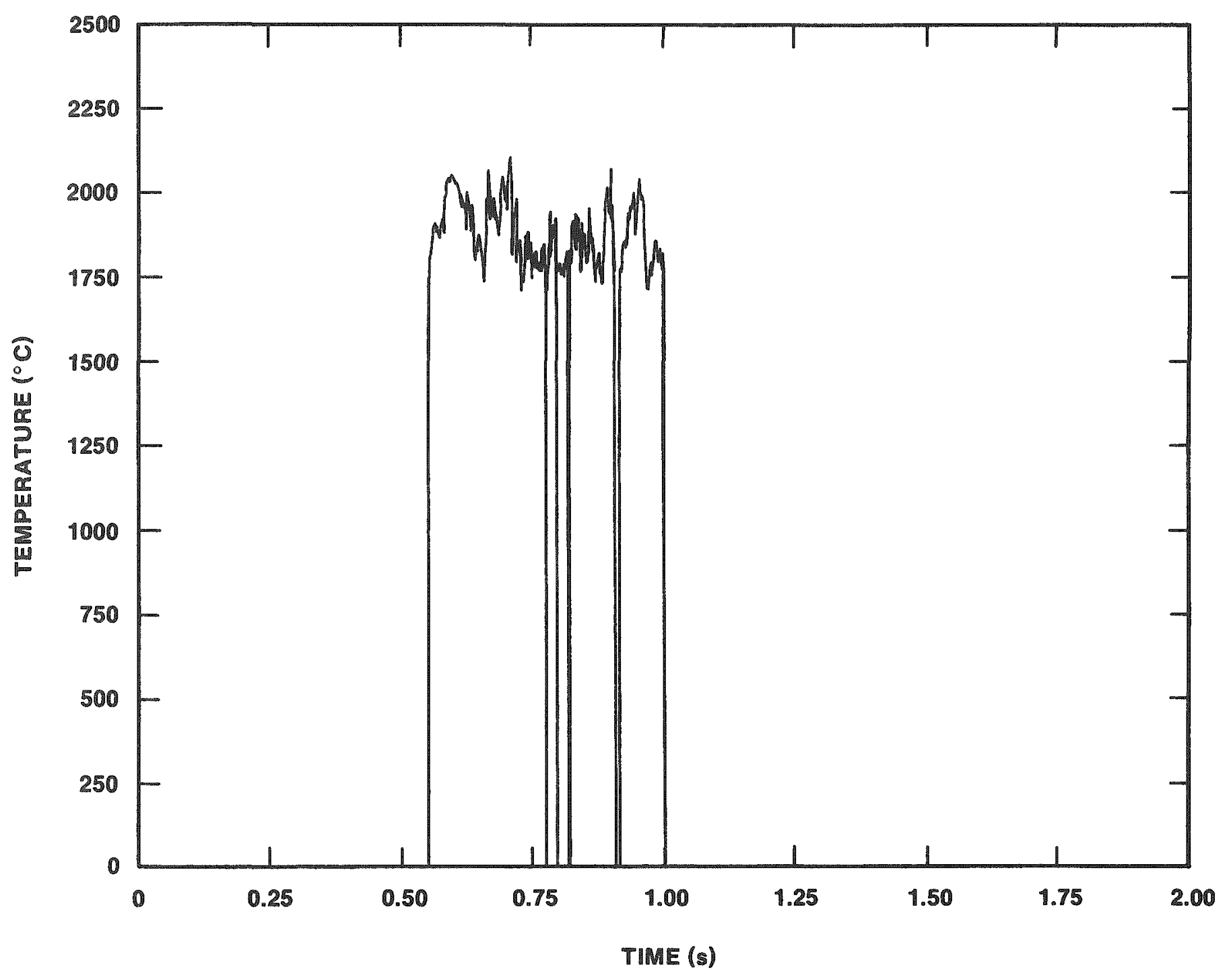

Figure 4-24. Temperature Measured with the $11 \times 20$ Dptical Pyrometer Focused at the Top of the Lucite Exit Chute in the HIPS-10S Test 


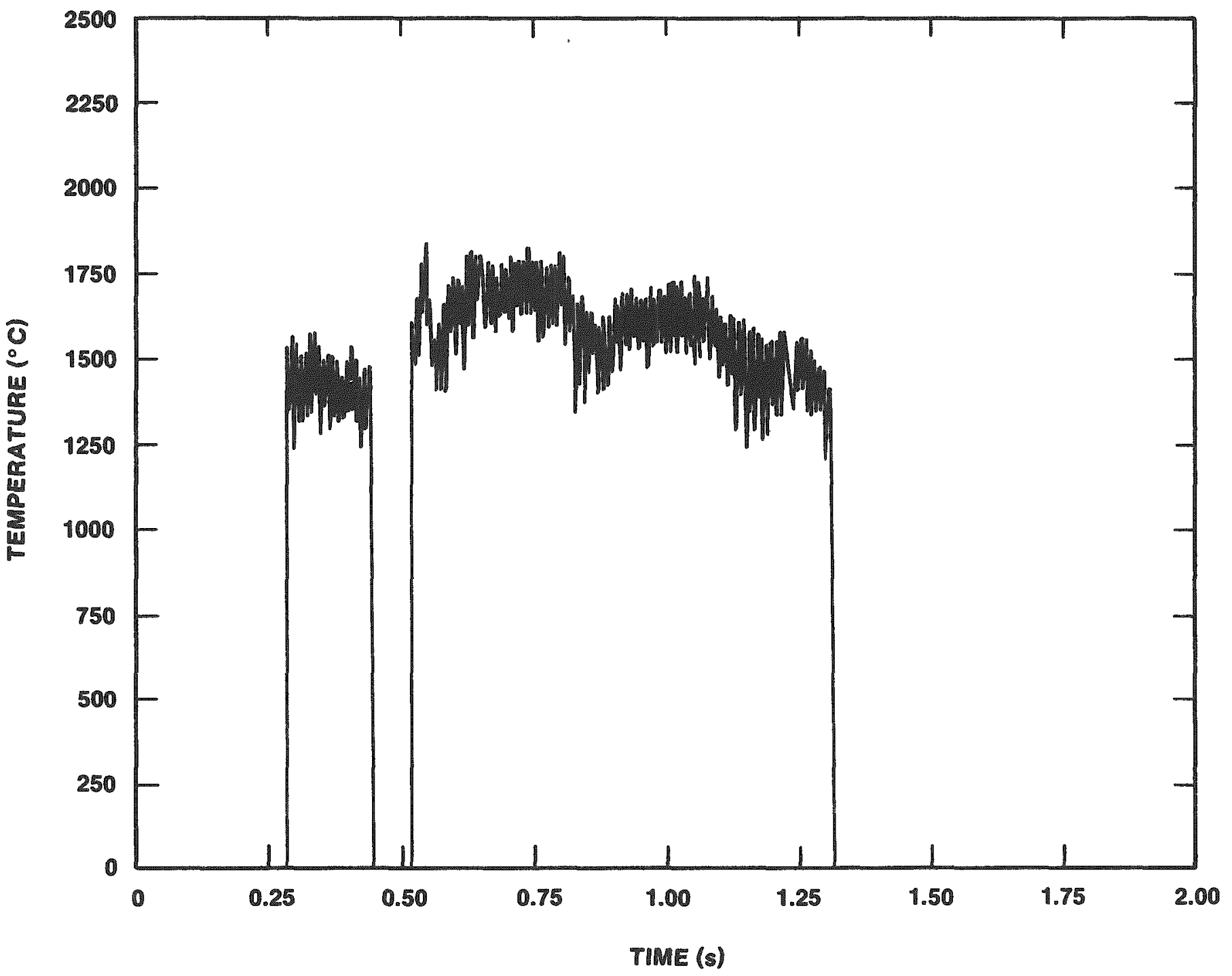

Figure 4-25. Temperature Measured with the Two-Color Pyrometer Focused at the Cofferdam Exit in the HIPS-10S Test 


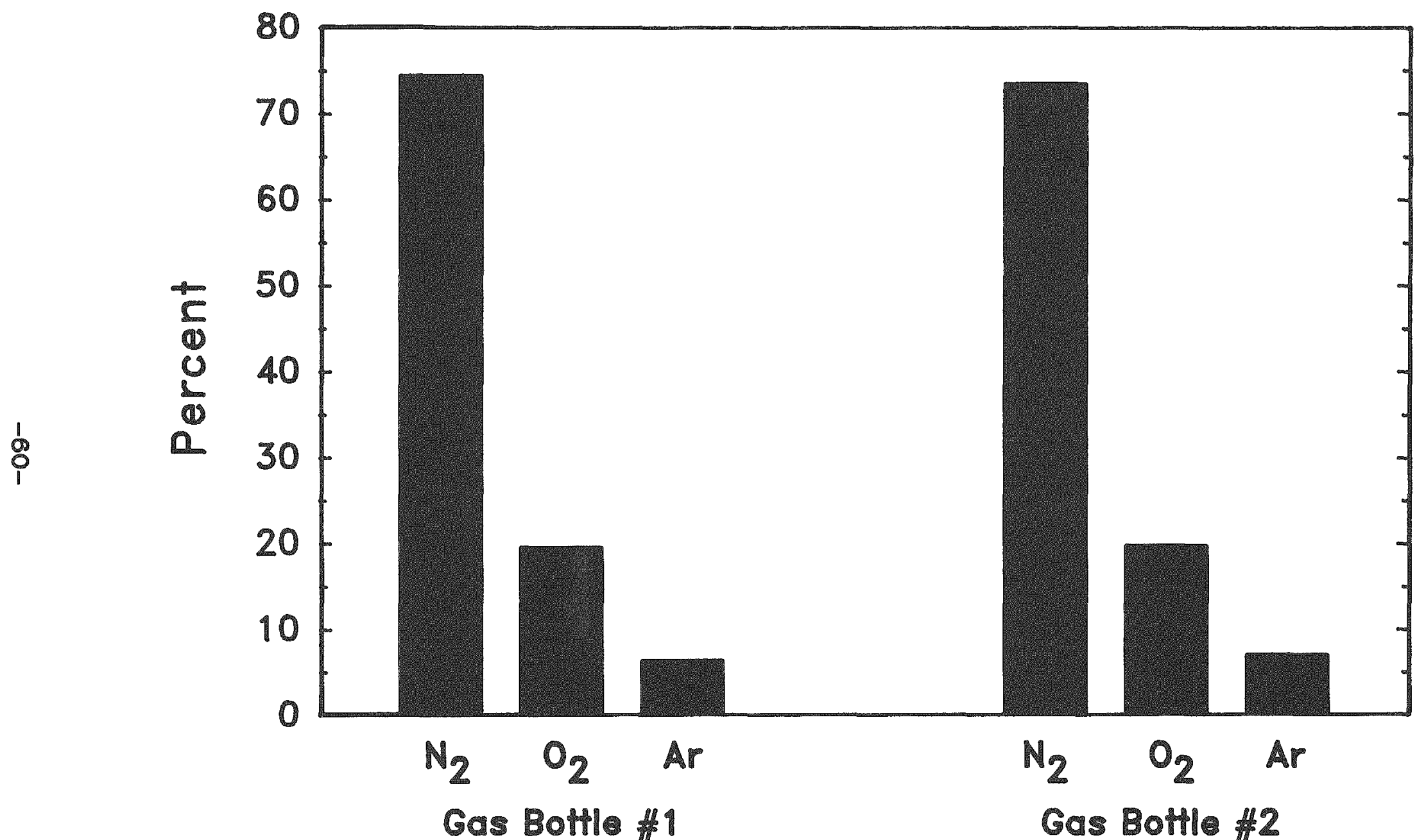

Figure 4-26. Background Gas Composition in the Cavity Prior to Melt Ejection Measured from Gas Grab Sample Set C, Bottles $\# 1$ and \#2 


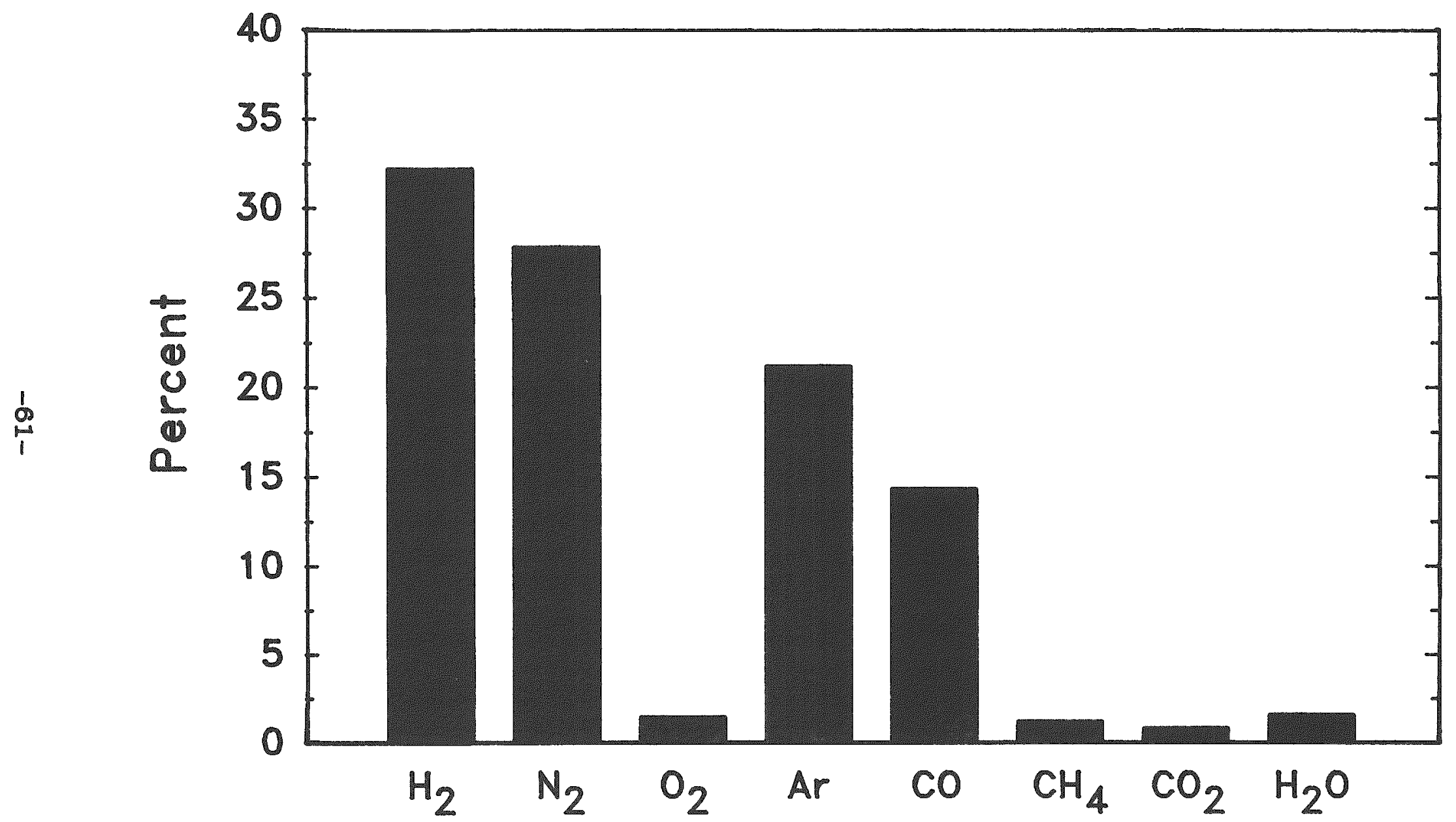

Figure 4-27. Gas Composition from Gas Grab Sample Set A, Bottle \#1 


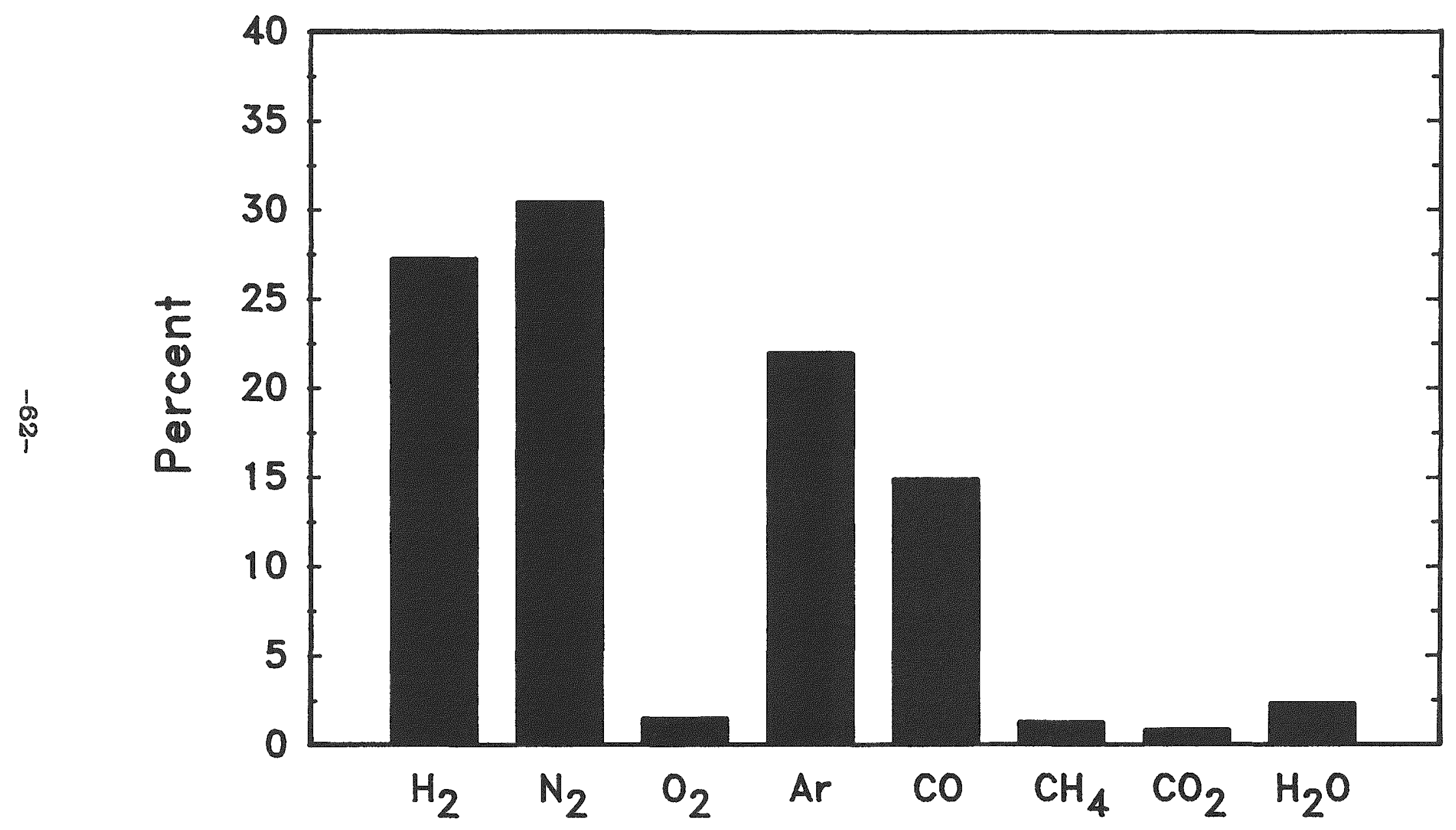

Figure 4-28. Gas Composition from Gas Grab Sample Set A, Bottle \#2 


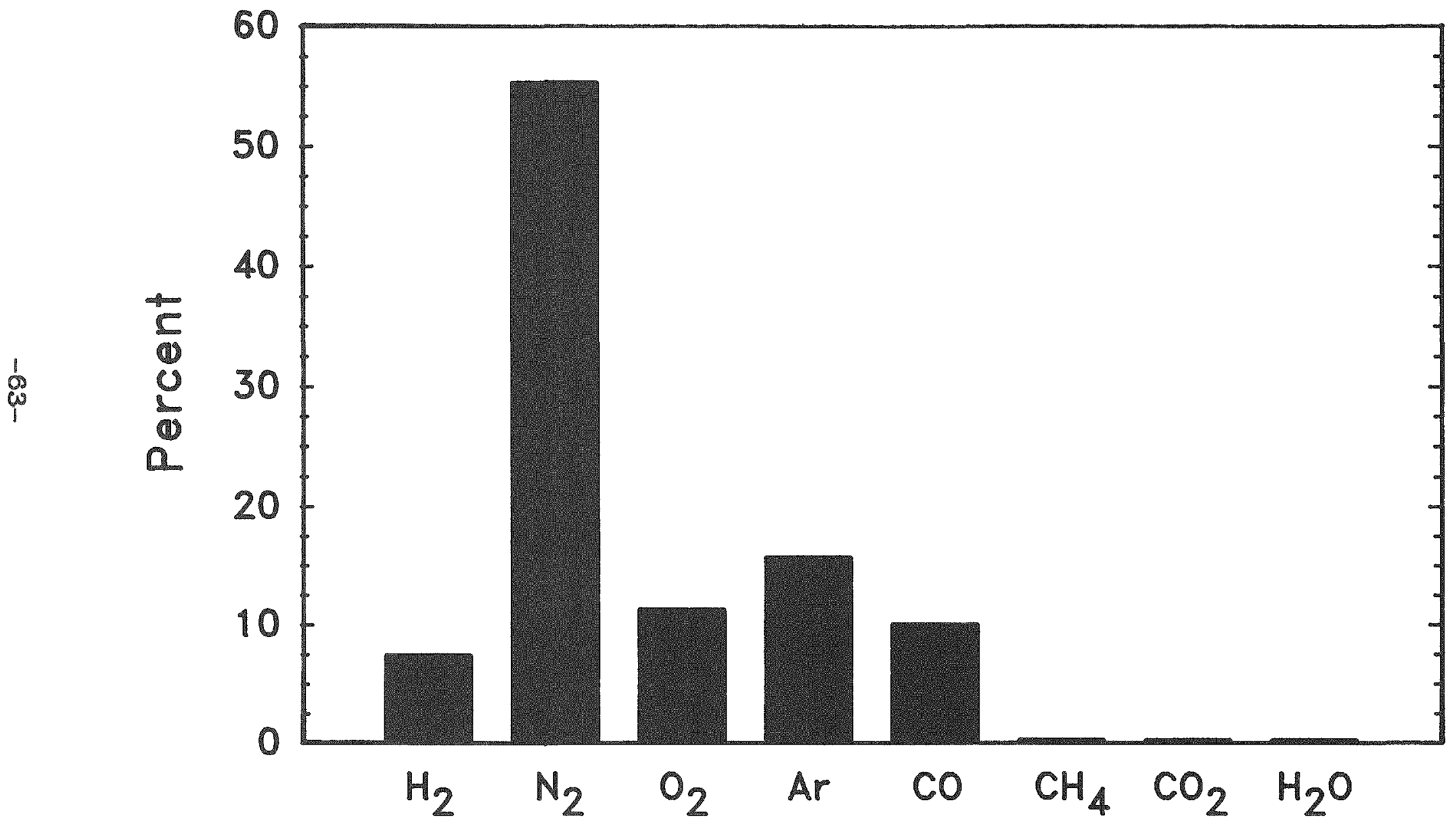

Figure 4-29. Gas Composition from Gas Grab Sample Set B, Bottle \#1 


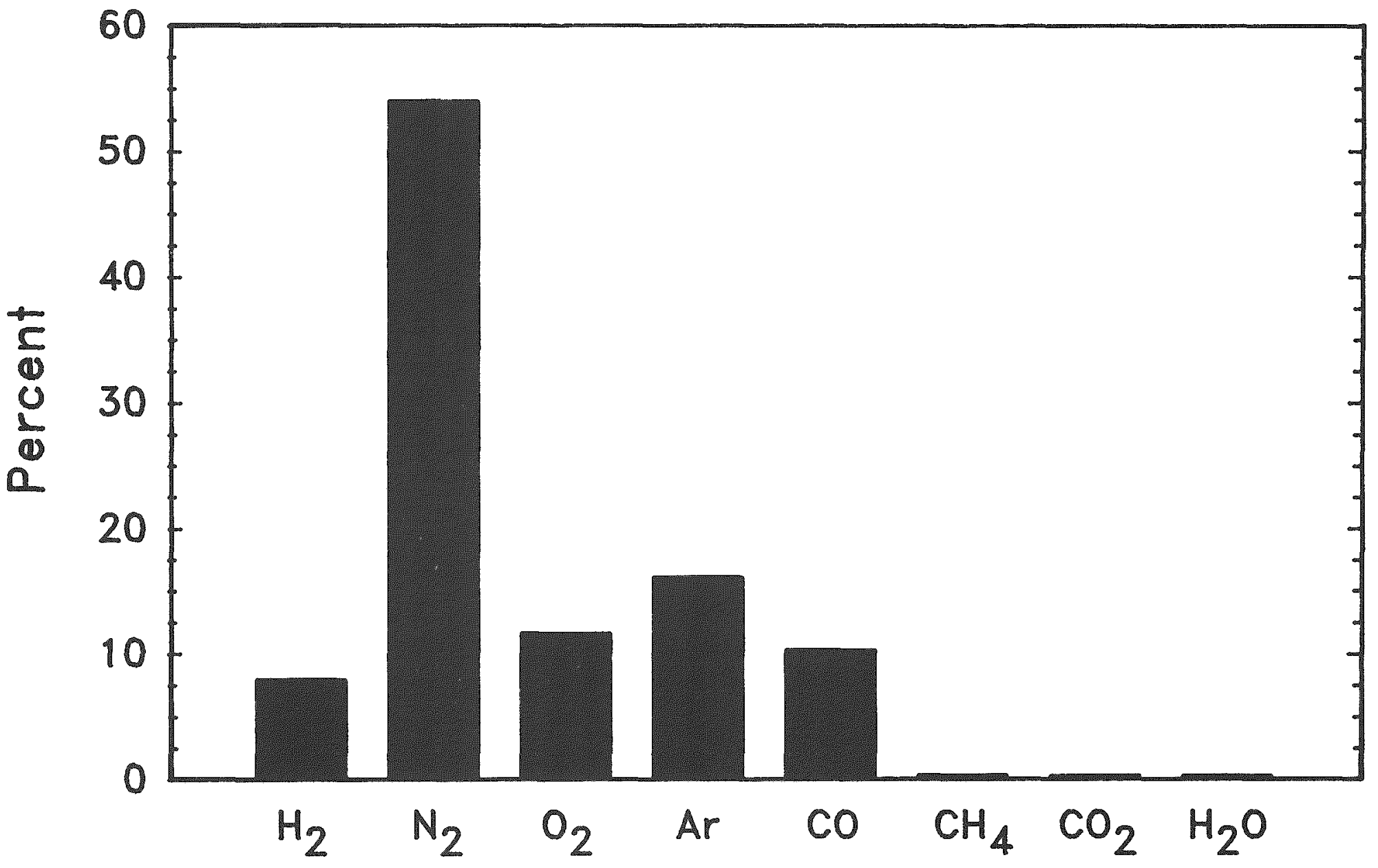

Figure 4-30. Gas Composition from Gas Grab Sample Set B, Bottle \#2 


\subsection{DISCUSSION}

The HIPS-1OS experiment was very important because it identified several minor experimental problems with the apparatus and instrumentation that must be corrected in future experiments. Unanticipated plugging of the crucible vent occurred, which caused the timing of the experiment to be off. The timing is critical in HPME experiments. In these experiments the high-pressure, superheated steam should contact the molten thermite just before the melt plug fails so that it will initiate the HPME at the proper time. In HIPS-1OS the crucible vent plugged, however this problem had no major effect on the success of the HIPS-10S test.

In HIPS-10S, heat from the metallothermitic reaction caused expansion of gas in the crucible, and also generated additional gas from impurities in the thermite. The gas flow through the crucible vent was substantial. Molten thermite was entrained in this gas flow, causing the debris to plug the crucible vent line so that back pressure built up in the crucible. This back pressure caused the differential pressure across the rupture discs of the burst diaphragm to be too small to fail the burst diaphragm at the proper time. To correct this problem, the crucible vent will be relocated in subsequent experiments, as shown in Figure 5-1. The crucible vent will be located on the left-side of a tee in the 10-cm diameter steel pipe on top of the melt generator. The crucible vent will include a steel baffle welded into the pipe and a filter, composed of ceramic balls and stainless steel turnings, to prevent plugging of this vent line. In addition, the vent valve will be normally closed. It will act like a pressure relief valve, controlling the crucible pressure between 1.0 and $1.4 \mathrm{MPa}$. The reason for this is that at elevated pressures the generation rate of additional gas from impurities in the thermite is substantially reduced. When the argon in the apace between the rupture discs of the burst diaphragm is dumped to the 2-1iter bottle (Figure 5-1), the minimum differential pressure across the burst diaphragm will be $2.74 \mathrm{MPa}$ (i.e, $4.14 \mathrm{MPa}$ in the accumulator minus 1.4 MPa in the crucible), which is greater than the pressure required to fail the burst diaphragm (i.e.2.68 MPa). When the timing probe (a typo-K thermocoupla) that is located 7.5 cm above the brass melt plug senses the nelt front, it 
will close the crucible vent valve permanently, and $0.5 \mathrm{~s}$ later it will open the valve between the burst diaphragm and the 2-1iter bottle. The burst diaphragm space, which will be prepressurized to $2.0 \mathrm{MPa}$, will be dumped to the 2-liter bottle. This reduces the pressure in the space between the rupture discs of the burst diaphragm to approximately 0.43 $\mathrm{MPa}$ within 0.1 s and will fail the burst diaphragm.

In future DCH experiments the prepressurization of the burst diaphragm space will be accomplished using an argon feed/bleed system so that the pressure can be very carefully controlled and monitored to prevent an unplanned failure of the burst diaphragm. Valves on the steam accumulator tank can also be used to carefully control the pressure in the accumulator.

Additional modification to the system include thorough trouble shooting and maintenance of the boiler so that it will operate more reliably and a complete review and upgrade of the data acquisition system and electronics. Some of the modifications that have been made are (1) replacing all 24 volt power supplies (which have proven unreliable in the past when multiple supplies are operated in a circuit) with batteries; (2) all negative power supply terminals are tied together and to the Surtsey vessel; this will give a ground plane that is constant for the instrumentation terminating at the computer; (3) the gates of the silicon controlled rectifiers (SCRs) that are in danger of being damaged due to heat or mechanical impacts during the tests are isolated; (4) the relay on the burst diaphragm vent valve has been changed from a solid state to a mechanical relay; and (5) the pyrometers will be checked and recalibrated; and (6) redundant parallel circuits and relays have been added for critical components of the system. These modifications enhance the reliability of the experimental apparatus. 


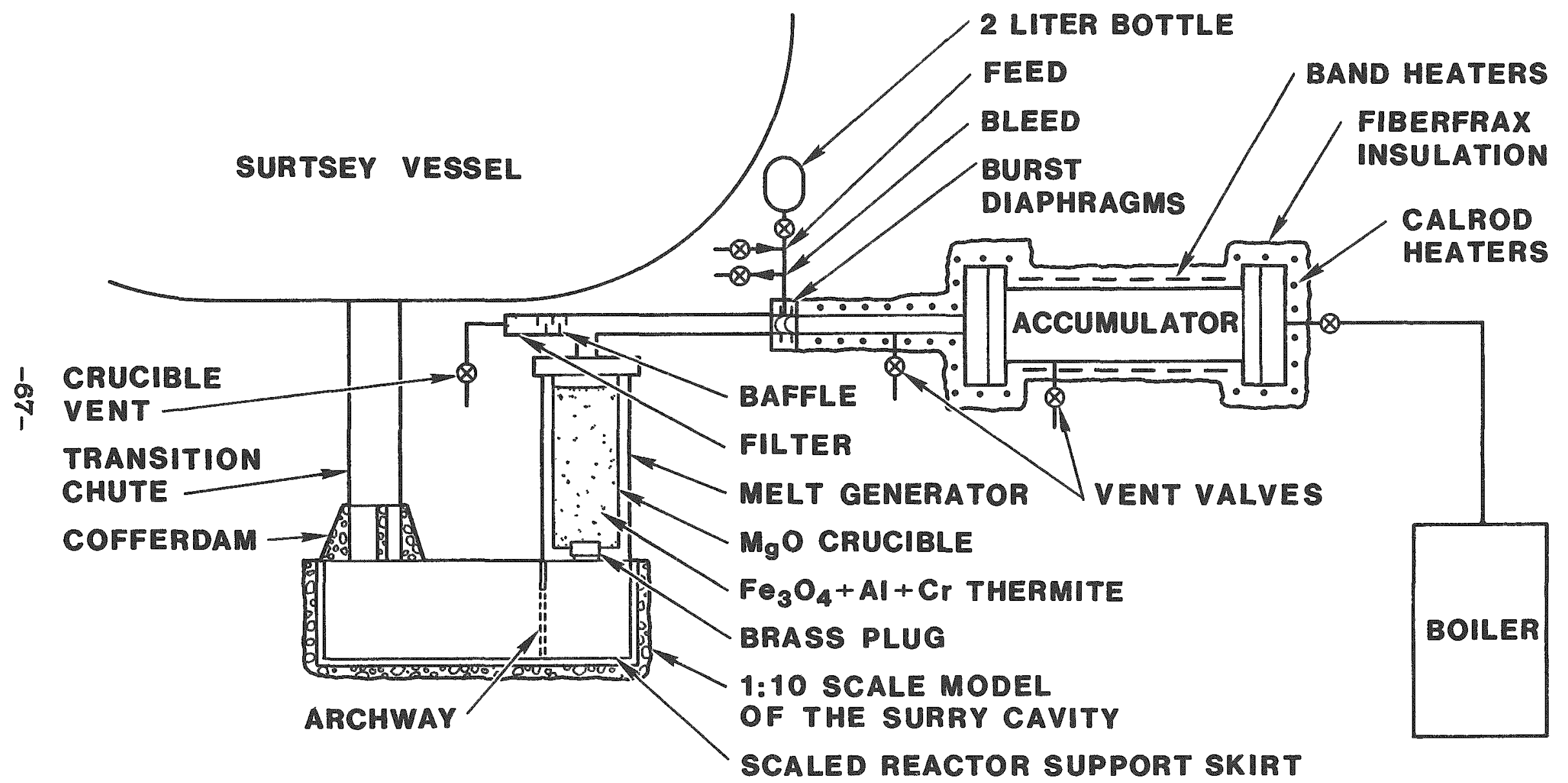

Figure 5-1. Experimental Setup To Be Used in Future DCH Experiments 


\subsection{CONCLUSIONS}

The HIPS-10S experiment demonstrated that the technology has been developed for generating steam-driven, high-pressure melt ejections. It is important to perform experiments in which steam is used as the driving gas because in real reactor accidents metallic debris can react with steam to form hydrogen, which may deflagrate and therefore impose an additional load on the containment. Gas grab sample measurements taken from the scaled Surry cavity used in HIPS-1OS indicated very efficient conversion of steam to hydrogen. This is a significant result since it at least qualitatively verifies model predictions. In subsequent DCH experiments, the Surtsey vessel will be inerted with argon to prevent the recombination of hydrogen with oxygen. Thus, the total amount of hydrogen generated in DCH experiments can be measured using gas grab samples.

The wires used to represent scaled instrument guide tubes were torn out of the cavity and ejected with the molten thermite into the atmosphere. In subsequent DCH experiments, we do not plan to use instrument guide tube models.

HIPS-1OS used chromium in the thermite melt simulant to reproduce the composition of steel used in LWR cores. This was considered important, as the presence of chromium is expected to simulate the hydrogen production and the energy released due to steam/metal reactions in a severe reactor accident at a nuclear power plant. The thermite reaction was self-propagating with the chromium added and efficient conversion of steam to hydrogen was measured in HIPS-10S; thus, all subsequent DCH experiments will have chromium powder mixed with the iron oxide/aluminum thermite and will use steam or steam/hydrogen as the driving gas. 


\subsection{REPRRENCES}

1. U.S. Nuclear Regulatory Commission (1975) Reactor Safety Study - An Assessment of Accident Risks in U.S. Commercial Nuclear Power Plants. WASH-1400 (NUREG-75-014), Nuclear Regulatory Commission.

2. Zion Probabilistic Safety Study, Commonwealth Edison Co., Chicago, Il (1981).

3. W.W. Tarbell, J.E. Brockmann, and M. Pilch, High-Pressure Melt Streaming (HIPS) Program Plan, Sandia National Laboratories, Albuquerque, NM, NUREG/CR-3025, SAND82-2477, August 1984.

4. W.W. Tarbell, M. Pilch, J.E. Brockmann, J.W. Ross, and D.W. Gilbert, Pressurized Melt Ejection Into Scaled Reactor Cavities, Sandia National Laboratories, Albuquerque, NM, NUREG/CR-4512, SAND86-0153, October 1986.

5. B.W. Spencer, J.J. Sienicki, and L.M. McUmber, Hydrodynamic and Heat Transfer Aspects of Corium-Water Interactions, NP-5127, prepared by Argonne National Laboratories for the Electric Power Research Institute, March 1987.

6. N.K. Tutu, T. Ginsberg, C. Finfrock, J. Klages, and C.E. Schwarz, Debris Dispersal for Reactor Cavities During High-Pressure Melt Ejection Accident Scenarios, NUREG/CR-5146, BNL-NUREG-52147, July 1988.

7. Estimates of Ear1y Containment Loads from Core Melt Accidents, Nuclear Regulatory Commission, Washington D.C., NUREG-1079, December 1985.

8. M. Pilch and W.W. Tarbell, Preliminary Calculations on Direct Heating of a Containment Atmosphere by Airborne Core Debris, Sandia National Laboratories, Albuquerque, NM, NUREG/CR-4456, SAND85-2439, July 1986.

9. D.C. Williams et al., "Containment Loads Due to Direct Containment Heating and Associated Hydrogen Behavior: 
Analysis and Calculations With the CONTAIN Code," NUREG-4896, SAND87-0633, May 1987.

10. J.E. Brockmann and W.W. Tarbe11, "Aerosol Source Term in High Pressure Melt Ejection," Nuclear Science and Engineering 88, 342-356, 1984.

11. M. Silberberg et al., Reassessment of the Technical Basis for Estimating Source Terms, Nuclear Regulatory Commission, Washington D.C., NUREG-0956, 1986.

12. Severe Accident Risk Assessment: An Assessment of Five U.S. Nuclear Power Plants, Volumes 1-2, Summary Report, Second Draft for Peer Review, Sandia National Laboratories, Albuquerque, NM, NUREG-1150, June 1989.

13. Integration Plan for Closure of Severe Accident Issues, Nuclear Regulatory Commission, Washington D.C., SECY $-88-147,1988$.

14. Uncertainty Papers on Severe Accident Source Terms, Nuclear Regulatory Commission, Washington D.C., NUREG-1265, May 1987.

15. K.K. Murata, D.E. Carroll, K.E. Washington, F. Gelbard, G.D. Valdez, D.C. Williams, and K.D. Bergeron, User's Manual for CONTAIN 1.1: A Computer Code for Severe Nuclear Reactor Accident Containment Analysis, NUREG/CR-5026, SAND87-2309, November 1989.

16. D.C. Williams and D.L. Louie, "CONTAIN Analysis of Direct Containment Heating Events in the Surry Plant," presented at the 1988 Winter American Nuclear Society Meeting, Washington, DC (1988).

17. K.K Murata, K.D. Bergeron, P.E. Rexroth, M.J. Clauser, J.L. Tills, F.W. Sciacca, M.E. Senglaub, W. Trebilcock, and D.C. Williams, "CONTAIN: Recent Highlights in Code Testing and Validation," SAND83-1735C, International Meeting on LWR Severe Accident Evaluation, Cambridge, MA, August 1983.

18. K.K. Murata and K.D. Bergeron, "Experimental Validation of the CONTAIN Code," SAND83-1911C, Eleventh LWR Safety Information Meeting, Gaithersburg, MD, Dctober 1983. 
19. H. Karwat, "Rupture of a Large Diameter Pipe Withing the HDR Containment," Lehrstuhl fur Reaktordynamik und Reaktorsicherheit, Technische Universitat Munchen, CSNI Report No. 160, Vol. 1, June 1989.

20. L. Wolf, L. Valencia, and T. Kanzleiter, "Overview of the HDR Containment Tests," NUREG/CP-0048, Eleventh LWR Safety Information Meeting, Gaithersburg, MD, October 1983.

21. J.E. Shepard, "Hydrogen-Steam Jet-Flame Facility and Experiments," NUREG/CR-3638, SAND84-0060, Sandia National Laboratories, Albuquerque, NM, February 1985.

22. D.W. Stamps et al., "Uncertainties in Hydrogen Combustion," Fifteenth Light Water Reactor Safety Information Meeting, Gaithersburg, MD, October 1987.

23. J.E. Hustad and O.K. Sonju, "Experimental Studies of Lower Flammability Limits of Gases and Mixtures of Gases at Elevated Temperatures," Combustion and Flame 71, 283, 1988.

24. J.H. Bentz, "Description and Operating Procedure for the Surtsey Facility's Data Acquisition System," internal memorandum, Sandia National Laboratories, Albuquerque, NM, RS7537/88/1, February 1988.

25. V.A. Bogolyubov, "Towards A Theory of Aluminothermitical Processes," Stal" 1, 38-44, 1952. 


\section{DISTRIBUTION:}

U. S. Nuclear Regulatory Commission (17)

Office of Nuclear Regulatory Research

Attn: P. Worthington

N. Costanzi

M. Cunningham

F. Eltawila

C. N. Kelber

G. Marino

R. D. Meyer

J. Mitche11

B. Sheron

C. Tinkler

T. Walker

P. Worthington (6)

R. W. Wright

Washington, D.C. 20555

U. S. Nuclear Regulatory Commission (4)

Office of Nuclear Reactor Regulation

Atti: R. Barrett

P. Easky

B. Hardin

J. Rosenthal

Washington, D.C. 20555

U. S. Nuclear Regulatory Commission (6) NRC/RES

Attn: E. Beckjord

T. Lee

W. Lyon

Z. Rosztoczy

C. Ryder

T. Speis

Washington, D.C. 20555

U. S. Departrment of Energy (2)

Albuquerque Operations office

Attn: C. E. Garcia, Director

For: C. B. Quinn

R. L. Holton

P. O. Box 5400

Albuquerque, NM 87185

Electric Power Research Institute (4)

Attn: F. Rahn

R. Ritzman

W. Lowenstein

R. Sehgal

$3412 \mathrm{Hillview}$ Avenue

Palo Alto, CA 94303

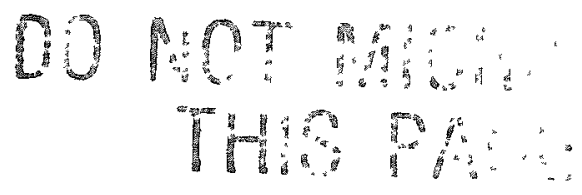


Brookharen National Laboratory

(6)

Attn: R. A. Bari

T. Pratt

G. Greene

T. Ginsberg

M. Lee

N. Tutu

$130 \mathrm{BNL}$

Upton, NY 11973

Professor R. Seale

Department of Nuclear Engineering

University of Arizona

Tucson, AZ 85721

Dak Ridge National Laboratory

Attn: T. Kress

P. D. Box $Y$

A. Wright

Dak Ridge, TN 37830

Argonne National Laboratory (8)

Attn: J. Rest

C. Johnson

I. Baker, Jr.

D. Cho

B. Spencer

K. Leong

J. Fink

V. Novick

9700 S. Cass Avenue

Argonne, IL 60439

Cathy Anderson

Nuclear Safety Oversight Commission

1133 15th Street, NW

Room 307

Washington, D.C. 20005

Battelle Columbus Laboratory (4)

Attn: C. Alexander

P. Cybulskis

R. Denning

J. Gieseke

$505 \mathrm{King}$ Avenue

Columbus, OH 43201 
J. E. Arti11

Berkeley Nuclear Laboratory

Berkeley GL 139PB

Gloucestershire, England

UNITED KINGDOM

W. G. Cunlifie

Bldg. 396

British Nuclear Fuels, Ltd.

Springfield Works

Salwick, Preston

Lancashire, England

UNITED KINGDOM

Professor Agustin Alonso

E.T.S. Ingenieros Industriales

Jost Gutierrez Abascal, 2

28006 Madrid

SPAIN

Dr. Alfonso Perez

Departmento de Seguridad Nuclear

Junta de Energia Nuclear

Arenida Complutense, 22

Madrid - 3

SPATN

R. Sherry

JAYCOR

P. 0. Box 85154

San Diego, CA 92138

Los Alamos National Laboratories

Attn: M. Stevenson

P.0. Box 1663

Los Alamos, NM 87545

UCLA (2)

Nuclear Energy Laboratory

Attn: I. Catton

D. Okrent

405 Hilgaard Avenue

Los Angeles, CA 90024

University of Wisconsin

Nuclear Engineering Department

Attn: M. L. Corradini

1500 Johnson Drive

Madison, WI 53706 
EGeG Idaho

Willow Creek Building, W-3

Attn: R. Hobbins

P. O. Box 1625

Idaho Fal1s, ID 83415

Battelle Pacific Northwest Laboratory

Attn: M. Freshley

P. 0. Box 999

Richland, WA 99352

W. Stratton

2 Acoma Lane

Los Alamos, NM 87544

Gese1lschaft fur Reaktorsicherheit (GRS)

Postfach 101650

Glockengrasse 2

5000 Koeln 1

FEDERAL REPUBLIC of GERMANY

Kraftwerk Union

Attn: Dr. M. Peehs

Hammerbacher Strasse 1214

Postrach 3220

D-8520 Erlangen 2

FEDERAL REPUBLIC of GERMANY

URAEA (8)

Attn: R. Potter 209/A32

A. Nicholas $102 / A 50$

B. Bowsher 105A/A50

J. Mitche11 01/A50

B. Morri: $216 / \mathrm{A3} 2$

P. Smith 215/A32

S. Kinnersly $203 / \mathrm{A3} 2$

D. Williams $210 / A 32$

Winfrith, Dorchester

Dorset DT2 8DH

UNITED KINGDOM

Nucleare e della Protezione Sanitaria (DISP)

Attn: Mr. Manilia

Mr. G. Petrangeli

Ente Nazionnle Inergie Alternative (ENEA)

Viale Regina Marghorita, 125

Casella Postale M. 2358

I-00100 Roma A. D.

ITALY

Dr. K. J. Briakman

Reactor Centrum Nederland

1755 ZG Petten

THE NETHERIAANDS 
Dr. S. J. Niemczyk

1545 18th Street, NW

\#112

Washington, D.C. 20036

Kernforschungszentrum Karlsruhe (2)

Attn: H. Alsmeyer

H. Rininsland

Postfach 3640

75 Karlsruhe

FEDERAL REPUBLIC Of GERMANY

Mr. H. Bairiot, Chief

Department LWR Fuel

Belgonucleaire

Rue de Champde Mars. 25

B-1050 Brussels

BELGIUM

Japan Atomic Energy Research Institute

Attn: $\mathbb{K}$. Sato

Fukoku Seimei Bldg.

2-2-2, Uchisaiwai-cho, Chiyoda-ku, Tokyo

100

JAPAN

Japan Atomic Energy Research Institute

Tokai Research Establishment

Attn: Dr. S. Matsuura, Deputy Director General

Tokai-mura, Naka-gun, Ibaraki-ken

319-11

JAPAN

Japan Atomic Energy Research Institute

Department of Fuel Safety Resarch

Attn: Dr. M. Ichikawa, Director

Tokai-mura, Naka-gun, Ibaraki-ken

319-11

JAPAN

Japan Atomic Energy Research Institute

Reactor Accident Laboratory

Attn: Dr. T. Fujishiro, Head

Tokai-mura, Naka-gun, Ibaraki-ken

319-11

JAPAN

Japan Atomic Energy Institute

Severe Accident Research Laboratory

Attn: Dr. K. Soda, Head

Tokai-mura, Naka-gun, Ibaraki-ken

319-11

JAPAN

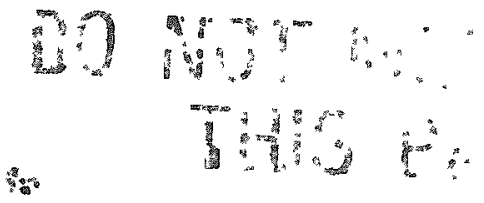


Vang Lu

TVA

400 Commerce, W9C157-CK

Knoxville, TN 37902

Peter Bieniarz

Risk Management Associates

2309 Dietz Farm Road, NW

Albuquerque, NM 87107

P. Fehrenback

Atomic Energy Canada, Ltd.

Chalk River, Ontario

CANADA KOJ IJO

URAEA (2)

Attn: A. Taig

M. Haynes

Safety and Reliability Directorate

Wigshaw Lane

Culcheth

Warrington WA3 $4 \mathbb{N E}$

Chesire

UNITED KINGDOM

J.R. Mathews

Aere Harwe 11

Didcot

Oxfordshire OX11 ORA

UNITED KINGDOM

UKAEA Culham Laboratory (3)

Atn: N. J. Brealey E5.152

B. D. Turland E5.157

F. Briscoe

Abingdon

Oxfordshire OX14 3DB

UNITED KINGDOM

H. J. meague (3)

UKAEA

Safety and Reliability Directorate

Wigshaw Lane

Culcheth

Warrington, WA3 $4 \mathrm{NE}$

UNITED IRINGDOM

M. Jankowski

IAEA

Division of Nuclear Reactor Safety

Wagranesrstrasse 5

P. 0. Box 100

A/1400 Vienna

AUSTRIA

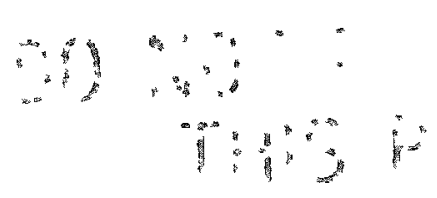


Statens Karnkraftinspektion

Attr: $\mathbb{L}$. Hammer

P. D. Box 27106

S-10252 Stockholm

SWEDEN

Studvik Energiteknik AB

Attn: K. Johansson

S-611 82 Nykoping

SWEDEN

Atomic Energy Canada Ltd.

Attn: H. Rosinger

D. Wren

Pinawa, Manitoba

CANADA ROE $1 L O$

Korea Adv Energy Research Inst

Attn: H. R. Jun

P. 0. Box 7

Daeduk-Danji

Choone-Nam

KOREA

Institute of Nuclear Energy Research Attn: Sen-I Chang

P. 0. Box 3

Lungtan

Taiwan 325

REPUBLIC OF CHINA

Juan Bagues

Consejo de Seguridad Nuckan

SOR Angela de la Cruz No 3

Madrid 28056

SPAIN

U. S. Department of Energy

Office of Nuclear Safety Coordination

Attr: R. W. Barber

Washington, D.C. 20545

Department of Energy

Scientific and Tech. Info. Center

P. 0. Box 62

Dak Ridge, TN 37831

Power Authority State of New York Attr: $\mathbb{R}$. Deem

10 Columbus Circle

New York, NY 10019 
M. Fontana

Director, IDCOR Program

ENERGEX

575 Dak Ridge Turnpike

Oak Ridge, TN 37830

Fauske and Associates, Inc.

Attn: R. Henry

M. Plys

16 Wo70 West 83rd Street

Burr Ridge, IL 60952

UKAEA

Reactor Development Division

Attr: T. Butland

Winfrith, Dorchester

Dorset DT2 8DH

England

UNITED KINGDOM

1810 D. W. Schaeffer

3141 S. A. Landenberger

(5)

3151 W. I. Klein

6321 B. D. Zak

6400 D. J. McCloskey

6410 D. A. Dahlgren

6412 A. L. Camp

6415 R. M. Cranwe11

6418 R. K. Cole

6420 W. B. Gauster

6422 D. A. Powers (2)

6422 M. D. Allen (5)

6422 F. E. Are11ano

6422 R. Blose

6422 J. E. Brockmann

6422 R. M. Elrick

6422 E. R. Copus

6422 D. A. Lucero

6422 D. W. Sweet

6422 M. Pilch

6422 R.T. Nichols

6423 K. O. Reil

6425 S. S. Dosanjh

6425 B. R. Bradley

6429 K. E. Washington

6429 F. Gelbard

6429 D. C. Williams

6454 G. L. Cano

6523 W. A. Von Riesemann

8524 J. A. Wackerly 